\title{
Extreme Audio Culture in the New Digital Underground
}

\author{
By
}

Tamatai-A-Rangi Ngarimu

\begin{abstract}
A thesis
submitted to the Victoria University of Wellington in fulfilment of the requirements for the degree of Master of Arts

in Media Studies
\end{abstract}

Victoria University of Wellington 



\section{$\underline{\text { Table of Contents }}$}

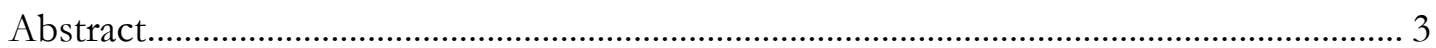

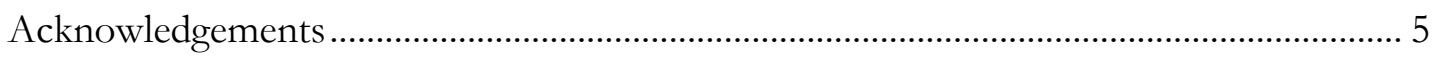

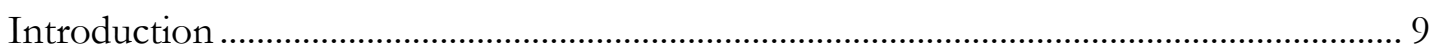

Chapter 1: Production - Machines and Cyborgs................................................................ 19

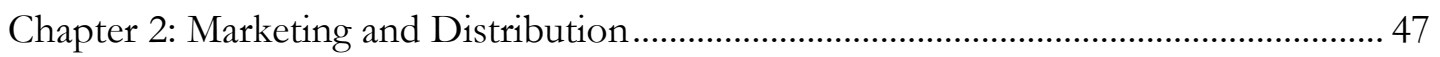

Chapter 3: Identity, Engagement and Social Interaction................................................... 83

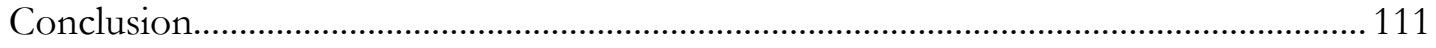

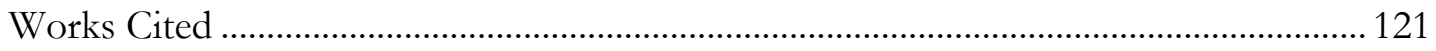




\begin{abstract}
$\underline{\text { Abstract }}$
This thesis examines the use of technology - particularly obsolete technologies and residual ${ }^{1}$ media - within underground and experimental music, using extreme audio culture (the genres of noise music and power electronics) and its relationship with the new digital underground of music and art as a primary focus. It seeks to illuminate issues surrounding not only the survival of underground music culture into the internet age (zines, ${ }^{2}$ mail order and independent production and distribution networks) but also broader, philosophical and sociological notions concerning humanity's relationship with technology within contemporary urban society, as well as examining how these notions have influenced alternative and extreme music cultures. This includes how these issues are addressed within underground and avant-garde scenes; specifically, the manner in which extreme audio culture (beginning with industrial music) voices critique upon the digital age and post-industrial environments by illustrating the negative and grotesque aspects of contemporary urban society through the employment of transgressive themes and subject matter, coupled with the use of materials, practices and ideas coded as residual or as 'noise' (reappropriating what dominant culture perceives as unwanted,
\end{abstract}

1 As discussed by Michelle Henning, Will Straw, et al., residual media are those media technologies and techniques which are no longer useful, fashionable or profitable within dominant culture and are thus seen as obsolete or 'noise' (residue). These technologies, laid to rest upon the 'scrapheap of dominant culture' (as we shall discuss in Chapter One) may be acquired, utilised and reappropriated by dominated, marginal - i.e. alternative and underground - cultures and, as examined here within the context of underground music culture, be given a new use-value within creative communities or fetishised by collectors. See Acland, Charles A., ed. Residual Media. Minneapolis: University of Minnesota Press. 2007. Print.

2 A.k.a. Fanzines: Independently produced, often hand-made, magazines. 
unfashionable, 'wrong' or taboo). By addressing these issues, we may work further towards understanding the progression of musical thought and the influence of sound upon the human psyche, as well as the ways in which music aids the continual transformation of culture within the digital/post-industrial age.

This research was undertaken from February 2012 until July 2013 with the primary methodological approach consisting of discourse analysis coupled with anthropological observations and historical contextualisation as we trace extreme audio culture back to its genesis within industrial music and the avant-garde. Drawing from the theories of Jacques Attali, Donna Haraway and Pierre Bourdieu, it will be argued that such music is prophetic of the way in which a society may develop over time, particularly in regards to our perceptions and attitudes towards technological advancement and urbanisation, not to mention our increasingly symbiotic relationship with machines as a prescriptive element of everyday urban existence. With these factors in mind, phenomena such as extreme audio culture and the new digital underground offer rich and striking considerations for the examination of digital age, post-industrial society from the perceptions of marginal creative scenes, extreme music, the avantgarde and contemporary underground music cultures. 


\section{Acknowledgements}

First and foremost, I wish to thank my supervisor, Dr. Geoff Stahl, whose patience, guidance and continued support has allowed this project to become the tangible, complete work that it is today.

I also wish to mention my colleague and office-mate Michele Fontana for his enthusiasm, advice and positive energy which contributed greatly to the completion of this thesis, and Anna Scanlen for proofreading my work and offering the outsider's perspective I needed in writing the final draft.

Thank you to all my other amazing colleagues, especially Abi Beatson, Robyn E. Kenealy, Grace C. Russell, Kim Thomas Wheatley, Russ Kale and Kelly Burt for your continued encouragement and friendship throughout this journey and everyone else at the School of English, Film, Theatre and Media Studies for your kindness and understanding. Special thanks also to Trisha Dunleavy for all her diligence and hard work.

I wish to thank Dr. Bevin Yeatman and Dr. Virginia Pitts for igniting my initial passion for the field of media studies and offering their continued support over the years.

Last but not least, for all my friends and family, and anyone else I may have missed whose compassion and humanity has allowed me to complete this journey, I offer my sincerest thanks. 
The Street finds its own uses for things - uses the manufacturers never imagined.

- William Gibson 


\section{$\underline{\text { Introduction }}$}

Nowhere is Gibson's statement more relevant than when observing the musical scenes, subcultures and styles that arose from within the urban environment during the 1970s and 1980s. Genres such as punk, hip-hop and house music were founded upon the misuse and abuse of established musical technologies and techniques; reappropriating and subverting dominant codes and conducts, and formulating creative practices that, at the time, were emphatically avant-garde in their approach. Thus, any study into popular music is primarily a study into technology; its perpetual advancement and impact. In turn, “Any study of technology's 'impact' is in consequence the study of a complex, intercausal relationship between one form of social behaviour and another" (Pfaffenberger 244). This leads us to the increasingly complex ways in which we interact with each other as a species, raising questions concerning such epochal issues as language, identity and society. Before we become too grandiose in our discussion, a closer look at the development of popular music and music technologies from 1970, and the beginning of the post-industrial, digital age of western civilisation, allows us to observe the manner in which technologies and techniques are utilised in order to form specific cultural identities and social behaviours. In other words,

Everyday life is constituted by the practices of popular culture, and is characterised by the creativity of the weak in using the resources provided by a disempowering system while refusing finally to submit to that power. (Fiske 47)

This brings us to the formation of 'underground' music, arts and culture; defined by codes and ideologies of authenticity, exploration and progression within 
creative thought whilst remaining vehemently opposed to commercialised mainstream cultural industries who often borrow readily from discoveries and developments made within these scenes and subcultures. Viewed in a socio-political manner, "What is called music today is all too often only a disguise for the monologue of power" (Attali 9). Genres such as industrial music sought to misuse and abuse musical technologies and techniques, harnessing dissonance and noise, in a manner which attempted to embody the artist's experiences within both the digital age and the urban environment. This was pursued through heavy experimentation with synthesisers and other sound-generating technologies in order to explore the new textures and timbres made available by humanity's ever-intensifying relationship with machines, often aiming to push the boundaries of aural potency to their most extreme. Contextualising this notion even further towards a broader social and societal analysis,

[M] usic appears in myth as an affirmation that society is possible. That is the essential thing. Its order simulates the social order, and its dissonances express marginalities. The code of music simulates the accepted rules of society. (Attali 29)

The recent phenomenon of extreme audio culture, i.e. noise music and power electronics, has defined itself as a culture on the fringe of artistic and 'musical' practices, ideologies and aesthetics; pursuing possible extremes in avant-garde music and art by exploring the sonic potential which lies within the use of noise as a creative material. Although the practice remains, as one may deduce, well within the confines of the extreme and experimental music underground (the current definition of which will be discussed in greater detail in the following chapters), the growing dominance of online media consumption over contemporary culture, particularly among young people, has seen extreme audio culture increase in popularity over the past decade, being embraced across a broad spectrum of alternative music, from the more likely aficionados of 
industrial music, extreme metal and hardcore punk to the psychedelic music and indie rock communities (building from the ideas laid out by bands like Sonic Youth and Flaming Lips). This amalgamation of style, taste and technique into a sphere which encompasses and explores the furthest intensities of the aforementioned genres became established with its own "marks of distinction" in accordance with "the struggle for life" which all artistic movements, schools and groups undertake to "produce existence in a universe where to exist is to be different, 'to make oneself a name', a proper name or a name in common (that of a group)" (Flaubert qtd. in Bourdieu, The Rules of Art 157).

As a musical scene, therefore, extreme audio culture positions itself within the 'research sector' of Pierre Bourdieu's field of cultural production, on the far edge of the sub-field of restricted production defined by specialist, small-scale and non-commercial artistic endeavour (The Rules of Art 120; Prior 308). The field of cultural production is divided into two sub-fields whose relationship will be examined repeatedly throughout the following chapters. These sub-fields consist of, on one side, large-scale production (i.e. the overground, the mainstream or, more specifically, dominant culture) and, on the other, small-scale/restricted production (i.e. alternative culture, the avant-garde or the underground). Although monetary capital is less of a factor in the motivation to produce works within the small-scale/restricted sub-field, the influence of symbolic and cultural capital becomes much more pronounced with these scenes and communities (extreme audio culture among them) operating within their own symbolic and cultural economies, defined by variables which fortify a scene's ethos and tradition. More explicitly, in order to address the unique function of each,

Symbolic capital refers to degree of accumulated prestige, celebrity, consecration or honour and is founded on a dialectic of knowledge (connaissance) and 
recognition (reconnaissance). Cultural capital concerns forms of cultural knowledge, competences or dispositions. (Johnson 7)

This is where the notion of the 'new digital underground' comes into play, as the networks and communities which once solely comprised physical locations (clubs, record stores, etc.) and tangible print media (zines and mail-order catalogues) have now adapted to intangible, internet-based frameworks in which they have carved an established presence within cyberspace. This cross-section of scenes and platforms, through their common relation in making use of 'residual' media and technologies, create a complex and dynamic theoretical convergence. Thus, in order to examine these aforementioned notions of music, culture, technology and society, a primarily sociological approach will be taken in examining the artists, practices and characteristics that extreme audio culture embodies. After all,

Technology, defined anthropologically, is not material culture but rather a total social phenomenon in the sense used by [Marcel] Mauss, a phenomenon that marries the material, the social and the symbolic in a complex web of associations. (Pfaffenberger 249)

Extreme audio culture, therefore, raises significant inquiries concerning our current relationship with technology as well as the changing nature of music as a cultural and artistic form. As we shall see throughout this discussion, such inquiries also work to illuminate our experience of sound within the post-industrial, urban environment and the ever-growing spectrum of textures and timbres that slowly integrate into our collective unconscious and, over time, seek to broaden the 'vocabulary' of accepted musical practice. 
Such discourses are at the heart of what opens extreme audio culture to scholarly analysis within the field of popular music studies and beyond: The works, the artists, their practices and the scene as a whole reflecting and expressing ideas relevant to identity and social interaction, social anxieties regarding humanity's relationship with technology and industry, as well as the negative consequences of urbanisation - mental illness, emotional isolation, crime, deviancy and addiction (Nash; Tellnes). Hence the reason scholars such as Paul Hegerty and Andrew Whelen have written on the subject and shall be featured regularly throughout this discussion. Thus,

As a set of aesthetic practices, an approach to sonic signification, and a mode of communicating the very real horror that happens to people, noise has a lot to say to researchers interested in music, politics, subculture, and their contemporary intersection with networked technology. (Whelen 472)

Furthermore, whilst humanity's ever-increasing connection with technology symbolically (through media), socially (through language) and materially (through the body) - remains a constant theme throughout this discussion, it is specifically the idea of obsolete and residual media technologies that is of interest here, with a focus on both how and why certain materials and machines are used within the scene and what discourses arise as a result. In validation of this approach,

Even though the greater weight of scholarly attention has been directed toward the study of diffusion and consumption of new forms of popular media, activities surrounding the decline of older technological forms, including analogue media formats such as the vinyl record, should also stimulate scholarly analysis and discussion. (Davis 222) 
Therefore, we establish a primary emphasis upon discourse analysis in the discussion of extreme audio culture and the new digital underground in relation to broader sociological and philosophical ideas. Discourse analysis remains a powerful methodology when analysing creative media and the performing arts as it allows us to explore with greater insight the cognitive impact of texts within a subjective, multifaceted framework.

In other words, just as there can be no firm distinction between the 'mental' and the 'physical', so there can be no pure 'activity', no merely physical 'experience' which is not also discursive, in that all activity and experience involves some degree - however slight - of thinking, classifying and meaning. (Gilbert and Pearson 51)

And, of course, 'meaning' can only be received if it is successfully decoded by the audience (Hall 204). The coding of a text by the producer lies within their bringing together of practices, platforms, symbols, ideas, techniques and technologies into a language which can be read and understood by its reader.

Furthermore, communications sciences and modern biologies are constructed by a common move - the translation of the world into a problem of coding, a search for a common language in which all resistance to instrumental control disappears and all heterogeneity can be submitted to disassembly, reassembly, investment, and exchange. (Haraway 434)

Although we shall arrive at this notion in earnest within the development of the following chapters, Will Straw's notion of the 'scene' and its use here in terms of music, the avant-garde, underground and online creative culture should be addressed in order to preserve clarity throughout this discussion. The title of 'extreme audio culture' is 
employed here as an umbrella term for the noise and power electronics scenes; encompassing offshoot styles such as harsh noise wall and death industrial (to name a few). Due to its fluidity, diversity and scope, 'scene' shall be used throughout this discussion rather than terms such as 'subculture' as it "serves to loosen up a sociological analysis rather than give it form. 'Scene' is, arguably, the most flexible term in a social morphology that includes such categories as art world, simplex or subculture" (Straw, "Scenes and Sensibilities" 250). Will Straw defines it as an open-ended and robust term which can encompass both specific locations within a city as well as a movement or phenomenon on a global scale. Although this may seem very broad at first glance, one may connect a scene to certain eras or localities by attaching signifiers such as 'the Portland noise scene' or 'the Wellington noise scene'.

A musical scene $\ldots$ is that cultural space in which a range of musical practices coexist, interacting with each other within a variety of processes of differentiation, and according to widely varying trajectories of change and crossfertilisation. The sense of purpose articulated within a musical community normally depends on an affective link between two terms: Contemporary musical practices, on the one hand, and the musical heritage which is seen to render this contemporary activity appropriate to a given context, on the other. (Straw, "Systems of Articulation" 373)

Straw ties this notion back to Bourdieu's field of cultural production in a manner which allows one to map a given scene and its designated position therein. 'Scene' is an appropriate term with which to discuss and analyse noise music and power electronics as individual established scenes and affords us a vantage point from which to observe them and their place within the field of cultural production as a whole; particularly in relation to large-scale, commercial production and dominant culture. 
However, there are three theorists in particular whose ideas, once combined, have sought to mould the trilateral structure and theoretical motif of our discussion; Bourdieu taking his place as the first in the trifecta, primarily in light of the field of cultural production, described above. As we shall examine, in a recurring theme, the discourses concerning the negative, taboo aspects of contemporary urban society, Jacques Attali's Noise: The Political Economy of Music proves itself to be a vital resource when forming arguments around the impact and influence music has upon society, culture and how they may develop over time, establishing him as the second of our three theorists. Attali's main argument outlines the prophetic nature of music, as it reveals to us a plethora of discourses, codes and social behaviours that are gradually absorbed into the collective unconscious. Further,

Like the cattle herd of the Nuer discussed by [René] Girard, a herd that is the mirror and doubles of the people, music runs parallel to human society, is structured like it, and changes when it does. It does not evolve in a linear fashion but is caught up in the complexity and circularity of history. (Attali 10) Thus, we shall also use historical and anthropological frameworks to analyse extreme audio culture and its discourses surrounding urbanisation and technology, not to mention its use and the fetishisation of certain technologies and machines. When examining the relationship between man and machine, particularly in regards to their perceived symbiosis, the concept of the cyborg presents itself as a fitting definition of this phenomenon, as is formulated within Donna Haraway's “Cyborg Manifesto". For this reason, she becomes the third primary theorist within our triangular framework. Speaking from a feminist perspective, Haraway discusses the image of the cyborg - a cybernetic organism, the symbiosis of biology and technology - to examine the myriad of ways in which technology and machines are becoming an integral part of our 
everyday lives such that they are extensions of our very bodies and minds themselves; hence her argument that, "By the late twentieth century, our time, a mythic time, we are all chimeras, theorised and fabricated hybrids of machine and organism; in short, we are cyborgs" (429). In defining the cyborg she states,

A cyborg is ... a creature of social reality as well as a creature of fiction. Social reality is lived social relations, our most important political construction, a world-changing fiction. (429)

Thus, when analysing electronic and machine-based art and music such as noise and power electronics - styles of which are dependent upon the artist's immersion within and connection to sound generating machines - the vision of the cyborg makes for a vivid correlation. And while it may seem, on the outset, that this study is somewhat deterministic in its standing on the impact technology has upon society, we have attempted to take neither, in the words of Bryan Pfaffenberger, a deterministic (technology governs society) nor somnambulistic (society governs technology) approach to these aspects of the discussion. Rather, we have tried to maintain a third position of technology as "humanised nature" (243) by grounding ideas within the aforementioned sociological and anthropological frameworks. Hence the recurring themes of culture and society that arise within our discussion, constantly tying us back to Attali as well as to Bourdieu's categorical understandings of social behaviours within the field of cultural production; ergo,

Bourdieu's theory of the field of cultural production covers, as indicated above, both the material and the symbolic production of cultural works, which entails taking into account the multiple mediators which contribute to the works' meaning and sustain the universe of belief which is the cultural field. (Johnson 20) 
With our primary theoretical foundation established, we can see these three theories operating in a perpetual cycle of cultural evolution. Extreme audio culture presents a special case, however. And as we shall discover in the following chapters beginning with production (technology), then moving onto distribution (society) and, finally, consumption (culture) - there is much more to be learned from 'removing our blinders', so to speak, and attending to the peripherals of these cultural flows; such as extreme audio culture and its brethren scenes within the new digital underground of music, arts and culture. 


\section{Chapter 1: Production - Machines and Cyborgs}

In an underground club in Philadelphia on the $5^{\text {th }}$ of March, 2012, an assortment of materials lies upon a table: Chains, cables, metal boxes, effects pedals, a mixing desk and a CB radio transmitter amongst other items (Breathmint). We see and hear noise artist Tinnitustimulus begin to manipulate these materials, starting with a slow turning of knobs in order to bring forth a resonant clanging sound, much like that of a broken analogue telephone ringing to no avail. As a curious audience begins to gather around, the tone and density of the clanging begins to increase into a perpetual tumbling of metallic chaos within a range of textures that one may associate with a busy scrap yard or perhaps even a demolition site in the midst of the post-explosion cleanup. Soon, however, the crashing, tumbling percussion becomes distorted into a blurred, fearsome rumble, interspersed with screeching steel-tinged spikes of sound. He then moves around the table and begins manipulating the innards of the steel box, which is revealed to be a home-made 'spring guitar', the vibrations of the steel springs fed through effects pedals and amplified to the point of a machinic roar, eliciting imagery of heavy industry like that of a steel mill. With further twiddling of effects knobs, the pitch soon lifts into a mournful robotic howl which reverberates in a tone offering suggestion that these materials may have gained entrance into the realm of the living, the sentient; gasping for breath and battling with the painful, terrifying realisation of consciousness. However, as we soon witness, this transition is not entirely exclusive, as Tinnitustimulus further extends his mental faculties through these technologies, reaching a psychic peak with his equipment: The granular, water-blast growl of the materials locking him (and various members of the audience) into a trance, generating reflections regarding the 
cognitive connection between artist and machine as well as the intuitive physicality of machinic noise; the interweaving of the biological and technological to create a new entity, one born from the realm of the residual, the unwanted and discarded.

The materials being manipulated are the refuse of dominant culture. Machinery and outdated resources which were once rendered useless and obsolete have now been modified, customised and recontextualised in order to explore their unrealised artistic and sonic potentialities. As discourses concerning industrialisation, mechanisation and the connection between artist and machine make themselves apparent, we realise that it is with artists like Tinnitustimulus where the crux of this discussion ultimately lies.

This chapter will establish an analytical framework surrounding the discussion of production and performance practices such as these within extreme audio culture which argues for the scene's sociologically and philosophically discursive connection to notions such as cyborg theory, residual media, transhumanism/singularitarianism, urbanisation, post-industrial/digital age economies and the psychological consequences - alienation, isolation, mental illness, etc. - for humanity therein; where our species stands, according to numerous discourses that arise from the works of the artists discussed below, in an evolutionary tug-of-war between the animal and the post-human.

To exemplify and contextualise these notions, a range of artists who embody various pertaining discourses shall be discussed. Beginning with Luigi Russolo, arguably the first composer to both recognise and utilise machine noise as a creative material (Medina), we start to explore the impact of industrialisation and mechanisation upon human hearing. One can also examine the inexorable impact these phenomena had upon one's identity within industrial society. This observation, taking form in the potent, confrontational manner first deployed by Russolo and the Futurists, was revived by the 'first wave' of industrial music in the mid-1970s; lead by artists such as 
Throbbing Gristle, SPK and Whitehouse who applied the approach taken by punk rock to an experimental, aggressive, nihilistic machine and electronics-based music which sought to illuminate the darker, more sinister aspects of post-industrial society. Throughout the 1980s and 1990s, artists like Merzbow took this formula into the realm of an all-encompassing form of sound art which became 'noise music' as one would recognise it today. And throughout the past decade or-so, artists such as Cementimental, Atrax Morgue and Grunt continue to explore the potentialities of noise, the materials from which it may be generated and its use as a creative element, to explore the aforementioned notions concerning technology, humanity, identity and evolution. As will be argued, the genres of noise and power electronics embody these anxieties in ways which allow us to question and examine the potential developments of contemporary urban society as we continue to utilise the organisation of sound, the language of music, in order to make sense of the cacophony of our surroundings, and decode this dissonance in forms that are increasingly extreme and, as argued by Jacques Attali, uncannily prophetic. Focusing upon production and performance practices, the relationship between artist and machine will be examined within the scene, with emphasis placed upon embodiment relations and the revelatory nature of noise as a voice which forces its audience to confront the urban, post-industrial environment unfiltered, allowing material, social and symbolic (Pfaffenberger 249) residue to seep through into our awareness, compelling the audience to address and question the 'noise' they have been conditioned to mask and/or ignore.

Extreme audio culture (and the production practices employed within it) deliberately seeks to traverse the outskirts of dominant culture in terms of its practices, ideologies and aesthetics; sometimes in protest, other times in parody, sometimes as critique, at others purely for a sense of liberation from forced social expectations, and 
always with a sense of exploration, in revealing that which has been masked by dominant culture and unearthing the hidden, discarded and taboo. ${ }^{3}$ In this sense, many artists (particularly in the styles of harsh noise and power electronics) seek to explore transgressive and grotesque subject matter. Yet extreme audio culture is incredibly diverse in its range of artistic expression due to its appropriation of 'noise', which remains a universally significant notion for all electronics and machine-based music (including rock), within the works these artists produce; extending through an eclectic spectrum of genres and scenes that share positions within the new digital underground of music culture. Conjoined by their mutual affection for noise, the link between those on the transgressive hemisphere (darker, heavier styles such as harsh noise and power electronics, which will be the primary focus of this discussion) and those on the psychedelic/dada hemisphere (related more to lo-fi indie rock and no wave) is the cyborgian relationship between artist and machine which lies heavily apparent within the art-form through its physicality and emotionally engrossing nature. Donna Haraway's "Cyborg Manifesto" exemplifies this concept clearly,

Why should our bodies end at the skin, or include at best other beings encapsulated by skin? From the seventeenth century till now, machines could be animated - given ghostly souls to make them speak or move or to account for their orderly development and mental capacities. Or organisms could be mechanised - reduced to body understood as resource of mind. These

\footnotetext{
${ }^{3}$ Many noise and power electronics artists claim a therapeutic sensation in the production of their works. For example, Gordon Ashworth, a.k.a. Oscillating Innards, states in the 2007 documentary People Who Do Noise, directed by Adam Cornelius, "I always felt that you could explain or describe or invoke certain emotional states only possible through noise. I try as much as I can to really get as deeply involved in the sound as I can and put myself in as much of a trance or a state where I feel that connection. And also, you know, that can be a highly cathartic aspect."
} 
machine/organism relationships are obsolete, unnecessary. For us, in imagination and in other practice, machines can be prosthetic devices, intimate components, friendly selves. (443)

Furthermore, this notion of the residual remains a markedly discernible attribute. In order to fully understand the production of extreme audio in these terms, it is necessary to cast our attention back to the second decade of the twentieth century, to Europe in the grips of the second industrial revolution, on the eve of the First World War; the evolution of the machine signalling potential both for our progression as a species, as well as our annihilation.

Although some theorists (Lewis Mumford (1967), Haraway) may have disagreed with the dating, the transformation of our aural experiences due to the industrial revolution can be summed up in the reflection that,

Ancient life was all silence. In the nineteenth century, with the invention of machines, noise was born. (Russolo 23)

The rise of industrialisation throughout Europe from the mid-eighteenth century onward had a drastic impact upon man's perception, ideology and engagement with reality and society as the age of the machine continued to develop. By the end of the nineteenth century, humanity's bond with the machine was becoming ever more intimate, with our ears and minds becoming conditioned to their textures and timbres, broadening the vocabulary of everyday sounds as well as our aural understanding of the urban environment, gradually extending our mental capacity for recognising and codifying sounds that are unknown in the natural world. Machines gave rise to new sensations, new states of being, new ways of living and, most specifically for the purposes of this discussion, new ways of hearing. By the dawn of the twentieth century, 
the urban centres of Europe were marked by the sounds of machines, the city of Milan being no exception. It was in this environment where Futurist artist Luigi Russolo moved away from the visual art of painting and began to attend to the aural nature of his surroundings and the extent that urbanisation and industrialisation had impacted the very nature of sound as perceived by human ears. The concept of noise was more obvious now than ever. Yet noise, by its very definition, is sound which is undesired and unintentional; by majority it is detested and/or ignored, heard but not listened to. Paul Hegerty, in his work Noise Music: A History, states,

Noise is negative: It is unwanted, other, not something ordered. It is negatively defined - i.e. by what it is not (not acceptable sound, not music, not valid, not a message or a meaning), but it is also a negativity. In other words, it does not exist independently, as it exists only in relation to what it is not. In turn, it helps structure and define its opposite (the world of meaning, law regulation, goodness, beauty and so on). (5)

Russolo, by contrast, was one of the first artists to stop and listen to this negativity, to attempt to illuminate, exemplify and give artistic value to these new textures, tones and sensations which had appeared in the face of the industrial age and their slow, yet certain, absorption into the collective human unconscious as well as their potentialities to enrich the language of music by exploring ways of utilising this new aural vocabulary within composition and performance. With the issuing of his manifesto The Art of Noises in March 1913 his intentions were made clear,

As it grows more complicated today, musical art seeks out combinations more dissonant, stranger, and harsher for the ear. Thus, it comes ever closer to the noise-sound. This evolution of music is comparable to the multiplication of machines, which everywhere collaborate with man. (Russolo 24) 
In November of that same year he was performing his first 'noise orchestra' with his home-built 'intonarumori' or 'noise intoners' (Serafin). Some of the noises produced by the intonarumori mimicked those of factories, cars or natural sounds such as wind and thunder, whereas others created sounds completely unique in their timbre.

For Russolo, as well as his Futurist brethren, the value of art lay in its potential to move humanity forward onto new perceptions, ideologies and states of being which were much more in line with the evolution of the machine and paid attention to increasingly perpetual innovation within the realm of technological advancement, our triumph over nature and subsequent humanising of it in order to fulfil our needs.

The Futurists loved speed, noise, machines, pollution, and cities; they embraced the exciting new world that was then upon them rather than hypocritically enjoying the modern world's comforts while loudly denouncing the forces that made them possible. (Scarborough)

By extending his faculties and perceptions through his machines, Russolo was unearthing these noises which were undesired, even detested, and with them creating a new musical palette to draw from; exposing the residual aspects of industrial, urban society in ways which won him both acclaim and infamy. Infamy arose in large part from an opposition to and rejection of both bourgeois commercial art and academic social art to blur the division between them and fall into the third position of 'art for art's sake', which stands as a "position to be made" within the field of cultural production, “devoid of any equivalent in the field of power and which might not or wasn't necessarily supposed to exist" (Bourdieu, The Rules of Art 76). Through drawing attention to the use of noise within musical composition and production, he was able to extend the boundaries of creative thought deeper into the realm of the machine, within which its boundaries continue to be explored and expanded; solidifying the notion that, 
Even though it is inscribed in a potential state in the very space of positions already in existence, and even though certain of the romantic poets had already foreshadowed the need for it, those who would take up that position cannot make it exist except by making the field in which a place could be found for it, that is, by revolutionising an art world that excludes it, in fact and in law. (Bourdieu, The Rules of Art 76)

After Russolo's death in 1946 came significant innovations in musical technologies which, in many ways, carried on the notions touched on with his noise orchestras. Most obvious would be the compositional aesthetic of musique concrète, which sought to discover and explore new timbres and textures by manipulating recorded sound, with material often gathered from the composer's surrounding environments such as trains, footsteps and factories; although they also manipulated conventional music, experimenting with the sonic properties inherent within gramophones and vinyl records (Taylor 45). Later, composers like John Cage - with his 1959 composition Water Walk, for example, utilising household objects such as radios, pressure cookers and electric blenders in order to explore their sonic properties (Empiricus; holotone) sought to build upon these ideas, further developing the notion of 'machine music' by capturing and manipulating sounds from their surrounding environment.

It was not until 1976, however, when the more nihilistic tendencies of futurism began to reappear within experimental, machine-based music. Along with Russolo, the 'first wave' of industrial music presents the first group of artists within what Bourdieu labels as the "consecrated avant-garde" in terms of their age, influence and longevity within extreme audio culture; the 'classics' of the scene who give foundation and structure to its heritage and legitimacy as such (The Field of Cultural Production 149). Although much has been written concerning Throbbing Gristle and their role in laying 
the foundation of what would become industrial music (see Simon Ford, Andrea Juno and V. Vale, et al.), their influence within extreme audio culture cannot be overlooked, particularly in the case of DIY production and distribution methods (discussed in Chapter Two) as well as the notion of the residual within these musical realms. It is notable to observe that the band rose from the ashes of the controversial performance art group COUM Transmissions, whose performances often included such practices as self-mutilation, vomiting, urination and various sexual acts (including intercourse) ("COUM Transmissions"; Nessi); all of which are coded as unwanted or taboo - 'noise' - in the social arena. Around the same time punk rock was emerging, industrial music was utilising a range of machinery and found objects in order to recreate and recontextualise the sound of urban alienation and decay.

The sonic experiments conducted from Throbbing Gristle's 'Death Factory' in Hackney, London saw the band constructing their own amplifiers, synthesisers and effects devices (including the now-famous 'Gristleizer' (Carter)) in order to give the audience a "psychoactive" experience in terms of aural intensity (KingHotPants). Accompanied by the startling imagery and subject matter that graced their album art and lyrics - pornography, the holocaust, serial killers, etc. - the band helped set the tone for industrial music, which became a genre typified by its interest in transgression and breaking taboos, both in terms of sound as well as visuals and ideological aesthetics; extending the concept of 'noise' past material aspects and into more social and symbolic expressions.

Australia's SPK and England's Whitehouse were bands contemporaneous with Throbbing Gristle, helping to define the foundation which would lead to the rise of extreme audio culture through the 1980s. SPK's 1979 7" single for the track 'Factory' is notable for containing two B-sides: 'Retard' and, more significantly, 'Slogan'. These two 
tracks seem to encompass not only the experimentation and confrontational nature of early industrial music yet they also bring forth a range of materials and sonic aesthetics typical in much of noise and power electronics; screeching metallic howls, coarse rumbles, a frantic and seemingly desperate energy and lyrical content pertaining to societal ills and the more grotesque aspects of human nature, delivered in an aggressive, physically threatening manner: "Kill, kill, kill for your inner peace! Bomb, bomb, bomb for your mental health! Therapy through violence! Working circle explosives!” (SPK, "Slogun.”)

The next major stepping stone is Whitehouse, who would go on to coin the term 'power electronics' with their own brand of abrasive, abstract and boundarypushing industrial music which saw them gain both notoriety and a dedicated fan-base. Much like Throbbing Gristle, Whitehouse shared an interest in the taboo, the transgressive and the more undesirable aspects of human behaviour, albeit on perhaps a more intense and pronounced level than their predecessors. Despite the controversy the band managed to instigate throughout the 1980s they remained, not surprisingly, an underground phenomenon, yet their influence on extreme audio culture is important. For instance, "their third release, Erector, was one of the first to fully take advantage of the dynamic potential of electronic music. Considered by many as the first power electronics record, Erector set the standard for aggressive experimental noise" (Schaefer). However, as shall be discussed in due course, Whitehouse and the broader power electronics genre pose some vital questions within the context of the moral, ethical and philosophical. ${ }^{4}$ Akin to the field of 'shock art' in many respects, power electronics soon

\footnotetext{
${ }^{4}$ Their debut album, Birthdeath Experience (1980), exemplifies many of the notions we explore with power electronics concerning the overlooked underbelly of contemporary urban society. The album artwork features a dilapidated apartment block, complementing such lyrical themes
} 
proved itself to be a style which decocted the transgressive nature of industrial music to its most provocative and extreme form, and what lies at the heart of many works are desires very much in line with both Throbbing Gristle and even Russolo: The unearthing of the residual, the 'noise' of urban living and industrialisation which is embodied by much of the taboo and anathematic subject matter of their releases. While the band's excessive approach to industrial music remains noticeably influential, there began to emerge a number of artists who saw the potential of the genre in constructing more refined and conceptual music which further blurred the line between high and low culture.

In 1979, Masami Akita began operations of his Merzbow project in Tokyo, Japan; as well as his own DIY cassette and mail order label 'Lowest Music and Arts' (Couture). Unlike Whitehouse, who emerged out of the post-punk and industrial scenes, Akita began his musical career in numerous progressive rock bands before shifting his interest to purely avant-garde practices. Taking his influence from free jazz, musique concrète and other electro-acoustic techniques - borrowed from composers such as Karlheinz Stockhausen - Merzbow began taking a more refined approach to noise music, emphasising the craft of shaping dissonance and feedback into a sonic sculpture, drawing upon the perceptions of another major influence, Iannas Xenakis, who states,

Music is unified with the sciences in thought. Thus, there is no break between the sciences and the arts. ... Henceforth, a musician should be a manufacturer of philosophical theses and global systems of architecture, of combinations of structures (forms) and different kinds of sound matter. (qtd. in Attali 113)

as deviant sexual acts, rape, sadism and a seemingly brutal critique of mainstream popular culture (especially in the track 'Rock and Roll'). 
What Akita shares with his Western contemporaries, however, is a fascination with the taboo and transgressive (i.e. social and symbolic noise), especially in regards to the erotic. He would go on to write for various pornographic magazines, score music for bondage performances (which would accumulate into three albums) and author numerous books on BDSM and fetish culture. In fact, his early Pornoise cassette releases were packaged along with home-made collages of pornographic images.

I made many collages using pornography as it was a very important item in my mail art/mail music. I thought my cheap Noise cassettes were of the same value as cheap mail order pornography. These activities were called Pornoise. In this direction, I would say that I used pornography for its anti-social, cut-up value in information theory. (Akita, Interview with Chad Hensley)

Most interesting of all, especially in regards to the theme of this discussion, are Akita's observations and literature surrounding both animal rights advocacy and urban architecture. Here we can observe not only an interest in the urban environment in the Merzbow project through his admiration of and authorship around modern architecture, but also the critique of the treatment of animals as commodities (Akita, Interview with Roger Batty; "Merzbow”); voicing concern regarding such socially accepted practices as the killing of animals for the production of meat products as well as industrial institutions such as slaughterhouses. Socially accepted these institutions may be, they are also problematic in their function of death and dissection, as well as the aural noise and pollution they emit. Hence their location on the boundaries or surrounding countryside of towns and cities, remaining out of sight, and thus out of mind, of the general populace. Connecting this notion back to Merzbow and extreme audio culture in general, 
When music is central to ritual, to sanctioned transgression, it is effectively not music: It is the noise that will gradually, progressively be excised in the same way that, for [Georges] Bataille, we move cemeteries and abattoirs to the outskirts of towns. (Hegerty 7)

As with Russolo, the pure essence of noise music and power electronics is a praxis which alerts us to that which we usually ignore or filter out from our sonic landscape, extending also to the social, moral and ideological aspects which underlie and are governed by the technological and industrial factors at work in contemporary society. Extreme audio culture reifies the amplification of that which is around us all the time; the gathering of aggregate sonic and philosophical residue which condenses around the exterior of our field of perception and experience as citizens of both the digital and post-industrial age. The production of noise and/or power electronics connotes a sense of exclamation and emotional chaos due to the increased pressure of social and emotional isolation brought about by the rise of urbanisation (Hynes) and the notion of a growing apathy between individuals in the social field (Yudkowsky). Particularly over the past twenty years, with the rise of internet technology and cyberculture, one's personal barriers are noticeably stronger than ever due to a sense of our existence becoming more personal (Marche); the suggestion of collective human consciousness becoming digitised, and thus its physical presence being somewhat redundant. It has always been the role of dominant culture to define that which is obsolete or disposable in terms of the material (technologies and machines), social (language and meaning) and symbolic (codes and value systems). As Michelle Henning states in her essay "New Lamps for Old", "Yesterday's latest thing is today's trash, and history can be seen not as an onward march but viewed backward, as the production of obsolescence, the piling up of detritus" (60). The vacuum of Moore's Law (the idea in 
which computer power doubles roughly every eighteen months) is testament to this culture of obsolescence and brings into question issues concerning outmoded and discarded technologies, practices and ideas; their value and unrealised cultural potential remaining unexplored as they are laid to rest upon the 'cultural scrap heap' constructed by these positions of dominance.

In an artistic sense, within the context of the field of cultural production, we may observe this seemingly volatile relationship between the dominated and the dominant as a cyclic movement, a yin-yang scenario where the underground (restricted sub-field/'pure' art) and the overground (large-scale sub-field/'commercial' art) share the commonality of a mutual existence defined by their contrariety.

Even if they are totally opposed in their principles, the two modes of cultural production, 'pure' art and 'commercial' art, are linked by their very opposition, which acts both objectively, in the form of a space of antagonistic positions, and within minds, in the form of schemas of perception and appreciation which organise all perception in the space of producers and products. And the struggles between holders of antagonistic definitions of both artistic production and the very identity of the artist contribute to determining the production and reproduction of the belief which is both a fundamental condition and an effect of the functioning of the field. (Bourdieu, The Rules of Art 166)

We may thus begin to understand how those within the dominated position of the 'pure' artist make use of discarded, unwanted materials; cyborg upgrades that allow them to give their thoughts and perceptions a realised form. In order to fully recognise the cyborg in extreme audio culture it is useful to draw upon visual, as well as aural case studies to observe and illustrate the relationship between the artist and the machine; how one extends oneself and his or her human faculties through the practice of the 
production of extreme audio and what new species is created in the process. Many of these ideas can be found in the work of artist Tim Drage, a.k.a. Cementimental, whose use, misuse and abuse of both standard musical equipment and modified soundgenerating machinery work to connect both artist and machine into a symbiosis which seeks to illuminate and amplify the notion of noise and the residual in terms of the creative act. It is interesting to observe how noise music has become such a hobbyist's culture within the past decade or so with as many extreme audio projects active now than ever. Although there are certainly more social and symbolic avenues at work here in terms of the attraction to extreme audio culture, there is also a sense of great intrinsic value connected to the practices of constructing gear set-ups, circuit bending, deconstructing and modifying equipment and the satisfaction attached to combining art and technology within these creative practices. In this sense, the notion of the cyborg exists within the parameters of the utilisation of the equipment itself, as art and machine become intertwined within a complex set of ideologies and resulting discourses pertaining to creative expression, and the numerous codes and connotations that surround perceived notions of how sound should be organised and how machinery should be used to fulfil this purpose. Said discourses include connotations regarding the wastefulness of dominant culture, planned obsolescence, etc.; where much of the residual materials Drage uses to produce and perform still contain utility and value within an artistic context at least. Yet there also exists observations concerning not only a physical connection with the machine, but also an emotional, cultural connection which extends, in one way or another, throughout the youth of the digital age and their relationship to machines and electronics; whether purely as nostalgia and retro chic, or as something deeper and more meaningful which signals, either way, reflections of the man-machine, the cyborg, the post-human. 
The official Cementimental website (http://www.cementimental .com) contains a plethora of images, descriptions and audio samples of various circuit-bent devices including speak \& spells and toy keytars. Also contained among the assortment of modified devices are circuits taken from siren systems and toy ray guns rehoused inside of cardboard boxes and fitted with various amplification, pitch, feedback and distortion controls (drawing back to notions of Russolo's intonarumori). However, apart from the siren circuit, these modified, rearranged and recontextualised devices seem to instead offer discourses concerning sound-generating children's products and their role within consumer culture since the arrival of the digital age. Other devices include what Drage calls the 'Ghost Box', a Ghostbusters themed voice-changer toy which has been circuitbent and modified to produce "a range of harsh, distorted tones, sarcastic screams, and electrical crackling, as well as arctic gale soundscapes, laser barrages, a bassy hardcore beat and just sheer noise." There is also a modified battery-powered toy machine gun which acts as a beat generator and a 'vivisected' talking plush Pikachu key ring in which the voice is pitch-shifted beyond recognisability. From this we can gather a sense of the increasing interaction with electric and/or battery-powered sound generating devices that children of the digital age undoubtedly grew up with. The 'noise' of these devices has now been distorted and amplified in order to accentuate this notion of noise and elicit connotations regarding the rise of consumer culture within the digital age and the increased attraction of young people to electronics and machines. The same could well be said of the music genres of 8-bit and chiptune which centre around the 'hacking' and manipulating of sounds generated form outdated video game devices both hand-held and in console form. These generations who grew up mentally and emotionally connected to these toys and instruments are now reinstating cultural value and discovering new uses, meanings and pleasure from them which extend past their intended use, into the realm of the residual; the obsolete, outdated and discarded. 
Furthermore, as successive generations come to recognise and use digital devices and electronics as simply a prescriptive element of their everyday lives, they only continue to realise that, "to borrow [or, in our case, return to] a phrase from Haraway, the machine is not an it, the machine is a partner" (Albiez and Pattie 125).

Within the production and performance of his works, Drage incorporates not only a range of devices and machines (some his home-built contraptions, others more conventional musical equipment such as effects pedals and mixing desks, albeit misused and abused in typical fashion of extreme audio culture), as well as a frantic, immersive and seemingly trance-like engagement with his equipment and resulting sound; evidence of this lying in the video footage captured of a live performance at 2012's Splitting the Atom festival in Brighton, England (timdrage). This 'trance-inducing' aspect of noise production, these "existential technological relations", fit rightly into Don Ihde's notion of "embodiment relations"; by which he means,

...in this use context I take the technologies into my experiencing in a particular way by way of perceiving through such technologies and through the reflexive transformation of my perceptual and body sense. (507)

Much like any musician, there is established a cognitive link between the individual and their chosen musical technology which seeks to reinforce the cyborgian notion of extending one's body and faculties through machines, the artist channelling their thoughts, tenets, perceptions and emotions through their equipment, embodying it as if it were merely another limb, another mouth for which to speak, sing or scream. In the case of noise and power electronics, one may conclude that the emphasis is on the third technique here, as the machines continue their syncretisation into the realm of the biological (reflected within the physicality and bodily affect of the music itself); the fusion being incited by the artist wishing to assume the voice of the machine for an 
instant, attempting to formulate the specific tone or frequency which will weld this psychic connection in place with "total transparency", as Ihde would say; "total embodiment, for the technology to truly "become me"' (509). Further, this brings us back to both Haraway's cyborg as well as towards the idea of the 'post-human', for which transhumanist theory holds as our next phase of evolution as a species, when human biology and technology will share a truly symbiotic relationship (Bostrom). If this notion were to be realised, it would hold significant consequences for humanity, particularly as boundaries in the definition of our species would soon stand to be redrawn and redefined by those within positions of dominance.

The dichotomy between the human and the animal has, of course, remained one of the most important issues within philosophical thought. ${ }^{5}$ However, our current stage of societal evolution reveals a more complex series of questions concerning the relevance of this human/animal binary, centring upon not only our species' detachment from the status of animal, but the perpetuating theories concerning the next stage of our evolution. Particularly with the leap computer, communications and cybernetics technologies have taken since the 1970s and our entrance into the digital age, art (e.g. cyberpunk), science and the humanities have found common ground in addressing these issues which present pressing implications for humanity regarding their impact upon our physical, mental and (depending on one's beliefs) spiritual being in the everaccelerating advancement of the machine; leading us to contemplate issues such as the notion that,

\footnotetext{
${ }^{5}$ See Oliver, Kelly. "Stopping the Anthropological Machine: Agamben with Heidegger and Merleau-Ponty." PhaenEx 2.2 (2007): 1-23. Web. 26 Feb. 2013. Oliver discusses this notion by drawing from theorists such as Martin Heidegger, Giorgio Agamben, Maurice Merleau-Ponty and Jacque Derrida, et al.
} 
Transcending the body through technological improvement redefines its achievements as limits, and it offers endlessly renewed marks of privilege and power. Seeking power, we empower our extensions. The paradoxes of this translation return inevitably to haunt its subjects. (Berland 325)

From a contemporary standpoint, there is a significant struggle manifesting between mankind's archaic animal side and its progressive post-human side; the two trends evidently at conflict as issues such as war, terrorism, social unrest and economic ruin being at the forefront of concerns our civilisation confronts in the second decade of the twenty-first century. This battle between the two sides of our potential identity is what theoretical physicist Michio Kaku describes as the transition between what is known as a type zero civilisation and a type one civilisation. "The danger is the transition between type zero and type one, and that's where we are today. We are a type zero civilisation, we get our energy from dead plants; oil and coal. But if you get a calculator, you can calculate when we will attain type one status. The answer is, in about a hundred years, we will become planetary" (bigthink, "Michio Kaku: Big Think Interview"). He continues,

The danger period is now. Because we still have this savagery, we still have all the passion, we still have all the sectarian, fundamentalist ideas circulating around. But we also have nuclear weapons. We have chemical, biological weapons capable of wiping out life on Earth. So I see two trends in the world today. The first trend is toward a multi-cultural, scientific, tolerant society, and everywhere I go I see aspects of that birth. ... So whenever I open the newspaper, every headline I see points to the birth pains [author's emphasis] of a type one civilisation in formation. However, every time I open the newspaper, I see the opposite trend as well. (bigthink, "Michio Kaku: Big Think Interview") 
The aspects of the first trend relate to the emergence of type one (digital) technology - such as the internet, which Kaku describes as, "The birth of a type one telephone system" (bigthink, "Michio Kaku: Big Think Interview”) - a type one language (English), a type one economy (the European Union, for example) and type one culture (most notably popular music, but also fashion and sports); a globalised uniformity which remains unavoidably problematic as far as aspects such as identity are concerned. For transhumanists however, the attainment of the status 'post-human' lies within more than brain augmentation and cybernetic implants to improve our physical selves. They also argue that we must prepare for the coming 'singularity', where the advancement of technology becomes so rapid that it surpasses human intellect, the moment in which machines become just as advanced, intelligent and autonomous as ourselves (Kraft). However, we must not forget that this is all still very much within the realm of scientific and philosophical speculation, with some theorists remaining uncertain as to whether the singularity will happen at all (bigthink, "Michio Kaku: How to Stop Robots From Killing Us”). Yet these ideas still pose vital and fascinating questions regarding the status of our species; our fate, as we continue to delve into the transhuman age, into the realm of the post-human, Kraftwerk's Man-Machine or, of course, Haraway's cyborg. Now we can observe the opposite trend, which is where much of the anxiety surrounding transhumanism is born. This is the aspect of the animal, of the irrational and the purely instinctive. Referencing the realm of sciencefiction and cyberpunk, one of the greatest criticisms of transhumanist theory revolves around a recurring theme within cyberpunk fiction: The notion of a societal divide which goes beyond class, race or religion, and falls more into the realm of a new divide in genus; much like that of the animal and human, this new divide will lie between the human and the post-human. 
The extreme audio artists' engagement with their machines (particularly acts like Prurient and Grunt) present a violent, sadomasochistic relationship, and in the case of power electronics this physically and emotionally intense symbiosis tends to bleed through into not only the aural aspects of the produced texts, but also their visual and symbolic aspects. The genre of power electronics touches upon issues of this conflict which highlight the moral, ethical, psychological and political factors at play within the more cruel and visceral corner of the human psyche. The struggle between animal and post-human is presented in its most vivid form here as the style endeavours to traverse themes ranging from sexual obsession, deviancy, abuse, sadism, physical violence and murder to subjects such as fascism, racism and misogyny. Coupling these contents with extreme electronic frequencies and textures we have the devolved (the aforementioned subject matter; the animal) and evolved (the symbiosis of flesh and machine; the posthuman) at odds with each other upon the increasingly more vulnerable battlefield of the psychological.

The power electronics scene abounds with artists who portray this notion extremely well. Firstly, Marco Corbelli a.k.a. Atrax Morgue, whose works commonly dealt with what one may perceive as some of the greatest afflictions of urban, digital, post-industrial society. Corbelli himself suffered from severe mental illness (which tragically lead to his suicide in 2007). He was known to have a pronounced obsession with death, sadism and other deviant behaviours such as necrophilia, as well as a strong, perpetual sense of isolation and alienation from the rest of contemporary society, finding solace by expressing and venting his frustrations and inner demons through power electronics (“Interviews"), a style for which he became one of the most acclaimed and influential figures within the genre (Tommuel). In an interview for EsoTerra Magazine in 2001, posted on his official website 
(http://digilander.libero.it/atraxmorgue/pag/navigator.html), he states, "Alienation is just a rule for me. I have learned to survive with my alienation. But alienated by what? By people? By myself? I hate people, 'cause I hate myself. I despise people, 'cause I despise myself. I see the horror through others because I am the horror. It's all a reflection, a deformed mirror" (Corbelli). Later, when asked about his feelings on contemporary society in his native Italy he continues,

You can change any place in the world but you can't change your mind and your interior life. I've always felt outside of society, living in my closed, aseptic world. A world I've created specially for myself. I love to travel, but I'm always feeling the same sensation any place I go - like a visitor from an outer space. (Corbelli) Within the production of power electronics, there is indeed something to be said about the sincerity of the artists as evidenced in the works they create, particularly in terms of the subject matter presented and the raw, uncompromisingly emotional approach they take in performing, recording, packaging and representing their pieces. Bourdieu addresses this notion by claiming that,

Sincerity (which is one of the preconditions of symbolic efficacy) is only possible - and effective - in the case of a perfect, immediate harmony between the expectations inscribed in the position occupied and the dispositions of the occupant. One cannot understand how this agreement, for example between most journalists and their newspaper (and by the same token the readership and the newspaper), is established without taking into account the fact that the objective structures of the field of production are the basis of the categories of perception and appreciation which structure the perception and appreciation of the different positions offered by the field and its products. (Bourdieu, The Rules of Art 164) 
Although there are many arguments concerning how transgressive the works can be without the artists truly experiencing the subjects they present - complaints that many power electronics artists don't “walk the walk” (jesusfaggotchrist) - we must consider the fact that, "The genre exists (and stop me if I go too far) to explore power relations between people, to look at what it means to kill someone and why someone would kill, not to actually do it" (raperies (like draperies)). So, whether Corbelli actually indulged in necrophilia and homicide as he spoke about in his art is irrelevant. What is relevant here is his use of this art form to explore both himself and humanity in general. Embodying his chosen machines in order to explore his own mind - his illness, despair, anger, isolation, alienation, fantasies, urges and nightmares that plagued him up until his death - and attempt to understand it in a manner he felt most suited to venting and giving form to his internal world. And while some artists remain ambiguous in their sincerity, an approach which, to Andrew Whelen, remains ineluctably problematic when addressing transgressive and deviant themes within their works (468), there remains the signal discourse concerning the recording of noise and power electronics as a documentation of warfare within realms of the psychological, sociological, cultural, artistic, biological and, indeed, technological. The recorded texts themselves seem to offer testimony to an era beset by issues within these frameworks. As we shall explore further in Chapter Two when we discuss the recording, packaging and distribution of works, and Chapter Three through the examination of collecting and audience engagement, each release acts, in this light, as yet another document containing these exclamations and explorations; every CD, cassette, vinyl or MP3 "transports the particular text that marks its distinctiveness, but each, as well, transports and stores sets of cultural knowledges that may be mobilised in the viewing [or reading] of other texts" (Straw, "Embedded Memories" 9). 
In this regard, we can read Mikko Aspa's Grunt project as taking this state of conflict and aggression into the realm of the erotic. Much like Masami Akita (a.k.a. Merzbow), Aspa is heavily involved within the BDSM and fetish culture in his home country of Finland, producing numerous pornographic video works within the field (he also owns and operates the Freak Animal label and magazine, as well as the extreme audio magazine Special Interests). His pornographic works often feature as the visual element for his live performances, adding context to the aural elements by encompassing the erotic and sadomasochistic themes throughout the recorded works of Grunt. In video footage taken from the Deadly Actions V festival in Lille, France in 2002 (escapefromnoise), we can witness both the aural and visual elements of power electronics intertwining into a complex set of discourses concerning this animal versus post-human struggle within the sexual realm. As Aspa's droning, dissonant feedback and coarse, distorted vocals sound out the physical, erotic aggression of the machine, the video footage works to personify this notion as we see a leather-clad female figure bound to a bed-frame where she has melted candle wax dripped upon her bare flesh and is whipped by a masked man. A significant aesthetic feature here is the female subordinate of this act donning a gas mask which signifies a fetishisation of military equipment and also industrial, chemical production; the eroticisation of the machine. When observed through the context of the post-human and/or cyborg, we get a sense of this struggle of transition within the sphere of the physical, the sensual, as the mechanisation of the human body and the transformation of flesh into steel creates an urge to reconnect with our primal senses and instincts through bondage, pain and sensory isolation; BDSM culture drawing upon the understanding of the link between fear and elation, aggression and arousal, pain and pleasure. 
With Aspa's work, he exemplifies this notion in order to reveal the importance of the sensual realm, in both positive (pleasure) and negative (pain) aspects, as part of the spectrum of human experience; the latter remaining coded as social and symbolic noise, echoing the notions drawn by Hegerty explored earlier. There is a sense that, due to the graphic nature of the visual and lyrical subject matter of Aspa's work, he may be succumbing to the realm of sensationalism and 'shock value' in terms of his artistic output. However, as stated above, power electronics can be perceived as important within residual culture in this sense in much the same way as shock art or transgressive art by jolting the audience to attention and forcing them to ask questions concerning morality, artistic credibility and, in this case, the state of our species within contemporary society. As Anthony Julius states in his book Transgressions: The Offences of Art, one of the reasons it is important for art to transgress is "that it is the job of art to shock us into grasping some truth about ourselves, or about the world, or about art itself, and that one way in which it does this is to alienate us from our preconceptions, by making the familiar strange and the unquestioned problematic" (26). He continues, “Art's audience needs to be coerced out of its complacencies, and only the most jarring, disturbing art can do this" (33). However, there is also a danger here of becoming too celebratory in the deviant nature of the power electronics genre. Although one can argue that there is, indeed, considerable merit in it as a form of transgressive, boundarypushing art, the niche existence of power electronics proves to be somewhat problematic in this sense. If we use the metaphor of the production of power electronics as the production of pornography (much like Merzbow's Pornoise releases) then we may also look to Julius for further insight,

The subversiveness of pornography has been overstated. It can, on occasion, break the rules. It may, perhaps, subvert certain conventions. But its fantasies of 
licence tend to reinforce the regularities of conventional sexuality. It offers an imaginary universe in which certain given values are suspended. It cannot precipitate political liberation, notwithstanding the fears of cultural conservatives. Confined to magazines, clubs and the internet, it does not test its consumers, it feeds their addiction. (64)

We discover underground culture in the digital age as acknowledging a civilisation in the throes of a repulsion-fascination paradox in terms of violence and deviancy; the rise in the commoditisation of sexual imagery within advertising, music videos and most other visual media lays bare this paradox by illuminating a tacit social desire to reveal the hidden, primal animal nature of ourselves yet being restrained by an engrained sense of shame and outrage, especially when one surrenders to the increasing eroticisation of the fetishised material commodity - spreading out the dreams and repressed thoughts of a society upon the surfaces of images (billboards, posters, television) allowing myths, and therefore insatiable desires, to reign over the urban environment (de Certeau 19). When addressing the works of these artists, especially in regards to some of the more questionable subject matter presented within album artwork and promotional materials, perhaps Andrew Whelen best sums up this notion in regards to extreme audio culture by claiming that,

This is precisely the point noise raises: Pornography is a matter of how some media form is used, and conversely, the apparently pornographic can be used to critique the moralistic position which is unable to acknowledge that. As with the common use of pornography as album covers in grind[core], noise suggests that what gets defined as 'sick' and thereby criminal is based on a massive and constitutive other of media representations which spring from and normalise an ostensibly repressed interest in violence. (472) 
This idea seeks to reinforce the previous statement in positioning power electronics within the field of shock art or transgressive art. To the seemingly prudish and/or uninitiated, shock art stands as meaningless goading, yet this style of artistic expression is certainly not without purpose. The utility of shock art and/or transgressive art lies within the power it creates: The power to (of course) shock, to force the observer to think about what's in front of them, often - much like in the case of harsh noise and power electronics releases - ambiguous in its exact 'meaning', this ambiguity challenges the audience to make up their own minds and to question, problematise and reinforce notions of morality, decency, tolerance and humanity.

With this, we may conclude that the recorded works of extreme audio culture act as a metaphorical documentation of the cyborgian birthing pains attributed to the transition between our current, type zero, civilisation and the speculated, type one, posthuman civilisation. Although underground music has always been concerned with revealing the more overlooked and taboo (residual) aspects of dominant culture and society, with the ascendency of the internet as a primary communications tool and the increasing ease to which one may have access to underground culture (returning to the analogy of noise as pornography) these hidden aspects are percolating towards the surface now more than ever; particularly as extreme audio culture has now established itself as a legitimate and influential (albeit still very niche and divisive) art-form and hobby. Tying into Attali, we may reinforce this argument by observing that, If art can, as [Marshal] McLuhan suggests, teach us about our environment through which we swim like oblivious fish, then new musical practices will draw our attention to these processes in some way. They will illuminate the tension between old and new techniques and the new possibilities that arise from them. They will remind us of music's ability to evoke history and memory, changing 
configurations of the human body, and the social production of space and time. (Berland 326)

So, with the production of works and the recording of these documents, these artefacts of the transhuman age, we arrive at the processes and practices of their distribution which serve as our primary focus of discussion in the next chapter. Due to its position amid the new digital underground of online music and arts, extreme audio culture draws from its lineage within industrial music culture and the early practitioners of noise music as an art-form, by taking the ideas laid out by pre-internet DIY music culture and adapting them into the realm of the digital. Zines, mail order catalogues and underground, independent labels may be less prevalent in the physical realm, but within the new digital underground we may find that this culture is still alive and well; still functioning within the framework of the residual. 


\section{Chapter 2: Marketing and Distribution}

Although one must be cautious in addressing the punk movement in overtly celebratory and utopian terms, there is no denying that its approaches and practices regarding production, performance and distribution of works present a noticeable influence upon alternative and independent music which still resonates in the present day; creating "the grooves to which practices and affinities become fixed" (Straw, "Scenes and Sensibilities" 254). There had, of course, been various instances of independent and DIY practices within the marketing and distribution of music before the genre's official christening in 1971 (by music journalist Dave Marsh (Van Dorston)), however, the punk rock scene ${ }^{6}$ was unique in its outwardly political and strongly individualistic ideologies concerning the creative process and the utilisation of music as social critique and catalyst for raising awareness of societal ills, alternative views and various concerns regarding the power and influence of dominant culture; capitalism, consumerism, war, poverty and the increasing mechanisation and digitisation of society at the dawn of the post-industrial age. Although the scene eventually passed into mainstream culture and was transformed into more commercial styles, i.e. new wave (McDonald), there were a significant number of artists who continued to rally against 'the 'economic' logic of the literary and artistic industries which, since they make the

\footnotetext{
6 "Here, as elsewhere, 'scene' will describe unities of highly variable scale and levels of abstraction. 'Scene' is used to circumscribe highly local clusters of activity and to give unity to practices dispersed throughout the world. It functions to designate face-to-face sociability and as a lazy synonym for globalised virtual communities of taste" (Straw, "Scenes and Sensibilities" 248).
} 
trade in cultural goods just another trade, confer priority on distribution, on immediate and temporary success, measured for example by the print run, and which are content to adjust themselves to the pre-existing demand of a clientele" (Bourdieu, The Rules of Art 142). These perceptions permeated into the underground distribution of many bands, most notably anarcho-punk outfit Crass, which opted to remain strictly independent and in full creative control of their releases by handling the distributive and promotional work through hand-made zines, flyers, mail order catalogues, album sleeves and sending their recordings to the pressing plant themselves rather than relying on major record labels and constricting contracts; situating themselves within "the anti'economic' economy of pure art. ... ... oriented to the accumulation of symbolic capital" (Bourdieu, The Rules of Art 142). It is notable to observe how movements such as punk, hip-hop and, of course, industrial music began life around the same time as new technologies began to emerge and old technologies became much less expensive and easily accessible to the general public.

All they needed was the money to press their singles and a belief in themselves. Not only was this sometimes the only way a band could actually get their music released, it also continued the access aesthetic promoted in zines - that anyone could produce their own media. The news began to spread; that it was surprisingly easy to gain access to cheap recording studios and pressing plants, where your records would be manufactured. The demystification of the industry had begun; there was no big secret, the process of releasing records wasn't difficult to understand or achieve. (Spencer 324)

Thus, with the first wave of industrial music rising in 1976 we can observe the growing prominence of the notion of the residual in popular music as these distinctly urban forms (punk, hip-hop and industrial) begin to not only sound out this concept 
through performance and production of works but also their documentation in the process of recording and distribution; processes which extreme audio culture would seek to incorporate within the very structure of the works themselves, creating its own regimes of value within the trade and marketing of releases. This chapter explores the practices and intricacies surrounding the marketing and distribution of works (releases), focusing upon the ways in which institutions such as labels, as well as recording techniques, formats, packaging and album artwork, have evolved and adapted to become part of the new digital underground with artists and label owners taking full advantage of the subversive, exploratory mind-set and transgressive nature which the scene has consistently embodied.

Our notion of the residual is exemplified in many of the approaches and techniques used by the artists who would come to encapsulate the 'first wave' of industrial music. Through the subversion of marketing and distribution practices perceived as dominant in their coding, recontextualising the punk ethos and pushing it one step further to explore alternate modes of business practice, the scene came to stand in oppositional parody of the mainstream music industry in a manner akin to, yet arguably more abrasive, than that of its cousin (punk rock). Bourdieu, when discussing the restricted sub-field of cultural production and 'pure art', solidifies this notion by observing that it "is not merely a laboratory where this singular art of living that is the style of an artist's life is being invented as a fundamental dimension of the enterprise of artistic creation. One of its major functions, and yet one always overlooked, is to be its own market.” Furthermore,

This society [of pure art] offers the most favourable and comprehensive welcome to the audacities and transgressions that writers and artists introduce, not only into their works but also into their existence (itself conceived as a work 
of art); the rewards of this privileged market, if they do not manifest themselves in cold cash, have at least the virtue of assuring a form of social recognition for those who otherwise appear (that is, to other groups) as a challenge to common sense. (Bourdieu, The Rules of Art 58)

Returning to Throbbing Gristle and their independently owned and operated Industrial Records label, the band sought to experiment not only with the generation and organisation of sound but also with the way these organised sounds were recorded, packaged, promoted and marketed. As with their punk contemporaries, the industrial acts began to recognise the overtly Fordist functionality of the mainstream music industry. That is to say "... mass consumption combined with mass production to

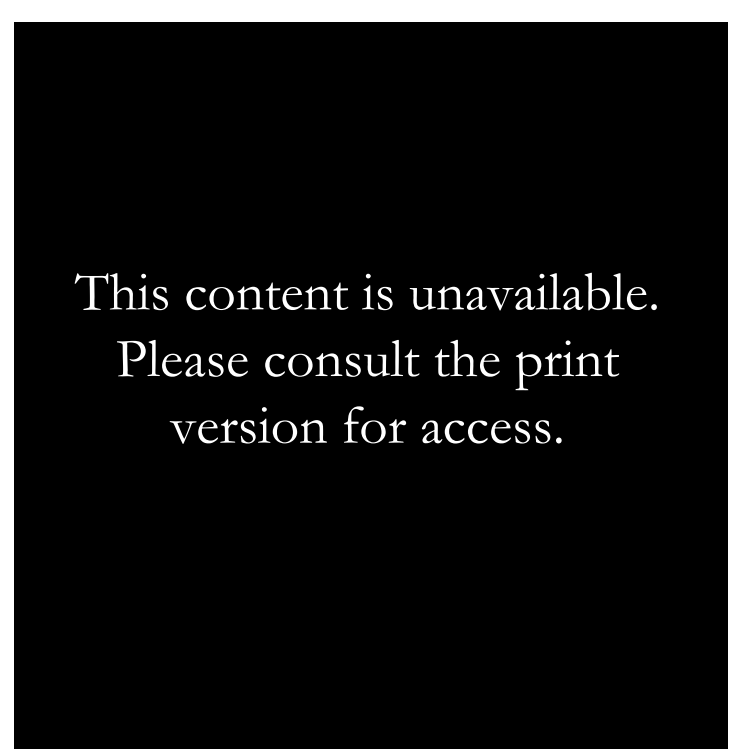

Figure 1: The Second Annual Report of Throbbing Gristle (1977), thephenomenalsneeze. "Review ::

Throbbing Gristle :: The Second Annual Report." Machine Dream. Blogger, 2012. Web. 14 Jan. 2013. produce sustained economic growth and widespread material advancement" (Thompson) or “.... a system of production based on the assembly line, which is capable of relatively high industrial productivity" (Gambino), and in the case of Throbbing Gristle and Industrial Records, approached the practices of releasing works with a strong emphasis on satire and détournement. ${ }^{7}$

${ }^{7}$ According to a 1959 essay, published in Internationale Situationniste \#3, détournement is "the reuse of pre-existing artistic elements to form a new ensemble. ... The two fundamental laws of détournement are the loss of importance of each détourned autonomous element - which may go so far as to completely lose its original sense - and at the same time the organisation of another meaningful ensemble that confers on each element its new scope and effect" (SI). This was a technique used by the Situationist International in order to make effective political 
The appropriation of dominant codes and structures inherent within post-industrial society - product manufacture, consumer culture, etc. - lay in accompaniment to their music as a stark critique of these hegemonic codes of practice. For instance, their debut LP, The Second Annual Report (1977), features a plain, white sleeve accompanied by standard black print, allowing the release the aesthetic of an official government or business document in a seemingly tongue-in-cheek mockery of not only the music industry, but mass consumer culture and dominant power structures which define the sterile materialism of post-industrial urban society (see Fig. 1). In these subversive acts, where dominant codes are reappropriated in order to change or even reverse their intended meaning, one can read works such as The Second Annual Report of Throbbing Gristle as portraying an overarching feeling of inhumanity inherent within postindustrial urban Europe. Continuing in this sense, into similar connotations drawn from noise music and power electronics, one may be able to consider that,

If an excess of life is death, then noise is life, and the destruction of the old codes in the commodity is perhaps the necessary condition for real creativity. No longer having to say anything in a specific language is a necessary condition for slavery, but also of the emergence of cultural subversion. (Attali 122)

A release which is also worth mentioning here is Throbbing Gristle's limited edition and highly sought-after 24 Hours (1980) box-set compilation, consisting of twenty-six cassettes featuring various live performances recorded from 1976 to 1980. The sheer length and scope of the project makes it a daunting release in terms of engagement, even for the hardened fan. But what makes this release all the more interesting is that it was packaged within a briefcase sporting the band's 'lightning bolt' logo (see Fig. 2) which, notably, was appropriated from the British Union of Fascists 


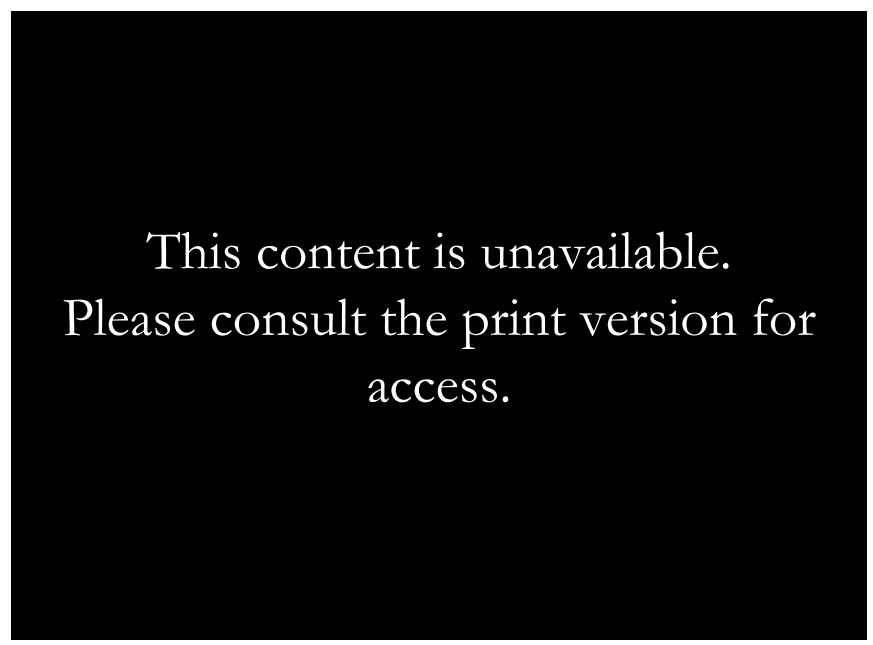

Figure 2: 24 Hours by Throbbing Gristle (1980), Zchivago, Jonny. “Throbbing Gristle - '24 Hours' (Cassette Version) Industrial Records 1980.” Die or D.I.Y.? Blogger, 2011. Web. 20 Aug. 2012.
(Bonomi). Connotations emerge

immediately for those individuals

'clued up' enough to be able to

decode these elements. "At the

limits of meaning", however,

when artists use taboo and

transgressive

materials/signification in their works without explanation or

context, "ambiguity and a refusal of closure is open to (mis)interpretation in the mundane ways one would expect" (Whelen 468) - which may attribute to the substantial controversy the early industrial groups tended to accumulate, the most notable for Throbbing Gristle being their labelling as the "wreckers of civilisation" by English MP Nicholas Fairbairn ("Throbbing Gristle"). Yet what acts such as Throbbing Gristle and labels such as Industrial Records were ultimately trying to make with such methods was a statement regarding the hegemony of post-industrial society. As Throbbing Gristle member Genesis P-Orridge stated,

Monte Cazazza suggested our business slogan should be industrial music for industrial people'. You get what you deserve. Or do you? Well, from the people with a vested interest in controlling and guiding society to follow their recommendations as to what attitudes you should have, what motivations should govern your behaviour and what goals you should be satisfied with, you do not get what you deserve. You get what you are given, and what you are given is primarily conditioning that pushes you towards blind acceptance, wasted 
labour, frustrated relationships and a vast sense of hopelessness. ("Industrial Records")

As we shall discuss further when we return to Mikko Aspa and Freak Animal, the vagueness and unapologetic lack of context surrounding much of the imagery and subject matter of industrial music (as well as noise, power electronics and extreme music in general) means its misinterpretation by uninitiated outsiders is somewhat understandable considering the conditioning of the general population to such signification and their inability to read between the lines in the way the artists may have intended. Moreover,

The challenge to the prevailing forms of thought presented by the symbolic revolution and the absolute originality of what it engenders have as their counterpart the absolute solitude implied by transgressing the limits of the thinkable. This thought which has thus become its own measure cannot really expect that minds structured according to the very categories that it challenges will be able to think this unthinkable. (Bourdieu, The Rules of Art 97)

Nevertheless, it is clear that the intention of The Second Annual Report is the détourning dominant industrial, government and business aesthetics - the formalities of the official document and leather briefcase - in order to represent the on-going social, technological and psychological struggle between the animal and post-human, as well as mapping out boundaries between the dominant and the residual in cultural terms. To summarise, P-Orridge also states,

Big record companies produce records like cars; we are connected to a contemporary social situation, not a blues-orientated past style; we work hard for what we want, we are industrious; we parody and challenge large industrial 
companies and their debasing ethics and depersonalisation; we work in an old factory; industrial labour is like slavery, destructive, a redundant institution so we call it the Death Factory. ("Industrial Records")

As previously mentioned, there is already a great deal of literature which documents and exemplifies the band's pioneering influence on the genre of industrial music (Ford, Vale and Juno, et al.). It is notable, however, that the band were influential in many other ways apart from their approach to production and performance as their use of transgressive, taboo and controversial imagery and symbolism (in an often unapologetically ambiguous nature), as well as their use of the format and packaging of their releases as part of the essence of the work itself (going further than mere album art, as the previous examples bear testament), began to resonate heavily with many of their peers within the first wave of industrial music.

One of the earliest and most striking examples is Pagan Muzak by Boyd Rice's NON, released in 1981 (see Fig. 3). The supposed album (which was a single-sided 7” vinyl record housed in a 12 " sleeve) comprises of seventeen locked grooves which are playable at any speed. The original release also featured "an extra spindle hole, drilled

\section{This content is unavailable. Please consult the print version for access.}

Figure 3: Pagan Muzak by NON (1981), CFK. “CFK's Trade List.” Dead Format. Dead Format, 2011. Web. 28 June 2012. 
off-centre by [Rice] himself since the manufacturing plant refused, theoretically

doubling the permutations of various sounds" (Semprebon). Therefore the release

offers the listener a markedly interactive and personalised experience as the numerous variables available to them were left completely open; i.e. there was no one 'proper' way to listen to the record, essentially making the listener part of the creative process as well. Of course due to the abrasive nature of the music (not to mention Rice's ability to spark controversy, ${ }^{8}$ which positions him as one of the most infamous figures of the industrial music underground, even to this day) there are questions arising regarding the practices and approaches that these artists took in order to get their work released. Returning to

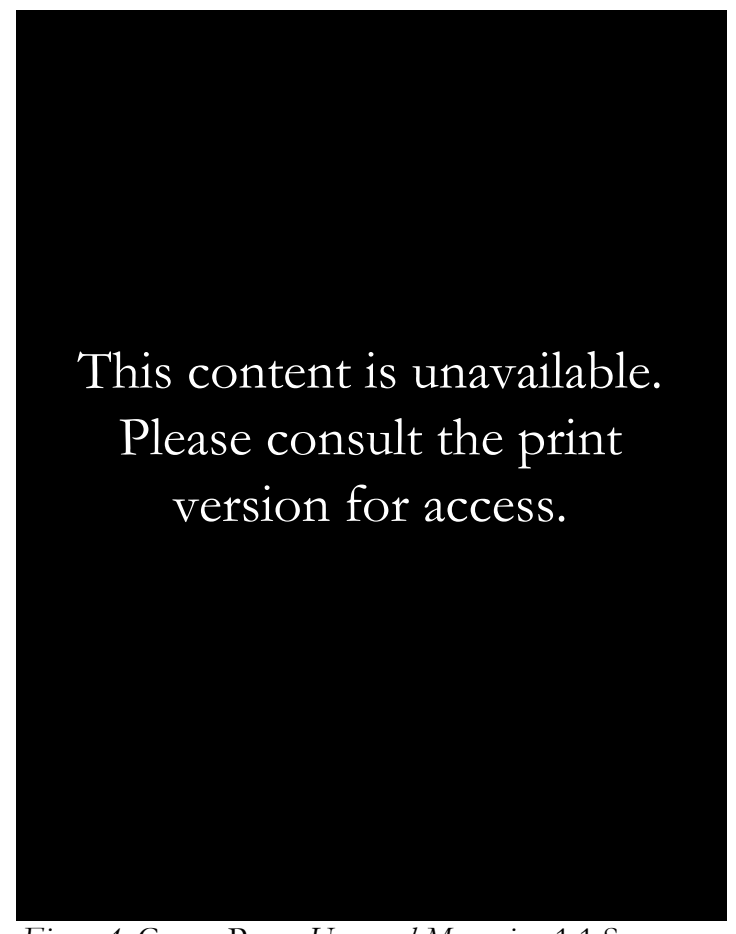

Figure 4: Cover Page, Unsound Magazine. 1.1 San

Francisco: Unsound/Auto-Text Publications, 1983. Print. industrial's more prominent cousin, punk

rock, the practices of this rising DIY

culture, including fanzines (zines) and mail

order catalogues, found a welcome place

within the extreme audio underground of

the 1970s and 1980s, and although a

definitive history of this scene has yet to be

documented - with the quality and

availability of resources being scant at best

- there is still much evidence to suggest

that, despite its niche existence, the early

network of extreme audio culture was both

${ }^{8}$ See Van Isacker, B. "Racist Boyd Rice Video Interview Causes Controversy." Side-Line Music Magazine. Side-Line, 21 July 2008. Web. 26 Nov. 2012. In this article, Van Isacker draws attention to Rice's appearance on an episode of Race and Reason; a white supremacist television talk show hosted by White Aryan Resistance founder Tom Metzger. A recording of the episode was unearthed and uploaded to YouTube where, according to Van Isacker, it has since caused controversy regarding Rice's stance on race and white supremacy. 
highly active and tightly-knit.

One such piece of evidence is the surviving zines of this period that offered a platform for artists and independent labels to promote themselves and their works. Unsound Magazine is certainly one of the most important and influential (see Fig. 4). Running from 1983 to 1988, it was a US-based publication centring on extreme audio culture in its early incarnation with featured artists ranging from Whitehouse to Sonic Youth. The publishing format of the zine has of course been a staple for DIY and residual culture as it allows both fans and artists alike a significant level of creative freedom in the creation and publishing of material and actively encourages subversion and questioning of dominant modes of media production. Apart from the word-ofmouth approach within small groups of artists and acquaintances who are 'in the know'

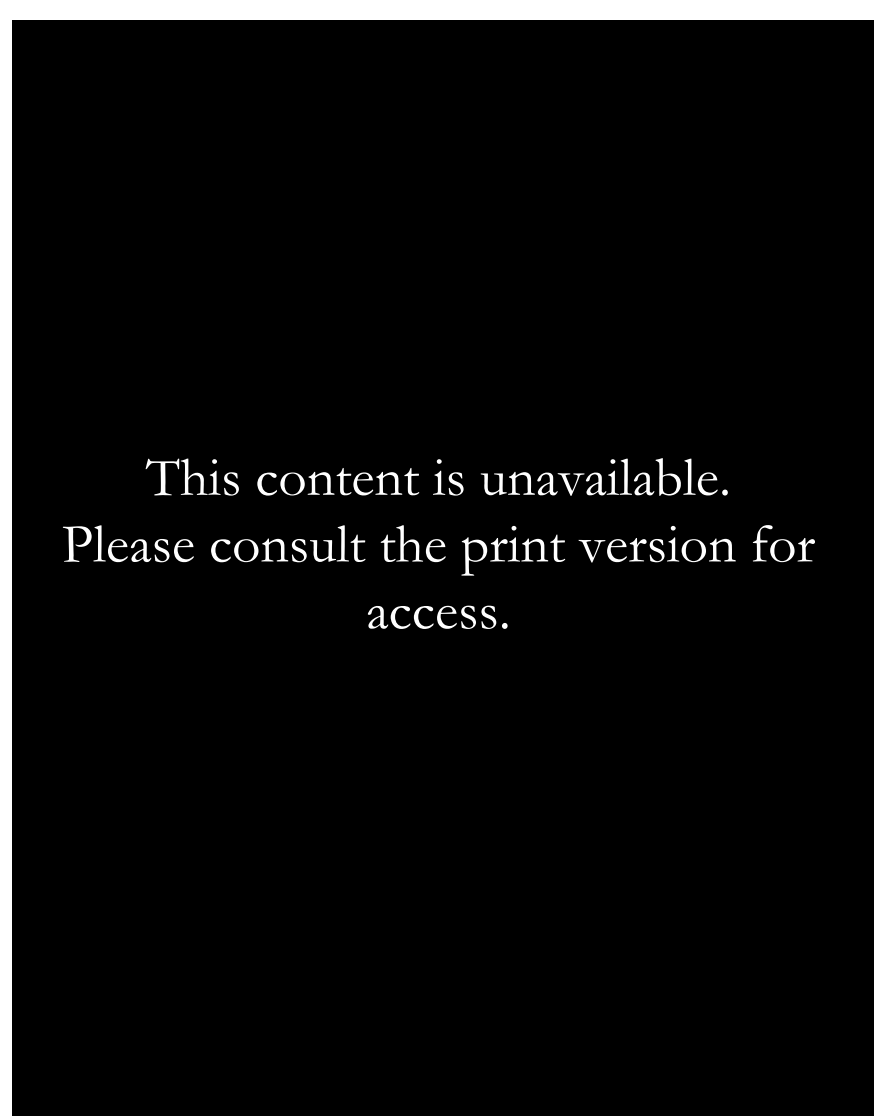

Figure 5: Pg. 9, A.R.P.H. Tapes catalogue, Unsound Magazine. 1.4 San Francisco: Unsound/Auto-Text Publications, 1984. Print. they were often the only way in which fans could engage with the artists, community networks could be established and a listenership could be attained. Of particular importance was the promotion of labels within the zines and the practice of mail order. The usual practice would consist of the label printing a small catalogue within the zine (see Fig. 5) or printing their address with the option of receiving a free catalogue upon 
request by mail (see Fig. 6). What is notable about zines such as Unsound is their operation, organisation and survival (though limited) on the fringe of arts and music culture, exemplifying the notion that extreme audio culture, from its very genesis, has been not only concerned with notions of the residual in its production and performance, but also in its marketing, distribution and promotion; operating in opposition, parody and surreptitiousness to dominant structures of both material and cultural economy. Hence, the survival of scenes like extreme audio culture hinge upon shared notions of progression and experimentation within the field of cultural production and the networks of information, knowledge and practice which form as a result. Therefore, as Björn Hartmann states,

If one looks at music not as a business, but as a communication medium, a more valuable social payoff comes into sight. It is the function of music as a

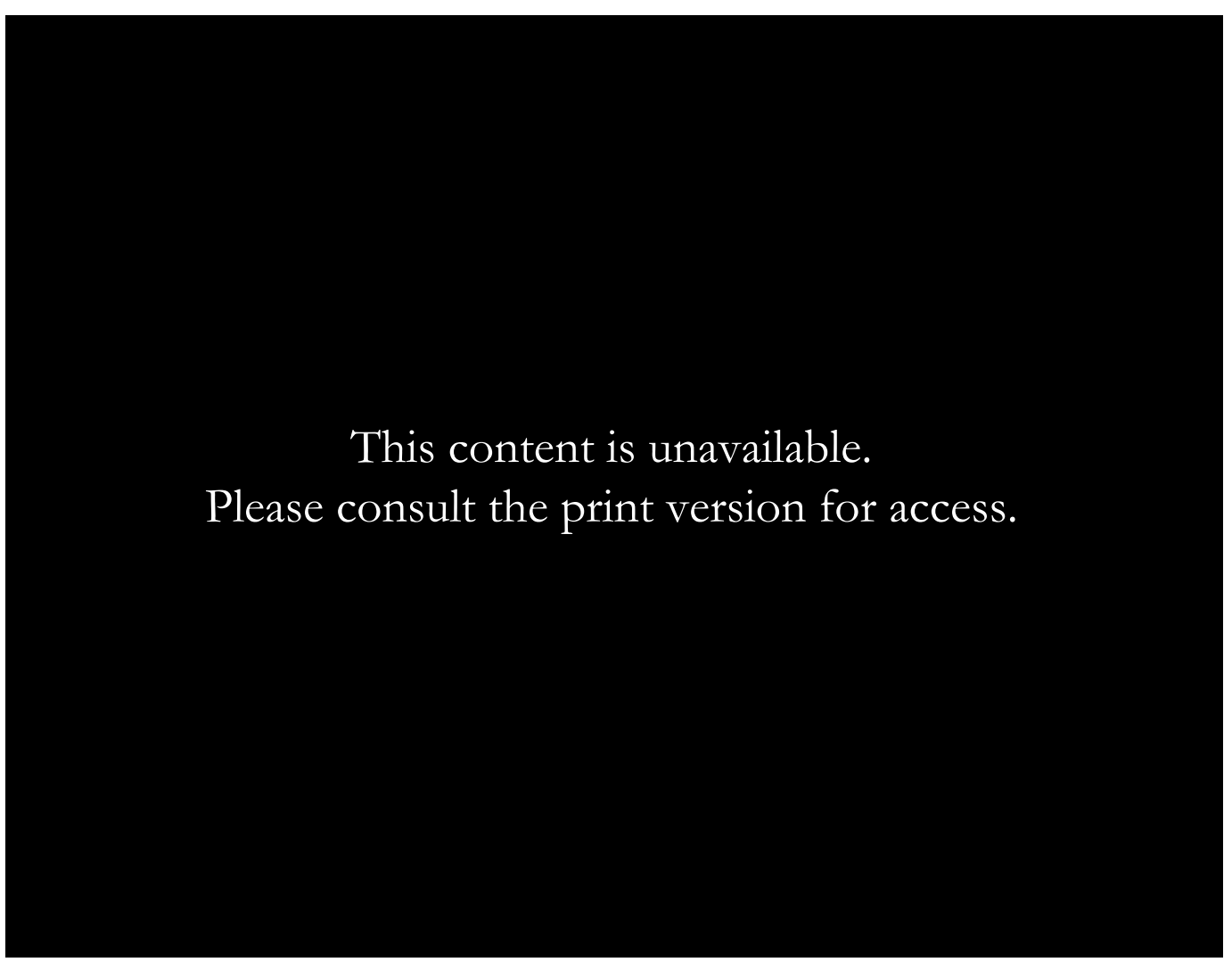

Figure 6: Pg. 34, CD Presents, Ltd., free catalogue by mail (on right), Unsound Magazine. 1.4 San Francisco: Unsound/Auto-Text Publications, 1984. Print. 
universal connector, a topic for community building, a nexus for artistic

exchange and creative experimentation that marks its true value. (2)

Included within the final issue of Unsound (Vol. 3, No. 2), for instance, are comprehensive 'Contacts and Reviews' and 'Advertisements' sections that list contact details and information on various labels, distributers and zines specialising in extreme and experimental music (see Figs. 7 and 8). Here we should return to Amy Spencer as she briefly discusses the form and function of underground, independent networks of music distribution. Particularly in Britain, record shops like Rough Trade and radio DJs like John Peel were championing underground, independent and DIY music culture in the late 1970s and through the 1980s, providing a solid foundation for these artists and labels to find their footing and garner the support they needed in order to survive.

Spencer describes this channel as a "shadow network, operating just below the surface of the music industry, along similar structures but with more ethical ideals" (339).

Observed in a different light, this notion is clearly related to Bourdieu's restricted sub-

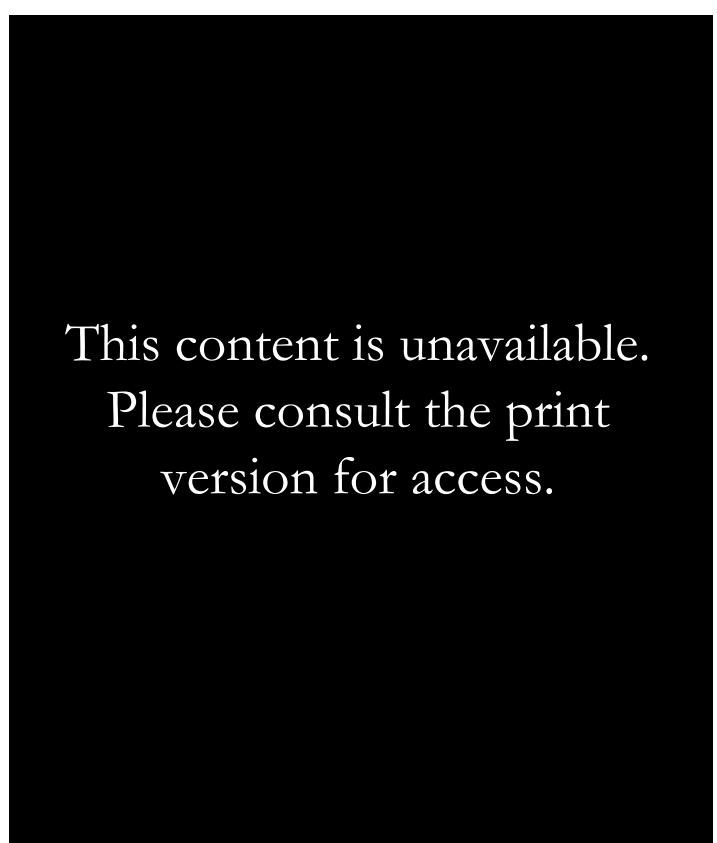

Figure 7: Cover Page, Contacts \& Reviews, Unsound Magazine. 3.2 San Francisco: Unsound/Auto-Text Publications, 1988. Print.

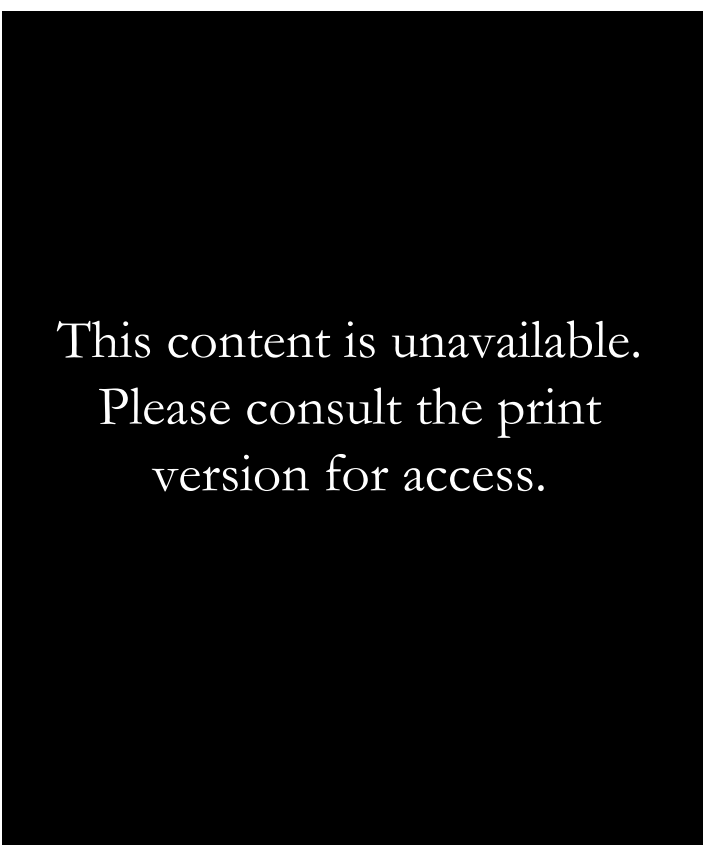

Figure 8: Cover Page, Advertisements, Unsound Magazine. 3.2 San Francisco: Unsound/Auto-Text Publications, 1988. Print. 
field of cultural production as defined in the following passage:

In contrast to the field of large scale cultural production, which submits to the laws of competition for the conquest of the largest possible market, the field of restricted production tends to develop its own criteria for the evaluation of its products, thus achieving the truly cultural recognition accorded by the peer group whose members are both privileged clients and competitors. (Bourdieu, The Field of Cultural Production 115)

As the pages of Unsound suggest, extreme audio culture in its early incarnation fell very much in line with this 'shadow network' as it remained an incredibly niche, specialist and esoteric movement, relying upon keen enthusiasts with an attraction to and appreciation of extreme music and subject matter. The similarities between preinternet and current approaches/aesthetics within the scene are notable, and add further

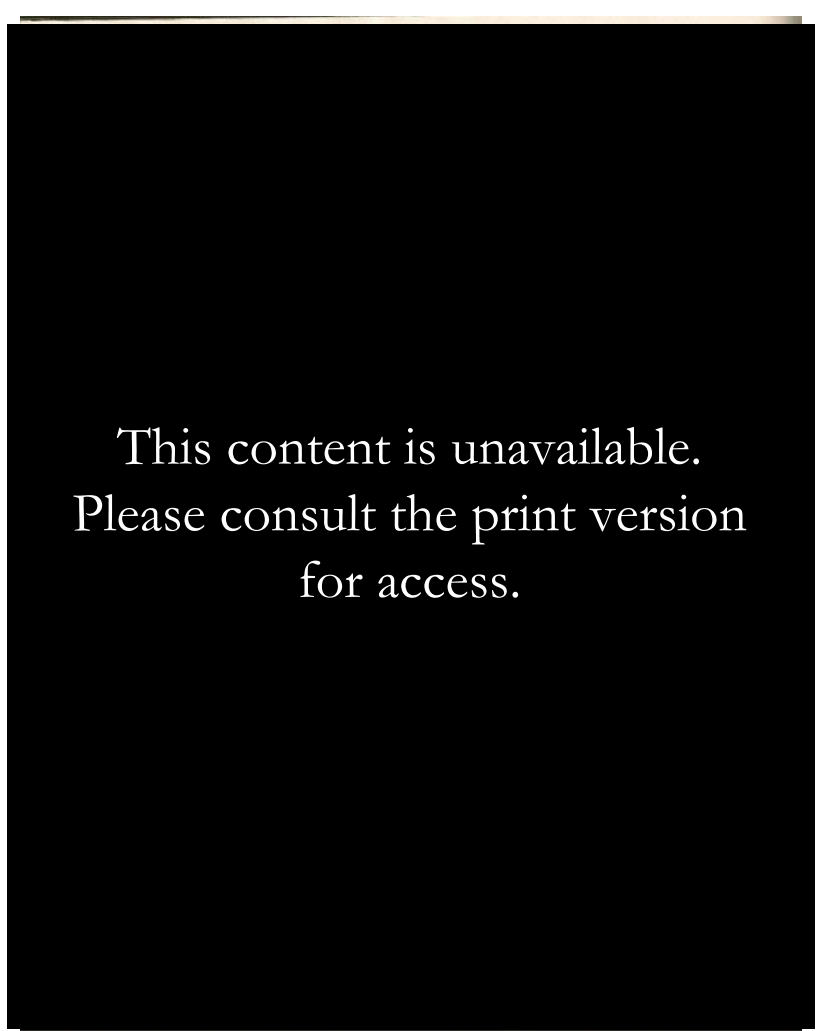

Figure 9: Pg. 18, Terminus Records advertisement (top), Unsound Magazine. 1.5 San Francisco: Unsound/AutoText Publications, 1984. Print. reinforcement to the digital age, post-

human anxieties discussed in Chapter

One. There is a distinct connection

once more between extreme audio

culture, shock/transgressive art and pornography. Yet when we address

the visual aspects of the culture, even

in these early years (see Fig. 9), the

connections are far more pronounced

and vivid, especially in the use of

collage art in much of the

promotional material (where one may be able to draw comparison to 
Dadaism, particularly as these artists "had little choice but to use the method of underground publishing to make controversial statements, to get their ideas heard and to shake the bourgeois sensibilities of the art world" (Spencer 123)); contrasting graphic medical photography with, for example, pornography, decontextualising these images, then recontextualising them in their new assemblage, and ensuring that the work remains alienated from mainstream popular culture.

Here we enter territory within the power electronics and harsh noise scenes which is as uncomfortable as it is fascinating. As mentioned in Chapter One, Mikko Aspa, who also produces and performs as Grunt, owns and operates Freak Animal; a specialist noise and power electronics label and magazine out of Lahti, Finland. Turning our attention to issue eleven of the Freak Animal magazine we find the cover (see Fig. 10) adorned with imagery which reinforces notions covered previously in our discussion in regards to the animal versus post-human dichotomy, the eroticisation of the machine and, in general, the overarching implicit theme of power electronics unearthing and exposing the more sinister and grotesque side of post-industrial, digital age urban society. Behind the image of the gas mask - which is in line with Aspa's fascination with BDSM and fetish culture, particularly the dehumanising aspects of such objects, as well as technology (namely military, chemical and warfare technologies) in general - is a collage consisting of a juxtaposition of photographs intended to form new meanings by their conglomeration. Included we have a medical photograph of the face of a baby which appears to be suffering from severe (perhaps radioactive) mutation, an image of hardcore pornography featuring ejaculation into the mouth of a female model, an image of male genital torture, a woman in pain being hung by her hands, a graphic murder scene, a microscopic image of what appears to be bacteria, a woman reading the bible and praying, a kitten playing with a piece of string and, most interesting of all, a mug 


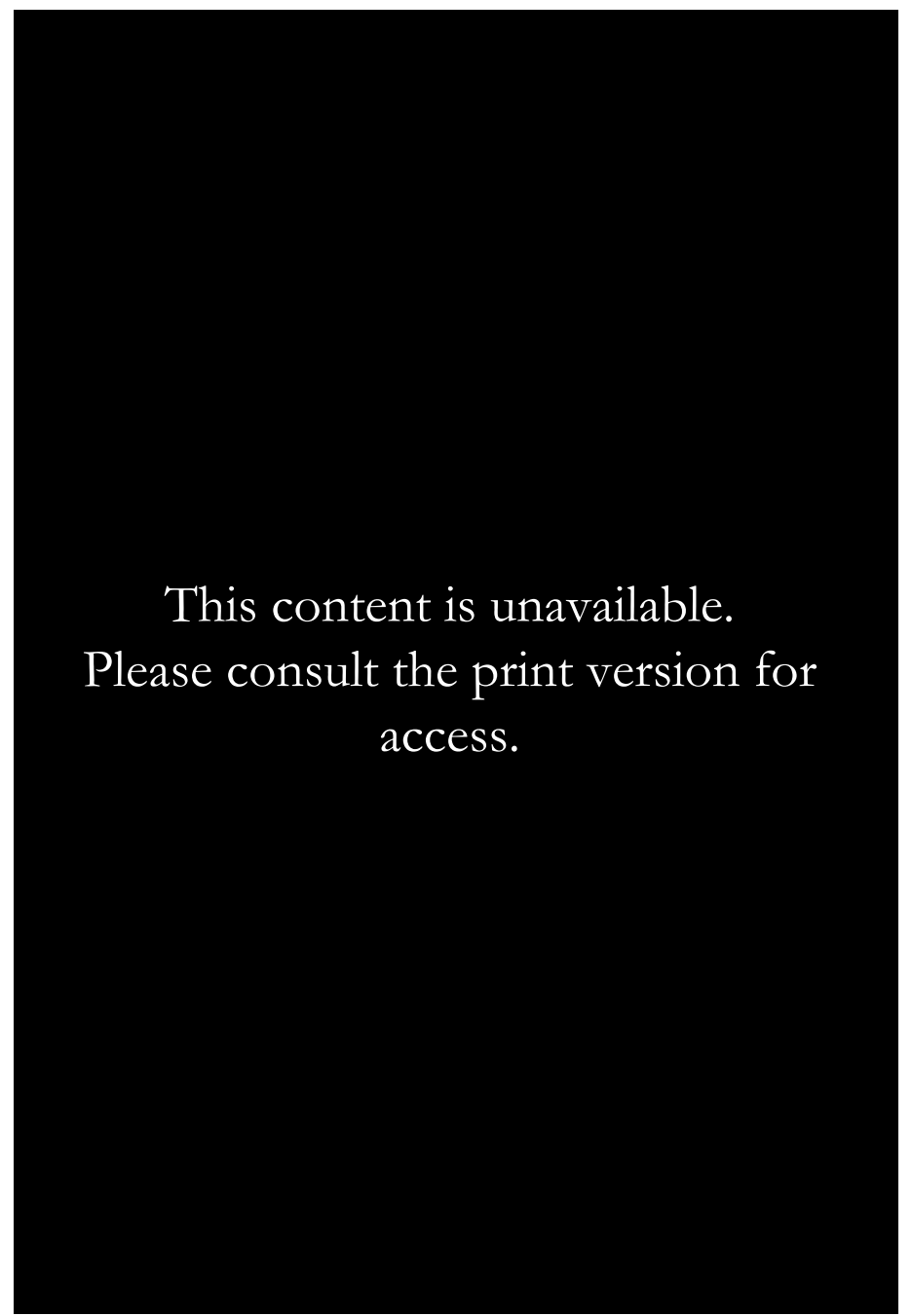

Figure 10: Cover Page, Freak Animal. 11 Lahti: Freak Animal, 1998. Print. shot (police photograph) of

Ted Kaczynski, a.k.a. the

Unabomber. Ted Kaczynski

was an anti-technology, 'neo-

luddite' terrorist whose mail-

bomb campaign (explosives

sent through the mail that

detonated once the package

was opened) was launched "in

an attempt to bring about 'a

revolution against the

industrial system"' (Ray),

resulting in the deaths of three

people. Kaczynski’s desire was

to liberate humanity from its

reliance upon, and supposed

slavery to, machines, attempting to pull back against the tide of the digital age and the lure of the cyborg; the symbiosis of man and technology. So what are we to make of Aspa's choice of imagery here?

If we return to the issue concerning the animal versus the post-human, what we may observe is the illustration of both the vulnerability and machine-like function of the human body. We must remember that extreme audio culture does not view Haraway's cyborg in celebratory terms and instead we may read these juxtapositions as the exemplification of the human body as both animal and machine in the grips of malfunction and decay, in line with the physically intense and complex nature of noise 
and power electronics works; i.e. pornography as the animal, primal urge and medical photography as the frailty of the human body and, in this context, a step away from Donna Haraway's notion of the cyborg (of humans and machines forming a friendly partnership) into a position of dominance and submission to the wrath of the machine, the oppressiveness of technology. Haraway does state, however, that,

Cyborg politics is the struggle for language and the struggle against perfect communication, against the one code that translates all meaning perfectly, the central dogma of phallogocentrism. That is why cyborg politics insist on noise and advocate pollution, rejoicing in the illegitimate fusions of animal and machine. (442)

Continuing along this train of thought, the use of Kaczynski's image implies a statement regarding this struggle against the machine and the post-human, the futility of the human condition. Although it may be argued as to whether these artists need to present such grim and morally questionable material, particularly in regards to the malformed child, we can return to Whelen who argues, "Part of the objective for noise as a genre is to refuse moral closure, to confront and disrupt the finality of interpretation" (470), or even Bourdieu in the statement that, "Uninitiated perception, reduced to the grasping of primary signifiers, is a mutilated perception" (219). Broadening our observations to the industrial music scene in general, its growing popularity during the late 1980s until the late 1990s connotes Jacques Attali's notion of the prophetic nature of music running in parallel with visions of William Gibson's (et al.) cyberpunk future as digital technologies - i.e. the internet - began to form intricate relationships with our mental fabric, becoming perpetually requisite tools in our changing social behaviours. 
As we give mention to the digital realm here, it is important to consider the form and functionality of the new digital underground in terms of the distribution and marketing of analogue formats, vinyl and cassette, as well as compact discs, within an intangible, digital structure. Items are paid for and ordered via primarily immaterial frameworks - services such as PayPal offering further efficiency in the ordering process - yet are packaged and distributed through networks of consumption in physical form. As discussed by producer Hal McGee, ${ }^{9}$ who was involved with extreme audio culture in the old print underground and is still active within the new digital underground,

I think that it was natural for me and people of my age group to pass through the stages that I did, because we started making our homemade music at a time that was pre-computer, pre-internet, pre-email, pre-MySpace and pre-Facebook. We handwrote letters, dubbed tapes, went to Kinko's and printed tape covers, packaged up the tapes, went to the post office and mailed them, etc. For people much younger than me, whose lives have essentially always been mediated by digital culture...I think that they are looking for authenticity, for genuine experiences, and in some ways I think they see online anything as drudgery, as work-related, as something that doesn't connect them to other people, but as something that is distancing and cold.

Thus, there is a distinct notion of tradition and authenticity within the new digital underground in terms of the releases themselves with perhaps the most noticeable change remaining within the structures of publishing, promotion and

\footnotetext{
${ }^{9}$ This discussion retrieved from a thread found on the Noisefanatics.com (a.k.a. Troniks) forum. It must be mentioned that this forum has now ceased operations as of May 2013. However, it has since been relaunched as the Maniacs Only forum: http://www.maniacsonly.com
} 
networking, bringing the idea of bricolage out of the printing press (or photocopier) and into the blogging service while the culture still manages to maintain the original flavour and ethos that had shaped it from its very beginning; the reinstatement of value upon materials, practices and aesthetics coded as outdated or obsolete aiding in the foundation of survival tactics which allow such scenes to adapt to impactful technological advancements. However, the biggest impact of the digital age is potential for accessibility and discovery, as internet technology trumps the distributive potential of zine culture no matter how tightly-knit the communities and publishers remain (we shall examine these notions further in Chapter Three). Of course, the main criticism of the internet and its relationship with underground culture exclaims the supposed downfall of the underground in terms of establishing a discernible line between it and overground, mainstream culture and practice. "The web has extinguished the idea of a true underground; it's too easy for anybody to find out anything now" (Reynolds qtd. in Graham). It is proposed that, with the easy access and usability of the world wide web, that media has now become 'flat', and that the mainstream and the underground now affords the same level of engagement and influence with the masses as mainstream culture. Thus, the very definition of the word 'underground' within the current cultural and artistic climate of creative media has become a highly contested and divisive issue. As is often argued,

...the overexposing light of the web means that that anything that has online presence simply doesn't feel underground in the way its precursors did in the age of the underground press and fanzines, tape trading networks and DIY labels. Even the coolest online music retailer selling the most esoteric, out-there music doesn't have the same vibe as an independent record store that is physically located, that you have to seek out and journey to. (Reynolds) 
For many who still use the term 'underground' when describing the artistic practice and function of various artists, scenes and subcultures, its definition has been modified to adapt to the growing amalgamation of DIY culture into the digital realm. Furthermore, there is also an understanding that there is still very much a hierarchy in the representation of both large-scale and restricted media within cyberspace and the knowledge that although accessibility has put the underground on much the same footing as the mainstream in this aspect, the underground is still coded as noise in a cultural, scenic sense (discussed further in Chapter Three) and needs to be actively sought and discovered through the efforts of the consumer themselves, which is not required in encountering many of the best-selling pop acts whose advertisements are peppered across mainstream websites such as YouTube and MySpace. As Frank Zappa once explained, "The mainstream comes to you, but you have to go to the underground" (qtd. in Graham); this idea still very much in line with the practices and functions of the new digital underground and the networks which are established within its diverse, yet connected, communities and scenes. Furthermore, as Stephen Graham argues,

...the underground is not simply about access, nor is it a mere description of the physical context of music. The underground is essentially a practice, a cultural philosophy of music that exists outside of the mainstream. This philosophy, rather than being extinguished, has actually been invigorated through new innovations in social media, digital technology and audio culture.

The reasoning as to why extreme audio culture is still such a niche and underground movement may be perceived as rather obvious: Its abstract, abrasive form, as well as subject matter and imagery ranging from the bizarrely surreal to the deeply grotesque, aligns it most certainly within the avant-garde in its coding - or, at least, 
under the umbrella of 'experimental music', for which dominant culture would be correct in its categorisation. What is interesting to observe in this instance, however, is noise's definition and labelling as a musical style and scene despite noticeable contestation and controversy surrounding its status within the sphere of popular culture and music. We may credit extreme audio culture's lineage within industrial music as one avenue of explanation here when we observe the blurring of the division between high and low culture within the scene; between the avant-garde and the popular as noise and power electronics remain in limbo amid the field of extreme music. There is often the simple and rather fair question for anyone exposed to the form for the first time: "Is this music?" To address this question we must consider some generalised perceptions of music within the mainstream (large-scale) music industry as well as the role music plays within dominant culture overall:

Fetishised as a commodity, music is illustrative of the evolution of our entire society: Deritualise a social form, repress an activity of the body, specialise its practice, sell it as a spectacle, generalise its consumption, then see to it that it is stockpiled until it loses all meaning. (Attali 5)

Bearing in mind the cultural coding of noise music and power electronics as underground practices, positioned on the fringe of musical experimentation, there is also the perception of extreme audio culture as a scene of the marginal and dispossessed (Brady); individuals who themselves feel somewhat alienated or discarded from dominant culture, who thus see the residual and obsolete as a way of building one's own identity and recycling dominant detritus in order to codify their perceptions and emotions into a creative outpouring. Michelle Henning reinforces this idea by stating that, "The obsolescent becomes the culture of the dispossessed and marginal, so the new becomes links to positions of dominance" (55). One literal example of this would 
be RRRecords and their famous Recycled Music series in which old, commercial cassette recordings were recorded over, or "repurposed", with new material from a selection of noise and power electronics artists (Howe).

As it has remained an important artefact within underground music culture since the 1970s, we shall return to the format of the audio cassette later in this chapter. In the meantime, turning our attention back to some important case studies, the following section is an attempt to offer a broad snapshot of extreme audio culture in the new digital underground and how the form, function and networks of these institutions have come to contribute to the overall landscape of residual DIY culture in the internet age.

As we saw with NON's Pagan Murak and Throbbing Gristle's 24 Hours, the format of an extreme audio work, and the container technology chosen to house the work, makes up an important part of what it means to produce, promote and market a release with much experimentation being conducted with both the physical function and sonic properties of certain formats. Container technologies can be defined as technologies which store materials, i.e. media, in order for them to be accessed and utilised later, once the container has been opened or 'activated'. Theorists such as Lewis Mumford (who originally coined the term) and Zoe Sofia take a fairly broad stance as to what can be defined as container technologies - Mumford even going so far as to call entire cities "container[s] of containers" (Strate). But when discussing media such as recorded music we may see container technologies as the recording format of a work the audio format the work is recorded onto and 'contained' in, CD, vinyl, cassette, MP3, etc. In addition to their storage capabilities, a container technology can also be viewed as an 'apparatus', with the added effect of transforming their contents as it holds them (Sterne 828); for example, a piece of recorded music has a different impact, signification 
and meaning depending on the format it has been recorded onto and in what context it is used/experienced (in the living room at home, through headphones, in the car, etc.). Bearing these factors in mind, the value placed upon certain containers within the scene lies within these and a range of other variables, including audio quality, interactivity, accessibility, novelty and whether a format holds true to the ethos and tradition of extreme audio culture: Noise, the residual and taboo. Vinyl is still a popular choice for noise and power electronics artists as the warm crackle of the disc, coupled with the personalised, interactive experience of handling and flipping the record, could be said to add to and enhance the recorded material itself. CD-Rs are the most popular format, as they are easy and inexpensive to burn, package and post to customers, not to mention the relatively high audio quality. Garnering the most controversy and debate in the new digital underground however, the MP3 is perhaps the easiest and most cost-effective way to distribute works. Returning to McGee on the on-going issue of analogue versus digital within extreme audio culture and the new digital underground, he explains that,

A couple of years ago I encountered a lot of resistance to and downright hostility toward online music in discussions on the Noise discussion boards. There were endless and highly-detailed complaints about the shitty sound quality of MP3s and about how online music wasn't genuine enough. Many people still wanted to have a physical object to hold in their hands with printed artwork, something tangible and 'real'. People 20-30 years younger than me were resisting what I saw as natural 'progress' - online music - and were, in my mind, regressing somewhat by insisting on physical container audio formats. Hence, the renewed interest in cassettes, as your [the previous poster's] study suggests. 
MP3s function by erasing the sonic frequencies which fall outside the spectrum of human hearing, the frequencies which our ears would filter out naturally anyway, in order to compress and minimise the file into as small a size as possible (Sterne 832). Because the genres of noise and power electronics are typically concerned with the impact and effect of sound upon the human mind and body, the MP3 in this instance could be seen as weakening or diluting a work, potentially lessening its influence upon the listener. Yet one cannot overlook the capabilities of this type of technology, particularly in terms of its recording and distributive possibilities; as artists can now record for however long they wish in a single take, the recording of which can be sent and received via the World Wide Web more-or-less instantaneously.

Perceptions and cultural values weighted upon various container technologies within the new digital underground vary from genre to genre. Within noise and power electronics, as mentioned, works/releases tend to embody numerous frameworks of mediation, from the audio recording itself to the visual aspect of the album art and even the very format the work is contained in. This allows, in some distinct cases, for the artist to take advantage of the wide range of variables available in producing a release, often aiming to uphold the character of extreme audio culture; part of which lies within making releases as challenging and inaccessible as possible (both in form as well as in function) to the general public. For example, we can observe that the format of the compact audio cassette now has a healthy half-life within the new digital underground as the preferred medium of choice for many artists, not only in noise and power electronics, but also in underground black metal and hardcore punk. The ethic and tradition of these scenes impart significant cultural and symbolic value upon such materials coded as both residual as well as a part of a scene or genre's origin or lineage; in this instance, the rise of DIY music culture triggered, in part, by the success of the 
cassette as an inexpensive and easily accessible recording format. If we extend the idea of using obsolete technologies in order to reinstate their cultural value, we arrive at some of the more bizarre and fascinating examples of distribution practices within the new digital underground.

Not is regulation to the obsolete necessarily the final stage in the social life of a thing, as things may be restored to commodity status by being revalued as collectibles or antiques. Also, the cultural and social standards of 'exchangeability' may produce the deterioration of exchange value in the obsolescent object, which may continue to have a high use-value. Its low exchange value makes it available to people who could not previously afford it. (Henning 54)

Ergo, we can now view labels such as Dictafawn Records as exemplifying the interactive, listener-inclusive hobbyist aspects of extreme audio culture by emphasising the effort of the consumer in engaging with the release on a level transcending conventional listening practice. Although the label has now, sadly, ceased operations, the following section seeks to illuminate how such institutions encourage experimentation with alternative recording formats, working to shape the innovative character of the noise and power electronics scenes.

"Dictafawn is a DIY music and noise label based around the obscure microcassette format" (My Lovely Figment). Built within the framework of the weblog (using Google's free Blogger service), Dictafawn functions in a straightforward and easily accessible manner: Listing items through blog entries - offering album artwork and information about the release - with contact information and PayPal options available for placing orders and making inquiries. In these respects, it follows the form and function of many labels within the new digital underground by taking advantage of 
a free hosting service (i.e. Blogger), making the ordering process as easy as sending a few emails including contact and postage information, then transferring money into a (relatively free, sans the initial opening deposit) PayPal account. This has indeed become fairly standard practice with a sizable and ever-growing network of labels, webzines and artists within just the Blogger service alone, with many more using services such as WordPress, Tumblr and free website-hosting platforms. For this reason we can argue that the internet has in fact strengthened the underground and helped to reinforce the DIY, residual, bricolage approach which acted as the foundation of these scenes since their inception. Indeed, "The internet, like the video store, is about abundance, but it is also about the inertial movements that bring commodities and images together into clusters and networks whose solidity decides their cultural and symbolic weight" (Straw, "Embedded Memories" 14). In the case of extreme audio culture in the new digital underground - spheres in which the machine, the flesh and, specifically, the mind converge into our animal versus post-human dichotomy - the World Wide Web is an obvious avenue of exploration. Once the correct tools and materials trickle down from dominant culture (those items that prove to be most fruitful in their utility within an underground context) they become demystified and open themselves up to reappropriation and experimentation. Drawing upon a historical parallel, online music culture echoes the demystification of the music industry during the punk era, in effect broadening and shaping new avenues of distribution and promotion in ways which further emphasise independent, DIY practice. Such trends remain at the forefront of contemporary underground music culture as digital communications technologies become more readily available and easy to use, particularly as internet connections and general usage continues to broaden into more subordinate cultural groups and institutions who previously had no access to what were considered elite, specialised technologies; in line once more with Haraway's 'cyborg myth' which, as she states, "is 


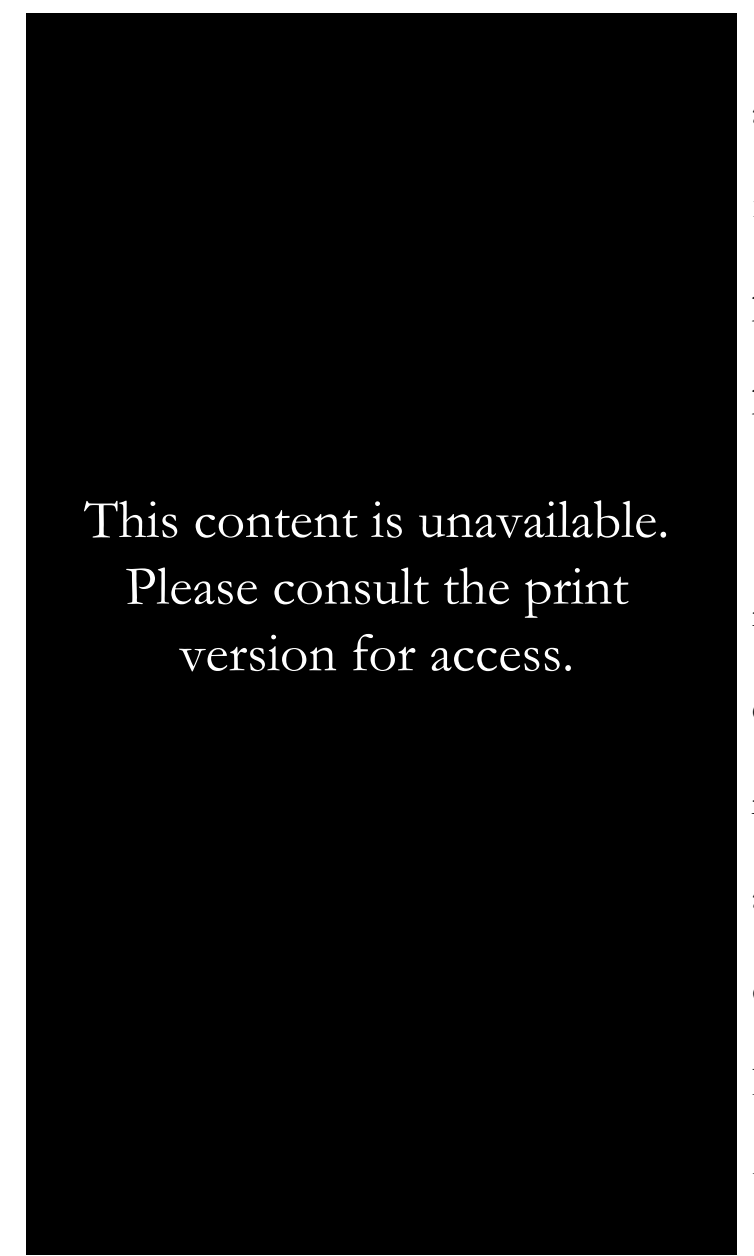

Figure 11: 6x3" Deluxe Noise Filter by Ctephin + Xdugef (2007), "Ctephin + Xdugef - 6x3" Deluxe Noise Filter (CDr) at Discogs." Discogs. Discogs, 2013. Web. 20 March 2013. about transgressed boundaries, potent

fusions, and dangerous possibilities which progressive people might explore as one part of needed political work" (432).

Reverting our discussion into the realm of the analogue and the use of predigital technologies, extreme audio culture itself seems to be well-aware of some accusation of elitism and pretention by critics and naysayers and, as a result, Industrial Records' parody flavoured, tongue-in-cheek marketing techniques defined a niche in a scene typified as by being challenging and inaccessible as possible.

It's not uncommon to see noise recordings released on floppy disk, minicassettes or 8-track cartridges. Lathe-cut records might be pressed on cardboard, discarded CDs, ice cream containers, fiberglass or even, in one case, on concrete. Releases may come bundled in leaves, taped to a block of concrete, wedged between rusted metal, dipped in latex, sewn into cage-like frames - or sealed inside an airtight bag with a dead rat. (Zylo)

Specific examples of such practices include a split release from Ctephin and Xdugef, 6x3" Deluxe Noise Filter (2007), which came packaged in a modified child's gas mask (see Fig. 11) and various releases from Italian label Toxic Industries who convert broken computer hard drives into housing cases for 3" CD-Rs (“[T+020] Fukte \& 
Orgasm Denial"). This takes the recurring theme of the reappropriation of the residual and obsolete to the level of the literal. Of course, as in the case of the dead rat, the more sinister acts within the harsh noise and power electronics scene take full advantage of this freedom in the DIY hand-made packaging of their works, often with the express goal of heightening and reinforcing the theme of the work to a more interactive, tangible level. One example is Cory Schumacher's 4 Teeth in a Ziplock Bag (2012) which, as the title suggests, comes packaged with a zip-lock bag containing four bloodied (presumably fake) teeth in order to invoke the feeling of shock, confusion and distress likely to be experienced upon discovering a bag of teeth has been mailed to you. In keeping with the concept of the album, the music attempts to express these sensations through the sub-genre of harsh noise wall (Brian). These practices inevitably lead to blatant practical jokes played upon the consumer. Collector's items they may be, with many consumers/listeners knowing what they are in for and purchasing the item merely for its cultural, symbolic and aesthetic value, but in addition they deploy parody and self-ridicule to not only produce aural noise (residual sound) but also physical, material noise (residual materials) in selling releases which are unplayable and worthless outside of the codes and conventions of the extreme audio community; valueless to everyone except those in on the joke. Furthermore, framing these notions within the field of art as a whole,

Apart from laying bare the desire to exclude those artists suspected of submitting to external demands, the affirmation of the primacy of form over function, of the mode of representation over the object of representation, is the most specific expression of the field's claim to produce and impose the principles of a properly cultural legitimacy regarding both the production and the reception of an art-work. (Bourdieu, The Field of Cultural Production 117) 
A noteworthy example would be Australian artist Fuck, the Retarded Girl and the aptly titled Unplayable (2008), which consists of a vinyl record severely scratched, spray-painted and warped with boiling water ("Fuck, the Retarded Girl”). Clearly this consists of parody targeted at the consumer themselves and the collector's culture which grows from the new digital underground; "his act would be nothing but a crazy or insignificant gesture without the universe of celebrants and believers who are ready to produce it as endowed with meaning and value by reference to the entire tradition which produced their categories of perception and appreciation" (Bourdieu, The Rules of Art 169), the prestige of owning certain releases due to their limited quantity and/or unusual format or packaging. Consumption will be covered in greater detail in Chapter Three, but in terms of format, packaging and album art in extreme audio culture which leans further upon the side of the strange and unusual, Paul Hegerty offers further insight into this practice, which has been an integral aspect of the scene since its inception,

All of these [examples] emphasise the materiality, the objectiveness of the item the exact opposite of a commodity, which tries to ascend in value, to gain a worth that becomes an essential part of the thing-made commodity. While it is clear that this is a parody of the capitalist music business, there is still the symbolic capital for the 'collector', who possesses rare items which are hard to find and which acquire the status of art objects, and, over time, many of these become financially valuable. (141)

Returning our attention to standard compact audio cassettes, labels such as Worthless Recordings, which trades solely in audio and video cassettes, offer a vivid example of the practices and approaches conducted in relation to the aesthetics and functions of the distribution process within the new digital underground. There is an 
apparent sense here of the self-awareness attributed to the cultural consequences of stocking audio works contained within obsolete technologies for sale and/or trade; the name of the label itself is testament to this awareness, which is also apparent in many other similar labels. For instance, Sexkrime Arts, a cassette-only 'extreme industrial electronics' label, bears the slogan, “Obsolete media for an obsolete culture” (Denial). There is evidence here of a sense of pride and acceptance of being part of the marginalised and dispossessed and building a scene from the discarded and unwanted technologies and ideas of dominant culture. Just as early punks wore residual materials such as bin liners and safety pins as clothing in order to express their alienation and cultural destitution, so too does extreme audio culture (and the industrial music scene in general) albeit taking a different approach, one less concerned with such visual tribal aesthetics.

Like punk, industrial music was suspicious of musicality, but its hatred of contemporary art and society went deeper, its critique harsher as a result. Like Dada, it offers an anti-aesthetic, using the tools of art to undo art. Unlike punk, the answer was not change, but awareness of the fetid state of capitalist society. (Hegerty 105)

In this light, we may be able to make further sense of the more thematically sinister and transgressive acts within harsh noise and power electronics, particularly in regards to the imagery and subject matter of releases. By using supposedly obsolete, subordinate technologies - such as the compact audio cassette - coupled with the visual and aural aspects of a release, one may argue that the ultimate goal of extreme audio works has remained true to the efforts of industrial music to raise the social awareness of its audience by combining the most 'fetid' aspects of post-industrial, digital age capitalist society into a specific artistic form; obsolescent technology, crime, violence, 
sexual perversion, war (e.g. Ctephin and Xdugef), urban decay and machine noise, wrapping these subjects within the codes and customs of capitalist economic practices and consumer culture, particularly the materialism of collector's cultures. Coded by dominant culture as an outdated and obsolete technology, cassettes, as previously suggested, have become the format of choice for a number of extreme audio artists and labels. This can present itself as somewhat of an anomaly to any contemporary music fan unfamiliar with the practices and perceptions at work within the new digital underground. Yet the elements that have contributed to the cassette's cultural and symbolic status have been accumulating and evolving since its initial use within underground music culture, many of which can be traced back to its initial, material usevalue for independent, DIY musicians, coding the format as a symbol of creative freedom, subversion, accessibility and $\operatorname{tradition}^{10}$ (as we have similarly argued in the case of the zine).

Compact audio cassettes, since their rise in popularity in the late-1970s, have provided an inexpensive, unfettered independent platform for which artists can record and distribute their work themselves; allowing anyone with a tape recorder and a blank cassette the possibility to get their music heard (Spencer 343-344). Of particular relevance is Throbbing Gristle's previously mentioned Second Annual Report, side A of which was notably recorded with nothing more than a cassette recorder, a condenser microphone and, of course, some blank cassette tapes (The Thing on the Doorstep). Given industrial music's early relationship with the cassette, and perhaps, more

\footnotetext{
${ }^{10}$ See Staub, Ian Matthew. "Redubbing the Underground: Cassette Culture in Transition." Hons. thesis. Wesleyan University, Middletown, 2010. Honors Theses - All. Web. 4 July 2013. This discussion offers further insight into these notions, including the survival of the audio cassette from pre-internet DIY music cultures into its current status within the new digital underground.
} 
importantly, its relative inexpensiveness and ease of use, this made the format an obvious choice for underground and DIY artists who may not have been able to afford well-equipped studios or expensive, specialised recorders. This cost-effective alternative ultimately worked to further demystify the music recording process for many artists working within the realm of residual and marginal underground music networks. It entailed that the artist could record their works from home, straight to cassette - a master of which could then be dubbed onto multiple blanks for distribution - and retain full creative control over their releases (Spencer 343-344). Furthermore, the format proved itself to be both accessible and versatile as a recording medium with the ability to record over previous materials, lending itself to the possibility of recycling (Spencer 348); a practice explored by the aforementioned RRRecords, et al. Unlike the limitations of vinyl, which had to be professionally pressed, the cassette lends itself much more appropriately to the ethos and function of residual culture as well as the practices and perceptions of extreme audio culture in terms of the recording, distribution and user interactivity of releases. Labels such as the now-defunct Come Organisation, owned by members of Whitehouse ("Come Organisation”), and Broken Flag, which is still in operation (Colegate), provided some of the first outlets for cassette culture within the extreme experimental music scene and reinforced the format's status and influence upon noise and power electronics in the freedom, functionality and costeffectiveness it presented. The concept of the limited edition release, in this respect, reveals itself as being born mostly out of necessity and limited resources, thus giving rise to the extreme audio release as collector's item; tape trading coming into particular prominence (Schenck), reminiscent of more mainstream subcultural practices such as the collection of comic books and trading cards. Saving this discussion for Chapter Three, the material properties of the cassette also become a markedly notable attribute 
to their appropriation within extreme audio culture and signal a purportedly more organic and, therefore, authentic nature within the form and sonic structure of a release.

Dictafawn takes this philosophy one step further and stands as one of the labour-of-love anomalies within the new digital underground. Developed in 1969, the microcassette format has mostly been known for its use in voice recording and transcription ("Microcassette Minicassette"). As with other physical formats, the digitisation of voice recording devices has seen the microcassette drop in popularity and modifies its coding into that of the obsolescent, the residual. In this instance, it is unsurprising that labels like Dictafawn should exist within extreme audio culture, actively creating a rift between the product and the consumer regarding the utility and ease-of-access to the music contained within the technology of the microcassette. One must surely own the appropriate equipment in order to allow the item any practical value, thereby further reducing the label's customer base to an extremely niche and select audience. Dictafawn, or even Cory Schumacher, present an opposition to the digitisation of music - a swing against the flow of the MP3 'revolution' - by adding a far more interactive and engaging experience within a release. This allows us to establish aspects of value within such practices and materials coded as 'noise' from the vantagepoint of large-scale cultural production, "For despite the death it contains, noise [symbolic, social or, in this case, material] carries order within itself; it carries new information" (Attali 33). Furthermore,

You can actually interact with a cassette, change it, erase the original contents, insert your own content. Aside from scratching and altering a vinyl record there's not a whole lot that you can do with a vinyl record. ... Like I said above, a cassette, standard or micro-, offers/invites interaction and open-ended creation. It's an empty container that awaits you, me, anybody, everybody. It 
breaks down the false barrier between artist and audience. Everyone can be an artist. (McGee)

Given the continued use and circulation of audio cassettes within scenes such as extreme audio culture, it would appear as confirmation that the new digital underground, although easier to access and navigate than its print-material predecessor, succeeds in continuing the tradition of DIY music and culture in which even communities as traditionalist as the underground black metal scene can adapt to the ever-increasing influence of the world wide web and remain within its preferred place among the residual, the marginal and the esoteric.

Since its genesis in the 1980s, the black metal scene has been typified by its emphasis upon authenticity and tradition (Spoto 1). Though similar to extreme audio culture, again there is indeed more at work here than accusations of elitism and gimmickry would suggest. To clarify, the preference of the audio cassette for many underground black metal artists also extends to the sonic properties of the format. Subgenres such as raw, atmospheric, depressive and suicidal black metal (not to mention fusion genres like black noise - a mixture of black metal and harsh noise - and blackened crust punk) place emphasis upon not only gritty abrasiveness but also an ethereal, otherworldly, hazy atmosphere; sonic textures which suggest darkened forests, forgotten tombs, bleak winter landscapes or the piercing, desperate pain attributed to severe mental illness and suicidal thought (THKD, "Worship Black Metal Cassettes"). We may continue to draw numerous parallels between extreme audio culture and underground black metal in this respect, and we will be exploring comparisons between noise music and the broader extreme metal scene in Chapter Three. Therefore, as the cassette tape is positioned within the realm of the marginal and obsolete as far as dominant culture is concerned, we can observe that both the material utility and cultural 
status of the format lends itself appropriately to the esoteric particularities of underground black metal. To consolidate this notion,

The recent resurgence of cassette culture within the US black metal underground (and elsewhere) seems to be foreshadowing a paradigm shift within the scene; perhaps it is the beginning of the death knell of 'Heavy Metal, Inc.' and a return to the DIY ethics that underground metal was built on. [...] ...a slew of bands and labels appear genuinely committed to taking the underground back underground, out of the hands of industry slime-balls, selfabsorbed mercenary 'journalists' and sloganeering try-hards, putting it back in the hands of those that matter, the truly dedicated artists and fans themselves. (THKD, "Blut Der Nacht")

As niche and esoteric as these scenes remain, in many respects one could also see the perpetual growth and connectedness of the new digital underground as a sign that they are taking a more welcoming and supportive stance towards the initiation of newcomers, the discovery of artists and labels alike, not to mention the construction of communities and networks that are truly global in their scope. Thus, the notion of underground music being as active and vibrant as ever can clearly be observed in the sheer multitude of artists and labels arising within. Therefore, technologies such as the cassette and the vinyl record still remain a vital part of the cultural and symbolic capital within these scenes due to their status within dominant culture as residual and obsolete. They also provide an interactive, specialist element which works to separate them from mainstream music culture (and, in this respect, even the remainder of online music culture), helping them retain their status and coding as 'underground'. Consolidating this notion, 
[Raymond] Williams pictures culture as a dynamic process, so that at any point we have not only a dominant culture (by which he means the culture which best serves the interests of the dominant social group) but also 'residual' and 'emergent' aspects of culture. By attending to the recently outmoded and the obsolescent, culture as a process becomes more evident. Yesterday's new thing does not simply disappear, nor does it just get refashioned by new technical process or as new media content. Instead it continues to exist at the margins of culture. To consider residual media is also to consider the residues of past social arrangements and relationships which continue in the present, although perhaps in fragmentary forms. As a stage in the social life of a thing or practice, obsolescence is determined not by the qualities of the thing itself but by the culturally produced regime of value. (Henning 54)

Through maintaining the notion of this cultural hierarchy, the network of underground culture has continued to survive by remaining upon the fringe of cultural economy. Although the argument put forth by Reynolds, concerning the flattening of culture, most certainly has its supporters from a theoretical standpoint, the new digital underground has provided a platform for which artists can find a place to work and acquire recognition away from the immensely saturated popular overground which continues to become overpopulated in what critics such as Andrew Keen would describe as a cacophony of attempted self-aggrandisement and a desperation to achieve the fifteen minutes of fame the World Wide Web seems to hint at. In the 2011 documentary PressPausePlay, directed by David Dworsky and Victor Köhler, Keen addresses the issue of media saturation within the World Wide Web as the first signs of a coming "cultural dark age", where dominant creative culture becomes flooded with mediocrity; the masses submitting to contentment in this diluting, this 'dumbing down', 
of art and culture at the hands of technology which allows anyone, anywhere to become a musician, writer, film-maker and so-on. This would suggest that the early twenty-first century is indeed a despairing and desperate time for any serious artist attempting to make a name for themselves within the all-out cacophony suffusing the digital mediascape. Although this idea is highly contestable - with much of the potential of online creative culture remaining, as yet, unexplored, not to mention the societal roles of the creative industries existing in constant revision in the online era - there still remains a feeling of hopelessness attributed to the online creative media landscape, particularly when one attempts to navigate and infiltrate its various avenues and networks.

Yet if we return to Hartmann's notion of music as a communicative act, rather than merely a commodity, a product to be bought and sold, there are suggestions of a gradual, though noticeable, redefining and re-evaluation of music in our current climate; its value to both artists and consumers alike, as well as its role within contemporary (especially urban) society. As the isolation and alienation of the individual becomes an increasingly problematic and thus noticeable factor within our transhuman age, the changing nature of music arises from a heightened desire to reconnect to one's humanity. Through the consumption of cultural artefacts and the increased accessibility of communications technologies such as the internet, many people adhere to a deeper, socially unifying notion of music, and creative culture in general, which allows for more personal connections to be made. This leads us to the next chapter of our discussion, where the aspects of community within extreme audio culture and the new digital underground come into focus, with practices such as tape trading, webzine publishing and centres such as forums and blogs serving as the pillars which hold the scene firmly in place. 


\section{Chapter 3: Identity, Engagement and Social Interaction}

Within a scene as niche and marginal as extreme audio culture the position of the 'fan' or consumer lies upon a diverse cross-section of practices, perceptions and ideologies concerning the meaning and purpose of consuming noise and power electronics works as commodities; fetishised by their esoteric nature, spectacular presentation and mythos, as well as a sense of taking pleasure in the efficacy of 'noise' itself. Although, as previously mentioned, extreme audio culture could be said to inhabit Pierre Bourdieu's restricted field of cultural production, positioned against the far edge of the avant-garde (The Field of Cultural Production 115), it also exists in tandem with more popular-derived styles through its presentation, performance, ethos and cultural coding which ties it back to its genesis within industrial music - itself a style which skirts the boundaries of the popular and the avant-garde - as well as offering numerous connections to scenes as diverse as extreme metal, hardcore punk, hardcore techno and psychedelic music. In many respects, this diversity and eclecticism can be reflected most prominently upon observation of the consumer and fan. Once again, this thought threads itself through not only the material aspects of extreme audio culture - such as collecting of releases, merchandise and other paraphernalia - but also aspects of the social and symbolic, extending to an incredibly diverse and sometimes conflicting set of codes and meanings as to what the scene does, can and should represent; politically, philosophically, creatively and culturally. Furthermore, as this project, overall, is primarily a discussion of technology, we must keep in mind that "[a]ny technology 
should be seen as a system, not just of tools, but also of related social behaviours and techniques" (Pfaffenberger 241), and, as Jacque Ellul observes,

Technique is not an isolated fact in society (as the term technology would lead us to believe) but it is related to every factor in the life of modern man; it affects social facts as well as all others. Thus technique itself is a sociological phenomenon[.] (183)

This chapter seeks to observe and analyse the consumption practices within extreme audio culture and offers a broad yet vivid overview of the role of the consumer and fan within noise, power electronics and the new digital underground in general. In addition, the role and status of the collector will be of significance to this part of our discussion, particularly in their relation to residual media and the fetishisation of certain items and technologies within their accruement of cultural capital;" "the vanguard of the antiques trade" as Michelle Henning dubs them, "their practice as the beginning of the recuperation of the obsolescent back into commodity status" (62). In view of the author's experience as fan and consumer, the chapter will aim to provide analysis both internal and external in order to illuminate and solidify issues and observations which present themselves when dealing with the consumption, interaction and engagement of the audience.

In many respects, the scene functions in a similar fashion to other niche music scenes, i.e. the more popular scenes which also share a large space within the new digital underground. Yet it also remains a unique and anomalous entity due to its diversity,

11 "Bourdieu defines cultural capital as a form of knowledge, an internalised code or a cognitive acquisition which equips the social agent with empathy towards, appreciation for or competence in deciphering cultural relations and cultural artefacts" (Johnson 7). 
inaccessibility and controversial, transgressive nature, not to mention the various technical and presentational aspects of its production and performance - the use, misuse and abuse of musical and sound generating technologies - which aligns its audience as audiophiles and 'gear geeks'. As music reviewer Pomo Brian once said of the sub-genre of harsh noise wall, "It's quickly becoming the death metal of experimental music"; commenting upon the style's distinctive sound and uncompromising approach. Yet if we were to take a social and, furthermore, symbolic view of this statement, perhaps extreme audio culture could be observed in a comparative manner with the extreme metal scene. In fact, Jack Harrell argues the case for death metal being “an unofficial expression of industrialism’s emotional isolation and violence” (Kahn-Harris, "Unspectacular Subculture?” 109), as we have similarly argued in the case of industrial music. Therefore, these comparisons in extreme music will be explored further in this chapter, drawing upon the work of Keith Kahn-Harris, to exemplify this cross-contamination of musical traditions, identities and ideas within the new digital underground.

In order to effectively articulate the diversity, disparity and scope of extreme audio culture at the level of fan and consumer, the work of Will Straw shall be drawn upon more explicitly in order to gain a more encompassing and efficient view of this entity as a whole. Straw's notion of 'scene' will be used, in place of such labels as 'subculture', in order to address the broad spectrum of identities and ideologies inherent within.

A musical scene ... is that cultural space in which a range of musical practices coexist, interacting with each other within a variety of processes of differentiation, and according to widely varying trajectories of change and crossfertilisation. The sense of purpose articulated within a musical community 
normally depends on an affective link between two terms: Contemporary musical practices, on the one hand, and the musical heritage which is seen to render this contemporary activity appropriate to a given context, on the other. (Straw, "Systems of Articulation" 373)

The instance of live performance, or 'live actions' (as they are commonly referred to in the harsh noise and power electronics communities), exemplifies two strikingly different yet tangible reactions to the performance of noise which illuminates this unique blurring of high and low cultural coding within both the art itself and by its audience. ${ }^{12}$ As stated by Straw, the character of an audience is "determined by the interlocking operation of the various institutions and sites within which musics are disseminated" (384). Due to the eclectic cultural status of noise and power electronics and the limbo between high and low culture that they inhabit, the character of their audience thus occupies a similarly cacophonous diversity. There are, on the one hand, those audience members who remain posed in deep thought throughout the performance, bearing an analytical, critical mind-set which positions noise within the realm of sound art as witnessed at live performances from Vomir (mengenerated) and Emil Beaulieau (Scott). Much like one would admire a painting or sculpture, this position solidifies extreme audio culture's status as an artistic avant-garde with attention favoured on the form, expression and innovative approach the given performer or artist brings to their craft. In many respects, this perception is what has given noise and power electronics a sense of legitimacy and purpose within academic art and literature

\footnotetext{
12 "Comprehension involves a decoding operation, and the ability to decode works of art as they are meant to be decoded (that is, according to the values established in the artistic field) is not a universally shared natural talent, since it involves much more than the direct and immediate apprehension of the work. Artistic competence is a form of knowledge which permits the beholder to situate the work of art in relation to the universe of artistic possibilities of which it is part" (Johnson 22).
} 
as an established form worth both observing as a researcher and undertaking as an artist. This returns our discussion once more to Pierre Bourdieu's notion of the 'research sector' of cultural production (The Rules of Art 120; Prior 308), with extreme audio culture sitting at the extreme end of the restricted field, governed by symbolic and cultural capital - the worth of which is determined by a work's legitimacy and influence within the field - rather than economic capital, which still remains a factor, although considerably less so than within the field of mass production (i.e. popular music).

Thus we can observe contrasting perceptions of noise and power electronics as 'extreme' music, the positioning of which yet ties them into the aforementioned margins of various orthodox genres. Here we can make sense of the live actions which feel similar in atmosphere and attitude as perhaps a hardcore punk or grindcore performance in the trance-like, immersive, often aggressive approach and behaviour of the audience. Head banging and moshing are a common practice at many performances within the realm of harsh noise or power electronics; demonstrated at the live actions (performances) of Death Pile (Sirrock) and the Incapacitants (mojuvideo). The often intense physicality of noise arises from the manipulation and exploitation of the sonic cues within music that allow its bodily affect; as shall be discussed below, it takes advantage of our bodily response to and absorption of sound through its use of dissonant tones and textures at high volumes (as can be said, to varying degrees, about extreme music in general).

Music is understood by this [western] tradition as being problematic in its capacity to affect us in ways which seem to bypass the acceptable channels of language, reason and contemplation. In particular, it is music's apparent physicality, its status as a source of physical pleasure, which is problematic. (Gilbert and Pearson 42) 
The artists themselves can often be seen as embodying a distinctly 'metal' or 'punk' mentality whilst performing, thus giving licence to a perception of extreme audio culture as removed from the realm of sound art or the avant-garde and having much more in common with simply 'extreme music'. Of course, once compared to other, less abrasive forms of avant-garde music and performance, it becomes obvious as to why noise and power electronics remain such unique entities within the underground.

So, while consumption in the field of large-scale cultural production is more or less independent of the educational level of consumers (which is quite understandable, since this system tends to adjust to the level of demand), works of restricted art owe their specifically cultural rarity, and thus their function as elements of social distinction, to the rarity of the instruments with which they may be deciphered. (Bourdieu, The Field of Cultural Production 120)

Much like its predecessor (industrial music), extreme audio culture moves to blur and perhaps even destroy the line between high and low art, between the popular and the avant-garde, in order to make use of the full spectrum of musical and artistic expression available.

This notion of a 'blurring' between not only high and low cultural forms but also scenic forms which have developed a strong legacy and loyal following over the past four decades or so, leads us to the observation of extreme audio culture within the frame of the musical scene for which it lies inside a mixture of extreme styles and forms, reinforcing the idea of 'noise' as not only a material aspect, but also as a social and symbolic aspect. This "cross-genre, cross-category, ultra-amplified and often ultraprocessed music" leads us to categorise noise music as a "hypergenre" (Hegerty 138); the notion of which can furthermore refer to a type of 'scenic noise' which has culminated into the noise and power electronics fan, exemplifying the diversity and 
multiple approaches to these styles, resulting in a cultural cacophony of distinctive forms which all find a common ground in the utilisation of noise as a creative material. Indeed, this notion meshes even further with the work of Bourdieu, particularly when he speaks of the legitimation and consecration (The Field of Cultural Production 121) of symbolic goods by those within various sanctioned cultural authorities such as academies, art galleries and educational institutions. Or in a different light, “...the 'logic' of particular musical culture is a function of the way in which value is constructed within them relative to the passing of time" (Straw, "Systems of Articulation" 368). By this token, we may be able to apply these ideas to the notion of 'scene' within the new digital underground in order to illuminate the ways in which extreme audio culture is able to develop and maintain its legitimacy as a scene by operating within the coding of hypergenre. As Straw argues,

...scenes function more and more as spaces organised against change. Within them, minor tastes and habits are perpetuated, supported by networks of smallscale institutions, like record stores or specialised bars. At this level, scenes might be seen as conservative, asserting the values of diversity dispersed across space over those of regularised obsolescence and renewal in time. ("Scenes and Sensibilities" 255)

If one were to trace a broader lineage back from noise and power electronics, there may be a sensation of 'all roads lead to here' in regards to its relationship to styles such as heavy metal, punk and psychedelia. "Music, exploring in this way the totality of sound matter, has today followed this its path to the end, to the point of the suicide of form" (Attali 83). However, one may also argue that abrasiveness is only one aspect of 'extreme' to explore within a given mode of musical expression. As William Bennett from Whitehouse states, “'Extreme' doesn't mean a lot to me because 'extreme' only 
means an outer limit; it doesn't necessarily mean which direction you're going." 'This returns us to some key ideas laid out in the previous chapters, that the perpetual increase of urbanisation, mechanisation and digitisation of society has resulted in a sense of social alienation and anxiety which extends throughout artistic and cultural practice and into one's sense of identity and belonging. This is particularly evident in terms of subcultural affiliation and the accumulation of cultural and/or symbolic capital.

Within our current, transhuman, age, subcultures - namely musical subcultures - are becoming increasingly rare and increasingly integrated, suggesting that culture and identity have succumbed to this post-human anxiety; the ability to express and distinguish oneself in a tribal manner within the urban environment falling victim to the unheeding saturation of autonomy and isolation of the individual within it, the paradox of humans being ever-expanding in number yet ever-decreasing in our cultural connection and unity (Weinzierl and Muggleton 12). As Geoff Stahl, citing David Muggleton, argues, "Subcultural styles become simulacra, copies with no originals. Accordingly, there is no longer space for originality, as referents have been displaced or 'disappeared' and the 'real' reduced to the play of surfaces, and infinite series of signifiers signifying more signifiers" (29). Therefore, extreme audio culture manages to stem the flow, so to speak, of this subcultural 'watering down' of the urban environment by offering a space in which individuals from a range of different strata may converge into an environment which seems to welcome a diverse collection of approaches, perceptions and subcultural standings so long as they continue to flow against the brick wall of the 'extreme'; of noise and the residual. ${ }^{13}$ The "notion of music

13 This is where Bourdieu's field of cultural production becomes problematic within our current cultural climate. Whilst the division and opposition between large-scale and restricted production still makes sense on the outset, the perpetual growth, multiplication and meshing of 
as reinforcing 'groupishness"' within contemporary society remains an important thought, particularly the ways in which it promotes "the formation and maintenance of group identity", "collective thinking”, "group synchronisation” and "group catharsis" (Cross 7). However, as the flow increases and the underground continues to gain membership and allegiance, this 'damming' of extremes continues to build and grow ever deeper until only two possible routes of continuation remain: Either these extremes will flood upwards into the field of mass production and popular music - as they are doing in many respects already, particularly within genres such as hard dubstep (more specifically sub-genres like brostep and filthstep) and glitch-derived electronic music styles - or the wall itself will ultimately break (as with those previously), leading to areas as yet unexplored by the language of music - online music culture having a lot to answer for in this respect, as the growing cacophony of digital distribution allows us to draw the analogy of this 'brick wall' as the 'guardian of the threshold' (or 'dweller of the threshold'), to borrow a theosophical term (Lytton), for which musical innovation and progression is constantly trying to defeat in order to move forward into a new realm of practices and ideas which aid to further evolve musical thought.

Indeed, the immense saturation of musicians and works currently available leads one to infer that out of this cacophony shall eventually arise a combination of techniques, tones and theories which will finally break through the guardian (the dweller) in order to allow the artist to pass through into the next plane of musical language; as has been the case in the evolution of music thus far. ${ }^{14}$ Citing Dick Hebdige,

sub-fields (genres, subcultures, scenes, etc.), in parallel with the growth of large-scale production, sees the field of cultural production, as a whole, becoming increasingly more dense in its complexity (Hesmondhalgh 222).

14 As electronic music producer DEV/NULL states in the 2006 documentary Notes on Breakcore, directed by David Kleinl and Bertram Könighofer, "Even though there's a lot of generic crap that comes out, because there are so many people now that are making so much music - and it's all building off of itself - even if a lot of it sucks, eventually really awesome, cool shit really does 
Oliver Marchart touches upon "the assumption that from the point of view of the media mainstream, subcultures represent noise, disturbance and blockage of the system of representation; and the tendency is strong to ascribe a subversive and resistant power to such noise" (86). Yet extreme audio culture suggests to many uninitiated observers a brick wall which remains thus far impenetrable; viewing styles such as harsh noise wall in an analogous light as this 'damming process' in literal action - musical thought having nowhere to go but sheer, all-encompassing dissonance. This 'brute force' approach embodied by harsh noise and power electronics seems to reflect the current state of extreme music and art in general by raising questions concerning just how much more 'extreme' musical expression can become in terms of sonic and emotional intensity.

One aforementioned aspect of extreme audio culture that we should expand on here is the engagement of the audience/fan/listener with recordings and performances. Tools and practices that remain coded as residual or 'noise' within the perceptions of dominant culture, such as distortion, abrasiveness and confrontational aesthetics, are certainly hallmarks of extreme music styles, the challenging, aggressive nature of which provide an attraction in their status as subversive and oppositional to mass, mainstream culture; allowing an opportunity for the individual to gain a sense of transgressing and transcending beyond the status quo, providing "a source of individual empowerment, responsibility and community among people who have suffered as a result of changes in the structure of capitalism” (Kahn-Harris, “Unspectacular Subculture?” 109), i.e. the emergence of a digital, post-industrial society. It is this sense of alienation from the mainstream and curiosity towards the underbelly of existence (society, humanity, technology, nature, the occult and the esoteric) for which extreme music gains its aura inevitable that something fucking brilliant is gonna shoot out of it somehow." 
of revelation and enlightenment. Here, the work of Keith Kahn-Harris illuminates the scenic comparisons and similarities between extreme audio culture and the broader extreme metal scene in terms of their spectacular presentation, transgressive subject matter and aggressive, abrasive stylistic approach. Styles such as grindcore and black metal contain within them an aura and mythos to their structure in terms of musical and cultural practices and ideas; the notion of the residual and the esoteric, uncovering a hidden secret concerning the nature of reality and humanity, and, again, the transgressive ${ }^{15}$ through their practices and reputations. We can also observe that the utilisation of transgressive material within extreme music (including grindcore, black metal, gabber, etc.) and the new digital underground in general, offers aesthetics and atmospheres which seek to add socio-political context to the work itself. Thus, "transgressive practice is practice not orientated towards utilitarian, rational ends. Rather, it is based on a simultaneous attraction to and repulsion from death" (KahnHarris, "Unspectacular Subculture?" 109). One may deduce that the same fascination that attracts individuals to true crime novels or horror films works similarly to draw fans into extreme music within a natural curiosity concerning the darker side of human nature in general (Whelen 472). Its esoteric status only seeks to further solidify this fascination, by adding the satisfaction of discovery and 'unearthing' which rightly accompanies the initiation into underground scenes.

If one were to question the attraction to extreme music even further, we only have to glance back at the history of rock music and the effect electrification (or even mechanisation) had upon the way we hear and experience sound (returning us to

15 What Kahn-Harris takes to mean as "experience produced through practices that cross over or (more usually) straddle the principle boundaries that structure our social reality; death/life, good/evil, pure/impure and so on" (“Unspectacular Subculture?” 109). 
Russolo). Although it is often immensely difficult to explain exactly the effect sound, particularly music, has upon the human body without becoming too emotive or abstract, we would be best to look towards nature and our harnessing of it as a species for the answers. Much of the effect of music is reliant upon our natural instincts, reflexes and perceptions towards sound - sounds of danger, predators, prey, water, vocal recognition, bodily functions, etc. - as required for our survival and growth as a species. Eventually we return to notions mapped out by the likes of Haraway and Marshal McLuhan when we realise that,

Music is constituted by waves of sound that vibrate through the air, vibrating the eardrum in specific patterns which are registered by the brain. But, importantly, it is not only the ear which registers these vibrations; deaf people can learn to play and 'hear' music. These vibrations are registered on some level throughout the body. (Gilbert and Pearson 44)

One might suggest then, that music is our harnessing of the sounds of nature in order to derive pleasure, emotion and stimulation from our body's natural reactions to them. This notion ties into the work of Ian Cross and, in particular, his discussion of Steven Pinker's bizarre definition of music as “'auditory cheesecake'; while music in his view is bound to the domains of language, auditory scene analysis, habitat selection, emotion and motor control, it does no more than exploit the capacities that have evolved to subserve each of these areas" (6). Cross continues,

Music is thus 'exaptive', an evolutionary by-product of the emergence of other capacities that have direct adaptive value. (6)

By the same token, technology itself is humanity's harnessing of nature in order to make our lives more comfortable, productive and beneficial for us as a species (in 
theory). Music itself, by its very nature, is technology, and as we have explored previously, especially through the work of Haraway and, in this case, Attali, the advancement of technology, its social meanings and uses, continues to have a vital impact upon man's psyche and vice versa, this two-way flow continually remoulding societies in ways which remain both wondrous and deeply problematic. It is argued by Bryan Pfaffenberger that we should view technology as "humanised nature ... to insist that it is a fundamentally social phenomenon: It is a social structure of the nature around us and within us, and once achieved, it expresses an embedded social vision, and it engages in what [Karl] Marx would call a form of life" (244). Thus the attraction to noise as a creative material lies within man's relationship to, and ever-growing symbiosis with, technology within material, social and symbolic relations of meaning. To put it another way, whilst also tying this notion back to Attali, Martin Heidegger observes that,

Technology is a mode of revealing. Technology comes to presence in the realm where revealing and unconcealment take place, where the alètheia, truth, happens. (255)

Music carries with it both the mark of the technology/technique used to create it, as well as the environment, context and circumstances surrounding its production, all of which adds to the qualities and affect of a work which is then absorbed by the listener/audience. Thus, extreme audio culture breeds a particular and discerning connoisseurship which "cannot be imparted entirely in the form of precepts or instruction" as Bourdieu would argue from the perspective of the art world, as "apprenticeship" must be gained through the repeated exposure, experience and familiarity with a range of works in order to acquire the necessary knowledge (cultural capital) in order for an individual to bear such a label (The Field of Cultural Production 228). 
We must also take into consideration the overarching societal and occupational factors contributing to the isolation, alienation and discomfort surrounding employment, social status and identity within post-industrial economies; the volatility of our current job market, the "[i]ncreased geographical and occupational mobility" associated with many positions of employment which aggravates "feelings of uncertainty", as well as "the need to function in large organisations" placing harsh demands on individuals to conform and 'merge' with a system which one may perceive as "degrading ... because it is interpreted as a subordination of humanity to organisational efficiency" (Mesthene 635). In addition, Russolo's intention to emulate the voice of the machine through the language of music is further realised within this notion as the artist's environment cars, construction, general urban cacophony - becomes part of the work, as well as their psyche, emotion, perceptions and ideologies which are transformed into the technology of music.

In Chapter Two, distribution and promotion of works was discussed, exploring factors such as the practice of artists and labels releasing works in strictly limited numbers, experimenting with packaging and album art, and the use of different container technologies (recording formats) in order to add a more interactive element to the consumer's engagement with the release as well as the notion of 'authenticity' in regards to issues surrounding the perceptions of analogue and digital technologies within extreme audio culture and the new digital underground in general. Noise music, by its very nature, is characterised as very much a DIY, independent and, of course, residual art form with a large emphasis placed upon the assembly of instruments and gear setups, the intricacies of the home-recording process and the aesthetic representation of one's work through artwork, packaging and promotion. Returning to issues discussed in Chapter Two, there remains the imagination and pranksterism 
imbued within releases whose recording format/container and packaging stand as at once comical, provocative and simply bizarre.

In order to navigate this arena of codes and discourses, collectors within scenes such as extreme audio culture equip themselves with various competencies when decoding the economic, cultural and symbolic value of an item, particularly in the case of what Kate Egan calls "languages of scarcity or exclusivity" (201), i.e. limited editions, works released on multiple formats, etc. Comparable to her research topic of 'video nasty' collectors in the United Kingdom, Egan adds that such discourses imbue video collectables "with an aura of authenticity while, in the process, targeting collectors as 'insiders', who are able to gain a heightened sense of 'intimacy' with a particular film and reinforce their status as discerning collectors and serious cinephiles" (201). Also worth mentioning is Egan's notion of "prize pieces" for which specific items not only house a significant amount of cultural and/or symbolic value (perhaps due to rarity or printing) but also perhaps an emotional and personal value for which two types of "personalised value" can be identified: "[A] esthetic/historical value and value of the rare or the singular' (209). 'Prize pieces' remain an important scenic phenomenon due to their role in both storing and circulating significant amounts of cultural capital, as well as generating and perpetuating mythos within a scene; stories, rumours and histories which create both an aura and allure to a scene by which it gains its character, distinctiveness and, on some levels, its legitimacy. ${ }^{16}$

\footnotetext{
16 Although it may not be the most exonerating example in terms of the circulation of morally (and legally) questionable material within extreme audio culture being representative of the scene as a whole, Andrew Whelen's discussion of the short-lived zine Pure illuminates the notion of 'prize pieces' by noting the zine's importance in the "origin myth" of extreme audio culture (471).
} 
To put it another way, the more the field is capable of functioning as a field of competition for cultural legitimacy, the more individual production must be oriented towards the search for culturally pertinent features endowed with value in the field's own economy. (Bourdieu, The Field of Cultural Production 117)

The accumulation of cultural capital within any collector's culture is a respected aim for its members. Within musical collector's culture, factors that weigh into the item's worth consist of variables ranging from its rarity to its pressing/production number (highest value being placed upon first editions, much like the collection of books) as well as, in regards to the work itself, its originality and peculiarity as a musical/audio release. All of these are symbolic attributes which create the cultural worth of symbolic goods. Of course economic capital is also a factor here, with many rare and out-of-print releases fetching high prices from avid collectors. Returning to Bourdieu,

Symbolic goods are a two-faced reality, a commodity and a symbolic object. Their specifically cultural value and their commercial value remain relatively independent, although the economic sanction may come to reinforce their cultural consecration. (The Field of Cultural Production 113)

As one noise producer and fan stated on the (now defunct) Noisefanatics.com a.k.a. Troniks forum, “...rare noise buyers must be one [of] the most wealthy buyers of music. Poor people trade or download. Also, to pay a lot is sometimes the fetish" (Sleep Of Ages), for which Emil Beaulieau replied, “Oh, most definitely. Collecting records/whatever is all about the bragging rights and the fetish satisfaction. 'Yeah, I got that LP - it cost me an arm and a leg - one of my prized possessions'." However, what is surprising about the new digital underground is also obvious in its identity as a residual culture and noise music as a subversive and oppositional DIY tradition which 
covets the obsolete, the discarded and the unwanted, both in terms of materials and practices. Citing Bourdieu, Charles R. Acland states that "there is perhaps no more telling indication of cultural capital than the ability to bestow value where there had previously been presumed to be none" (Acland xv). Furthermore,

Things operate in circuits of value, which themselves can be spatially located and temporally varying. Dear treasures in one part of town may be garbage, and laughable, in another. (Acland xv)

This is specifically relevant to the practice of tape trading, or trading of releases in general, which many collectors prefer over an exchange for economic capital for their collected items; even labels such as Smell the Stench prefer to trade items rather than sell their stock (Julian). These factors make extreme audio culture comparable to collector's cultures such as comic books or trading cards, as although there are certainly many who gain some economic capital from their collections, within close circles and between personal acquaintances the act of cultural and symbolic exchanges of capital allows the collector to inherit a certain amount of prestige and respectability therein.

Collecting involves a sustained commitment to the development and organisation of vast and detailed forms of scenic knowledge. Like other forms of scenic practice, it also involves participation in complex scenic networks, the accessing of which demands considerable commitment and self-discipline. (Kahn-Harris, “Unspectacular Subculture?” 114)

Learning about the ever-growing plethora of releases and salvaging them from their "isolation" are, in John Davis's opinion, the "two major practices of hunting among vinylphiles" (230), and the same idea could certainly apply to noise and power electronics collectors as the knowledge required to discern and be made aware of items, 
as well as the ability to 'salvage' them (a fitting term for discussion of both noise and residual media) ultimately falls into the reliance upon the new digital underground in terms of distribution routes (labels, mail order, etc.), blogs and webzines (discussed below); the networks the collector strives to discover, enter, build and maintain over their membership within a scene. Such structures of commerce, culture and community require a significant amount of time and effort on the part of the collector/consumer in order to constantly remain up-to-date and ahead-of-the-game when unearthing and pursuing new, rare and limited releases. As with any collector's culture (comics, action figures, etc.) there is indeed, on the surface, the personal, emotional intrinsic value which comes from the human (arguably masculine (Shuker 34)) desire to collect, organise and archive. We can equate this to not only commodity fetishism but also the lure of material, artistic aesthetics and personal discourses which emerge from creative media; e.g. the record collector/music enthusiast who identifies with his or her collection as a reflection of their personality and thus proudly organises and displays it so that others may be able to 'read' deeper into them by browsing through it. Such practices aid the collector in solidifying his or her identity, allowing them to form a heightened understanding of themselves and their interior world through the creation and exhibition of a collection as a singular entity. In many respects, the record collection can be observed as a map of the individual's psyche as we become privy to what music, and thus what sounds (tones, timbres and textures), resonate most explicitly with their personal perceptions and emotional experiences. Yet this pride and enjoyment of collecting, with the amount of time and energy it consumes, also equates as a form of labour, which Egan argues would place collectors in the "community roles of archivist, skilled shopper, and entrepreneur to present a powerful picture of a collector as the creator of his or her own alternative economic and cultural sphere" (217). Therefore, this archiving of releases endows the most extensive and immersive 
collections with a heightened cultural value as a scenic resource and catalogue, the stockpiling of which extends beyond what the collector would ever be able to listen to (Attali 101).

...arguably, these collecting roles and dispositions are alternative because they are not primarily generated or shaped by the discourses of contemporary marketing and distribution discourse, and specialist because they, instead, hinge so fervently around both situated and context-specific historical and cultural meanings, and the intimate knowledge and personal consumption and collecting history of the veteran video nasty collector. (Egan 217)

Or, in our case, the veteran noise and power electronics collector. As we have observed, there is certainly more value (monetary, cultural and symbolic) placed upon physical formats - vinyl, cassette, etc. - within extreme audio culture, yet its positioning within the new digital underground affords it with new avenues of recording and distribution to explore; equally intangible yet undoubtedly, paradoxically, 'present'. In terms of primarily younger and less militant/audiophilic members of the scene, it is worth mentioning the role of digital audio formats such as the MP3 and "[t]he struggle for the monopoly of legitimacy..." (Bourdieu, The Rules of Art 167); to be recognised as an 'authentic' container technology. This authenticity stems from not only the amount of artists and labels who use them or their efficiency, compatibility and versatility as a recording format/container technology, but also the ways in which the digital distribution of music has remoulded and adapted the notion of 'collecting' within music scenes in regards to the intangible yet undoubtedly 'present' realm of MP3 music libraries, broadband internet and the stockpiling of music by veterans and potential initiates alike. In light of instantaneous and accessible nature of these tools and avenues of consumption, potential initiates can gain the competencies necessary for entrance 
into the scene as fan/consumer by immersing themselves in recorded works to build experience of its aesthetics and flavours. With these shifts in the way an individual may consume music within cyberculture there emerges a distinct transformation of what it means to 'collect' through the sheer notion that,

What is being stored and accessed is no longer a fixed body of objects with fixed identities and contents. Moreover, the user seeking the information is not a subject who desires a more complete and reliable model of the world, but a person being ready to be opened up to ever new horizons. In short, the postmodern human being is not interested in collecting but is constituted by connecting. (Dreyfus and Spinosa 318)

In regards to the MP3, its use within extreme audio culture is varied and there are many artists and netlabels who offer free digital downloads of releases; e.g. the aforementioned Smell the Stench, run by Leigh 'Stench' Julian, which operates as both a traditional "D.I.Y. Tape/CDR Label” and an MP3 "Internet Label” with all downloads available free of charge. Furthermore, extreme audio culture does indeed have a noticeable presence on hosting sites such as Bandcamp and SoundCloud; sharing equal footing and listenership potential alongside the rest of the crux of online music culture. Pfaffenberger sums up this evolution and adaptation fittingly when he states,

To create a new technology is to create not only a new artefact, but also a new world of social relations and myths in which definitions of what 'works' and is 'successful' are constructed by the same political relations the technology engenders. (250)

As discussed earlier, artistic pursuits very often do bear the mark of the environment within which they were conceived and produced, adding to the character 
and flavour of the work as an entity. From what we learned from Throbbing Gristle and Whitehouse in previous chapters, the contemporary urban environment encompasses more than just machine noise and general technological/industrial cacophony which Russolo experienced in early-twentieth century Milan. It also includes noise and residue on a more social and symbolic level in the form of crime, violence, isolation, alienation, perversion and paraphilia.

This is where we may understand further the fascination and allure towards the more transgressive acts and aspects of the scene as " $[\mathrm{t}]$ he experience of transgression is the experience of something exceptional, removed from mundane everyday experience. It is understandable therefore, that transgression is felt most intensely on entry to the scene” (Kahn-Harris, "Unspectacular Subculture?” 116). Upon initial discovery of the new digital underground, there may be a sense of elation felt as the sensations (and sometimes frustrations) of navigating the contemporary cityscape can be neatly summarised within the context of noise and power electronics, as well as the feeling of subversion and undermining of dominant culture. From here, we may work further towards a definition of the word 'underground' in cultural terms, as it,

connotes a sense of concealment, even of contraband, and this is at the heart of what still defines it as a musical philosophy. The music's general abrasiveness repels the mainstream; the distinct willingness of the general public to either turn away or ignore its existence in the first place is what gives [the] underground its identity, not some farcical public inability to locate it. (Graham)

On this note, the final aspect of extreme audio culture (and its place within the new digital underground) to be discussed, is that of the online social engagement between fans/consumers and members of the scene in general (including artists, label owners, promoters, etc.). 
Indeed it is one of the aims of this project to illuminate the adaption and survival of underground music culture from the pre-internet old print underground to the new digital underground, and while zines still remain a noted staple in a range of underground scenes, there was, of course the inevitable digitisation of the format into the contemporary webzine. A phenomenon which adheres to the notable and common notion within media theory of convergence and convergence culture (Jenkins 34): As old techniques, although established and respected, become outdated in their function whilst maintaining a significant amount of utility, they may eventually merge with and evolve into new techniques (or, at least, have a heavy influence upon them); a convergence of old technologies into something 'new' (or at least a combination of technologies which, until now, had yet to be realised; i.e. cell-phone cameras). Specifically, in our case, the webzine merges and evolves into the graphic digital interfaces and frameworks of cyberspace in order to fulfil the previous function of the zine within updated modes of producing, accessing and displaying textual and image-based media.

Just as the internet has renewed the economic value of innumerable cultural artefacts from the past (from the high school yearbooks sold on eBay through the Old-Time Radio programs available on websites), so it has hastened their convergence on the realm of the visible, they come adorned with textual commentary and forms of graphic display that have become the basis of their public presence. (Straw, “Embedded Memories” 13)

However, further to our discussion surrounding residual media, obsolete technologies, etc., the catch-all terminology of convergence misrepresents such instances. Much like the difference between subculture and scene we may find more fitting terms within alternative theoretical frameworks. Citing J. David Bolter and Richard Grusin, Michelle Henning draws our attention to remediation; the ways in which old and new 
intersect and coexist (49). In her article "New Lamps for Old" she uses this term in regards to digital photography, touching upon both the content and the processes of the medium, as well as the reworking of one older medium's content in another, newer, medium, the transformation of one medium into another and the hybridisation of media (49). In this regard, we see this process of remediation within the contemporary webzine. Interestingly, the webzine Pure Stench (run by Ryan Stench) shares many of the aesthetic qualities of older noise and power electronics print zines like Unsound (discussed in Chapter Two), fetishising such nostalgic imperfections as photocopied, black and white images and typewritten text, setting them within the framework of the contemporary blog. Thus, we may establish the allure of the residual - the outdated and obsolete - enmeshed within retro chic codification by remediating community aspects of the old print underground into the new digital underground, upholding the aura of extreme audio culture from previous generations as well as the structure within which listeners and audiences can keep informed and up-to-date with their scene, allowing them to accrue and retain cultural capital. Ergo, Henning also reminds us - echoing the work of Pfaffenberger - that "remediation should be considered in terms of changes in social relations" (50). Our on-going desire for efficiency and abundance being what ultimately drives the advancement of technology (necessity being the mother of invention); the email trumping the postal service, the webzine rising in popularity and influence for its accessibility in regards to both time and geographical reach.

Furthermore, new initiates can become embroiled within certain areas of the new digital underground by the way webzines, blogs, forums, etc., are clustered together in free-flowing systems connected by hyperlinks. As discussed by Paul Hodkinson, these "webs of hyperlinks" work to insulate and organise online communities in such a way that newcomers can effectively immerse themselves within the scene; becoming 
easily and efficiently familiarised within a short period of time (288-291). This allows for much quicker initiation compared to the old print underground, aggravating the perpetual growth of extreme audio culture. As a more explicit comparison,

The post office, as a social system of communication, is intimately linked to the rise of ideas and practices that enhanced freedom of expression and promoted the concept of a free contract among individuals. This example clearly demonstrates how a communications infrastructure can be taken over by a cultural movement capable of transforming its social significance and stimulating its technological and organisational development. (Levy 105)

The format of the internet forum (or 'message board') has remained a familiar and intuitive part of cyberculture, particularly in the case of fan cultures and music scenes. Owing to the usability and flow of this framework, much information, knowledge and cultural capital can be gained within them, particularly when one engages in active discussions, directly communicating with other scene members and forming connections and networks which could cross into real life. When we take cases like the Maniacs Only forum, ${ }^{17}$ these communities can become welcome haunts and social hubs for artists both novice and veteran, who use these platforms in order to promote their releases or dates of live actions, trade items, share advice or just chat about common interests; all of which they also take offline, using the forum as a means of connecting with their peers. Thus,

${ }_{17}$ Previously known as the Noisefanatics.com or Troniks forum, which ceased operations in May 2013. Just prior to its closure, Maniacs Only was established as a continuation: http://www.maniacsonly.com/ 
As a cultural resource in the context of everyday life, then, the internet takes its place alongside a range of other resources through which young people are able to fashion meaningful and 'authentic' identities, framed around issues of knowledge, power and exclusivity - all key elements of subcultural memberships such as these are understood reflexively and enacted by young people. (A. Bennett 169)

Particularly when we take into consideration sections such as the tour listings (one section entitled America, another entitled Worldwide, signalling that the majority of the forum's membership is US-based), threads on gear setups, collaborations, classifieds, etc., we can plainly see that the new digital underground is by no means the be-all-and-end-all of extreme audio culture and the community structures built within platforms such as this seek to reinforce Stephen Graham's notion of the internet making the underground as strong as ever.

A virtual community is not unreal, imaginary, or illusory. It is simply a more or less permanent collective organised around the new global electronic mail system. ... It's reasonable to claim, therefore, that such virtual communities bring about true actualisation (in the sense of effectively putting people in contact) of human groups, groups that were merely potential before the arrival of cyberspace. It would be far more accurate to use the term 'actual community' to describe the phenomena characteristic of collective communication in cyberspace. (Levy 110)

With the lack of physical presence within these communicative transactions, there is a sense of these platforms operating on the basis of mere thought without the physical cues and body language which accompanies face-to-face communication. Yet we can still tie this notion comfortably into cyborgian and transhumanist frameworks by 
the user's extension of their mental (rather than physical) faculties, through these machines and interfaces. Hence,

It is not just that science and technology are possible means of great human satisfaction, as well as a matrix of complex dominations. Cyborg imagery can suggest a way out of the maze of dualisms in which we have explained our bodies and our tools to ourselves. This is a dream not of a common language, but of a powerful infidel heteroglossia. (Haraway 445)

And to set in place these suggestions even further,

If then the art of technology is correlative to the knowledge of nature, technology too acquires from its source that potential of infinity for its innovative advance. (Jonas 195)

This perpetual pooling of resources allows for intensive exploration of codes and techniques which, potentially, signals towards an increasingly heightened artillery in the demolition of our current 'brick wall' in musical progression. Yet observations such as this - the 'brick wall' remaining firmly in place - may also reinforce the thoughts of sceptics like Andrew Keen and Simon Reynolds (discussed in Chapter Two), illuminating the sheer dissonance imbued within our current musical climate with regard to the internet, online music culture and technological advancement allowing for the status of 'artist' to be attained through the growing accessibility and user-friendliness of the tools and techniques required. One must contemplate, however, the notions brought forth by the likes of Jacques Attali, who sees music as revelatory; illuminating how a society shall develop over time and making known the changes in values and perceptions of the populous, allowing us to glimpse into the constant refining and remoulding of collective human consciousness by how we harness the sounds around 
us - themselves coded with meanings both overt and covert, material, social and symbolic - and organise them in order to take advantage of our natural bodily instincts and reactions, decoded as meaning (emotion, symbolism, narrative, etc.). In this light, when we return to the thoughts of Keen and Reynolds, who perceive our current musical climate as the 'end of the road' in terms of the form's progression and development. Perhaps the answer to their critique does not lie within just the focus on and dissection of musical practices, ideas and techniques themselves, but within the direction we are facing as a society and the path we currently walk. And while this, cacophonic diversity and saturation within contemporary music, at first glance, may hint towards an ending in terms of the commodification and industrialisation of music, through the communities, innovations and techniques which have formed out of online music culture we can revisit Björn Hartmann's (2) argument of the redefinition of music as a communicative tool, rather than merely a commodity. The perpetual growth and normalisation of online music culture works to solidify this claim, the consequences of which are beginning to echo throughout society with the ubiquitous and evermore immersive ways in which one engages with music within their daily lives. Thus we may observe, particularly within the urban environment, the continual harvesting of arising tones and timbres which, over time, become absorbed and familiarised into one's consciousness, creating new reactions, sensations and emotions from the artist's navigation of contemporary society.

On this note, we can conclude on this examination of the consumption practices within extreme audio culture by returning to the observation of the scene as a documenting and archiving of cultural, social and technological warfare; man versus machine, animal versus post-human. The battles of this war continue to be waged within the field of cultural production as well as the more overarching fields of identity, 
power, social interaction and belonging within the contemporary urban environment. As social behaviours - i.e. advancements and developments in technology - change, so too do the battlefields, atrocities and strategies of the individual; the soldier. This painful birth and transition into our cyborg, transhuman stage of evolution continues to bring forth the screams, torments and melding of flesh and machine which noise and power electronics seek to capture and express; the documentation and recordings of which are stored for future access within the avenues and alleyways of the new digital underground. 


\section{Conclusion}

Music is prophecy. Its styles and economic organisation are ahead of the rest of society because it explores, much faster than our material reality can, the entire range of possibilities in a given code. It makes audible the new world that will gradually become visible, that will impose itself and regulate the order of things; it is not only the image of things, but the transcending of the everyday, the herald of the future. (Attali 11)

With this, Jacques Attali presents the overarching hypothesis explored within Noise: The Political Economy of Music, which we have used throughout this discussion for its adept and fascinating insight into the implications surrounding creative human thought, innovation and imagination in our harnessing and adapting of technologies within art, culture and language. In this instance, we have examined the universal human trait of musical expression and how technologies are used in order for music to adapt and evolve, illuminating broader questions concerning technological innovation and the various motivations and intuitions that constitute the drive for artistic creation and expression. Here Attali talks about a 'given code', adhering to semiological notions of society and culture being constructed of codes. These codes manifest themselves within discursive acts and events such as our ever-changing/evolving sets of social behaviours - constantly in the process of refinement as new codes are introduced and others are discarded as obsolete (or, of course, residual) - of which we are forever conditioned, deconditioned and reconditioned in order to recognise them as the norm, the status quo. Regulated by their acceptance by the majority, such codes are the 
accepted sets of commands as to how one should behave within one's environment. Primarily, these communicative signs accumulate to build language in all its multitude of forms: Verbal, written, bodily, etc. And we find that as these codes of social behaviour transform and develop, the evolutionary cycle of language (leading to the structure and development of society) becomes clear.

The hidden norms may become conscious or explicit when an alternative or contradiction presents itself. Because language contains a culture within itself, when language changes, a culture is also changing in important ways. By examining changes in descriptions of nature, we can then perceive something of the changes in cultural values. (Merchant 418)

Pierre Henry has stated that he considers music to be a language rather than an art; a method of communicating, to make oneself understood (qtd. in Taylor 61). Taken in this light, the codification of music acts in such a way as to express and explore notions for which conventional language has not the capacity; precisely the concept Attali illustrates in Noise.

Furthermore, in order to tie these theoretical strings into a more focused line of thought, we may return to Bryan Pfaffenberger, and his concept of technology being the continual advancement and development of exchanged social behaviours. It is the humanising of nature, our harnessing of natural resources and elements, combining and reworking them, in order to solve problems, overcome dangers and barriers, to evolve and (presumably) benefit our species (243-244). As we touched on in Chapter Three, in the same light, music is our harnessing of sound and our body's natural, intuitive reaction to tones, rhythms and timbres, in order to elicit stimulation and emotion from their specific organisation. And let us not forget Luigi Russolo, whose noise orchestras were composed in order to illuminate the ways in which technology, i.e. machines, was 
broadening and transforming the 'vocabulary' of sound and thus the ways in which we react to them when organised into the language of music. Therefore, the cultural practice of music - of organised sound - remains a key insight into the formation and status of a society due to its ability to make use of technology in ways distinctive of both artistic and linguistic endeavour. This effectively verifies Attali's notion by outlining the innovation which lies within musical technologies and their utilisation, bringing to light how our relationships with, and understanding of, technologies evolve and adapt, forming new and updated social behaviours and discourses in the process. Continuing with Pfaffenberger's notions of technology we must also keep in mind that,

The relationship between technological development and cultural practice is bidirectional: The latter being just as likely to drive and regulate the former as the former is the latter. (Gilbert and Peterson 126)

Hence the importance in the investigation of how individuals, producers and consumers alike, use media technologies, including music technologies, to interact and communicate bringing forth discourse, codes and language. In relation to cyberspace and the new digital underground, for instance,

These new technological forms have already inspired their own forms of consumer adaptation, from illicit digital media file exchange to multimedia mashups, and the degree to which these new technologies deliver on the longpromised 'celestial jukebox' will strongly influence how people collect recorded music, television shows, and motion pictures in the future. We need to be attentive not only of the ways emerging media forms are made obsolete but also how groups of users and audiences adapt to these kinds of changes and perhaps contribute to the survival of future residual media. (Davis 234) 
The adaption of audiences and the survival of residual media remain important notions in this regard, as they allow us to further understand the value, utility and influence of technologies within contemporary society, bringing forth more substantial frameworks with which we can illuminate increasingly complex issues inherent throughout humanity's technological progression. Over the course of this discussion, we have attempted to discern why these artists are drawn towards certain technologies, practices, materials and subject matters; the residual, obsolete, unwanted and taboo, reappropriated from the 'scrapheap of dominant culture', collected from the aggregate surroundings of the post-industrial, digital age urban environment. Henry's notion of music as a linguistic, communicative act brings to the surface much of what we have looked at in terms of the consequences of urbanisation, industrialisation and the isolation, alienation and anguish this brings upon the individual; artists within extreme audio culture using noise and the residual in order to express this in a language capable of depicting a faithful translation of these tacit sensations. The genres of noise and power electronics are unique beyond the economic, social and aesthetic parameters dissected throughout this discussion. They are unique in the ways in which they bring noise, dissonance and the cacophony of technology and urbanisation to the forefront of our aural perceptions, harnessing and shaping them into expressive artistic forms. The most profound aspect of music is its ability to give shape and substance to aspects of the human psyche, i.e. emotions, which other forms of language simply cannot realise; tying us back to Attali's given codes and the untapped possibilities of expression that lie within. Social and environmental stresses inherent within urban living suggest that further emphasis needs to be placed upon the mental, psychological impacts of urbanisation and technological advancement (Adli); a realisation that for many people indicates that perhaps society needs to operate at a slower pace. Even though "[i]t was the struggle for time that fuelled the embrace of technological innovation[,]" the 
detritus and 'run-off' of said innovation has become inspiration to those who are trying to get back in touch with a "sense of embodied time. This is one contemporary purpose of 'residual media', whose lasting popularity may help us to think through and balance the achievements of the new" (Berland 325). As we have observed, 'residual media' can take a number of forms, ranging from the overtly material to the social and/or the covertly symbolic, yet the one overarching principle is the idea of 'failure'; primarily within the eyes of dominant culture (large-scale production, the overground and/or the mainstream). It is this exploration of failure which further validates extreme audio culture as a scene from which one's perceptions of such notions may be tested and reexamined.

Indeed, 'failure' has become a prominent aesthetic in many of the arts in the late twentieth century, reminding us that our control of technology is an illusion, and revealing digital tools to be only as perfect, precise and efficient as the humans who built them. New techniques are often discovered by accident or by the failure of an intended technique or experiment. (Cascone 13)

Within this context, therefore (despite its deterministic sentiment), we can begin to understand the importance of addressing the bond between art and technology. However, this is not said to hold noise and power electronics up to some impossible level of grandeur, as it is merely a minute segment within the broad spectrum of creative media. Yet research into these areas of creative thought and expression ultimately links to much larger considerations. Returning to Attali, for example, and bearing in mind that technology is the material by-product of scientific discovery, we may realise that, "Western music theory is expressed essentially in the context of its relation to science and its crisis" (113). Whether it be speculations concerning transhumanism, the singularity and/or the post-human, the impact industrialisation and capitalism has had 
upon the natural world or the global plights of poverty, violence, injustice and social turmoil which envelop contemporary society, the state of musical thought and culture remain, as always, reflective of these factors, with the underground arena of extreme music embodying the furthermost emotions, struggles and grotesqueries of such phenomena. What's more, we may also return to Russolo's observation that, as new machine sounds slowly became normalised into the spectrum of human hearing, they began to be heard more commonly within music composition, performance and production. This consideration gives us a direct explanation of the rise of abrasive electronic dance music, which is becoming globally popular as normalised machine sounds - e.g. digital glitches and failures - gain permanent footholds within the collective unconscious, ultimately addressing questions regarding contemporary social behaviours, reflective of the aforementioned societal ills, and the ways in which technologies are being used and understood. As noted previously, the status of noise and power electronics (in addition to industrial music) as urban art forms allows us to read works in ways which illuminate these notions and present a deeper understanding as to the purpose, function and allure of extreme audio culture as a scene, calling for further dissection and mapping against various sociological, philosophical theory through the methodology of discourse analysis. This is indeed, however, an inherently subjective approach to research (as is the case when dealing with the decoding of any artistic/creative media) and is thus open to numerous interpretations which leads us towards Bourdieu's observation:

The ideology of the inexhaustible work of art, or of 'reading' as re-creation, masks - by the quasi-exposure which is often observed in matters of faith - the fact that the work is in fact made not twice, but hundreds of times, thousands of times, by all those who have an interest in it, who find a material or symbolic 
profit in reading it, classifying it, decoding it, commenting on it, reproducing it, criticising it, combating it, knowing it, possessing it. (The Rules of Art 171)

Extreme audio culture remains a rich, complex and, at times, problematic scene to analyse for many reasons. There are the theoretical technicalities of categorisation; i.e. is it music? Where exactly does it fall in relation to the avant-garde? Much like other forms of extreme music within the new digital underground however, there also comes the issue of the subject matters presented within many works - particularly, in extreme audio culture, the genres of harsh noise and power electronics - which can delve into territories of the transgressive, the taboo and seek to explore the darker, crueller and more gruesome aspects of the contemporary human psyche in manners more explicit and provocative than anything one may encounter within popular music. As explored in Chapter One, such tactics share a commonality with transgressive art or 'shock' art in their confrontational nature; the way in which they force the audience to think about what's in front of them. And although this is certainly a dangerous realm to traverse, particularly taking into consideration the victims of these issues and the potential triggering such approaches may have upon them, in general they remain important to illuminate and discuss, particularly in relation to artistic expression. Thus,

There's such a thing as 'provocative therapy'. People need to be challenged and to be stretched; it's important that they do that. It's important to have days in your life where you're scared of something, it's important to have days in your life where you are taken into these mysterious woods. It's what makes life worth living. (W. Bennett)

With underground music and its affiliated cultures gaining a pronounced grip within the structures and frameworks of cyberspace, coupled with the ever-increasing ubiquity and accessibility of music technologies to the general public, the creative 
freedom allowed to musicians continues to broaden in dizzying magnitude. This is why online music culture remains such a popular area of research within academia, despite the sensation that there is still much to be covered and much that has been missed in terms of addressing deeper, more significant and/or broader implications to art, technology, culture and society; the rigidity and ostentatious dogma of academic writing being of considerable hindrance. Yet one must not become disheartened when attempting to illuminate the ever-changing landscape of cyberculture and digital media. As Jonathan Sterne observes,

Our challenge is to break with common sense and to ask fundamental questions of all dimensions of the digital world, including all aspects of that world that may not, at first blush, seem digital at all. ("Digital Media and Disciplinarity" 253)

For example, residual, obsolete and discarded technologies (as well as practices and ideas) that become reappropriated by producers within the restricted field of cultural production. Although these statements seem tangential in nature, especially in regards to the topic of our discussion, this is ultimately where the heart of this research lies. Extreme audio culture and the new digital underground are phenomena that allow us to observe and examine the ways in which technologies are being utilised in artistic, communicative practice, acting as both a challenge and a warning to the audience and listener. A challenge in experiencing and accepting the residual and unwanted aspects of our material, social and symbolic world - our everyday life, the environment of the city and the highly digitised, machine-driven society we inhabit - and a warning as to what lies behind that which we filter out and ignore; noise, chaos, perhaps even transcendence in one form or another. Yet the very fact that these artists are finding 
solace and communication through these forms also reminds us that, "Technology spells only possibility, and is in that respect neutral" (Mesthene 619). And yet,

Its massive power can lead to massive error so efficiently perpetuated as to be well-nigh irreversible. Technology is clearly not synonymous with good. It can lead to evil. (Mesthene 619)

Thus, the discourses addressed within noise and power electronics concerning this notion alerts us to the very nature of noise as embodying the vision of negativity addressed by Paul Hegerty (5); positivity lying within harmony, the codes and perceptions established by dominant culture in grounding a sense of order within an increasingly chaotic and dissonant existence. Binaries find themselves threaded throughout our discussion. Whether they be as explicit as presented here or as covert as the underlying nature of the digital age itself (the product of coding, zeros and ones, on and off) this is, fundamentally, what discussions involving culture, society and technology migrate back to. And as the discourses examined within extreme audio culture continue to address the negativity inherent within our current, transhuman age, we find an ever-growing need to re-establish balance between these binaries; e.g. between the animal and the post-human.

That is another way of saying that more power and more choice and more freedom require more wisdom if they are to add up to more humanity. But that, surely, is a challenge to be wise, not an invitation to despair. (Mesthene 620)

On this note, what we can take from extreme audio culture and the new digital underground is a portrait of art and music coming to grips with the perpetual evolution of our relationship to machines and, through the reading of and engagement with the texts produced within the scene, the fallout which occurs within the individual in 
regards to identity, purpose and expectation under the gaze of dominant culture; the pressure and isolation which arises from the navigation of contemporary urban society, the sensation of obsolescence and noise. The existence of such a scene can allow us to reflect upon current attitudes and approaches taken towards both technology and society by bearing in mind the ideas put forth throughout this discussion by the likes of Attali and Haraway in the myriad of ways in which art and science find common ground in exploring and expressing our understanding of ourselves and the world around us. If our most current state of musical progression is of any indication, there shall be indeed much dissonance and chaos in store for us socially and culturally. Yet if we are to take scenes and styles such as noise and power electronics as warnings, given music's prophetic nature, then perhaps we may be able to look towards finding a balance between the positive and negative, establishing a much more euphonic vision of our post-humanity. 


\section{Works Cited}

Acland, Charles R. "Residual Media." Residual Media. Ed. Charles R. Acland.

Minneapolis: University of Minnesota Press, 2007. xiii-xxvii. Print.

Adli, Mazda. "Urban Stress and Mental Health." LSE Cities. The London School of Economics and Political Science, Nov. 2011. Web. 23 June 2013. <http://lsecities.net/media/objects/articles/urban-stress-and-mental-health>.

Akita, Masami. Interview with Chad Hensley. The Beauty of Noise. EsoTerra Magazine: The Journal of Extreme Culture, 13 June 2011. Web. 28 May 2012. $<$ http://www.esoterra.org/merzbow.htm>.

---. Interview with Roger Batty. Animal Instincts. Music Machine: Multi-Genre Music Magazine, 4 May 2005. Web. 28 May 2012. <http://www.musiquemachine.com/articles/articles_template.php?id=73>.

Albiez, Sean and David Pattie. "Kraftwerk: Playing the Machines." Kraftwerk: Music NonStop. Eds. Sean Albiez and David Pattie. London: Continuum. 119-135. Print.

Aspa, Mikko. Interview with Andy Ortmann. Mikko Aspa (Grunt, Freak Animal Label Owner): Interview. July 2009. Web. 17 April 2012. 
<http://www.tinymixtapes.com/features/mikko-aspa-grunt-freak-animal-labelowner>.

Atrax Morgue Official Home Page. Libero, n.d. Web. 1 June 2012.

$<$ http://digilander.libero.it/atraxmorgue/pag/navigator.html $>$.

Attali, Jacques. Noise: The Political Economy of Music. Trans. Brian Massumi. Manchester: Manchester University Press, 1985. Print.

Bandcamp. Bandcamp, n.d. Web. 26 Nov. 2012. <http://bandcamp.com/>.

Beaulieau, Emil. "DISCOGS ASSHOLE.” Noisefanatics.com. phpBB, 23 Jan. 2012. Web. 8 April 2013.

$<$ http:/ / chondriticsound.com/forum/viewtopic.php?f=6\&t=49792\&hilit=coll ecting\&start $=15>$.

Bennett, Andy. 'Youth Culture and Popular Music." Popular Music and Youth Culture. London: MacMillan Press, 2000. 43-51. Print.

Bennett, William. Interview with Keira Sinclair. "For Wild Music.” Fresh Air. The University of Edinburgh, 2 June 2005. MP3. 
Berland, Jody. “The Musicking Machine.” Residual Media. Ed. Charles R. Acland. Minneapolis: University of Minnesota Press, 2007. 303-328. Print.

bigthink. "Michio Kaku: Big Think Interview." Online video clip. YouTube. YouTube, 31 May 2011. Web. 1 June 2012.

<http://www.youtube.com/watch?v=7QLks9QkVLM>.

---. "Michio Kaku: How to Stop Robots From Killing Us.” Online video clip. YouTube. YouTube, 31 May 2011. Web. 26 Feb. 2013.

<http://www.youtube.com/watch?v=JPVOPzYiCeg $>$.

Blogger. Google, n.d. Web. 14 March 2012. <http://www.blogger.com>.

Bonomi, Giorgio. “Throbbing Gristle: Music from the Death Factory." Scenes from Rip It Up and Start Again. Blogger, 2011. Web. 7 July 2012. <http://scenesfromripitupandstartagain.blogspot.co.nz/2011/11/throbbinggristle-music-from-death.html>.

Bostrom, Nick. “Transhumanist Values.” Nick Bostrom's Home Page. University of Oxford, n.d. Web. 1 June 2012. <http://www.nickbostrom.com/ethics/values.html>.

Bourdieu, Pierre. The Field of Cultural Production. Trans. Randal Johnson. Cambridge: Polity Press, 1993. Print. 
---. The Rules of Art. Trans. Susan Emanuel. Stanford: Stanford University Press, 1996.

Print.

Brady, Francis. "Noise Cultures: Networks of the Marginalised." Jotta. University of the Arts, London, 14 Oct. 2010. Web. 23 June 2013.

<http://www.jotta.com/article/v2-critical-dialogue/1134/noise-culturesnetworks-of-the-marginalised $>$.

Breathmint. “Tinnitustimulus@ @ The Marvellous 05.03.2012.” Online video clip.Vimeo. Vimeo, 6 May 2012. Web. 30 May 2012. <http://vimeo.com/41657270>.

Brian, Pomo. "Cory Schumacher - 4 Teeth in a Ziplock Bag." Heathen Harvest 2.1. WordPress, 2012. Web. 20 July 2012.

<http://heathenharvest.org/2012/04/01/cory-schumacher-4-teeth-in-aziplock-bag/>.

Carter, Chris. The Gristleizer (aka The Gristleizer). Blogger, 1 Feb. 2010. Web. 25 May 2012. <http://gristleizer.com/>.

Cascone, Kim. “The Aesthetics of Failure.” Computer Music Journal. 24.4 (2000): 12-18. Web. 28 June 2012. <http://mitpress.mit.edu/journals/COMJ/CMJ24_4Cascone.pdf>. 
CFK. “CFK's Trade List.” Dead Format. Dead Format, 2011. Web. 28 June 2012. $<$ http://deadformat.net/tradelist/CFK/photos>.

Colegate, Mat. "LIVE REPORT: Broken Flag Weekender.” The Quietus.

TheQuietus.com, 11 May 2012. Web. 12 March 2013.

$<$ http://thequietus.com/articles/08775-broken-flag-weekender-ramlehconsumer-electronics-review>.

“Come Organisation.” Discogs.com. Discogs, n.d. Web. 12 March 2013.

<http://www.discogs.com/label/Come\%20Organisation>.

Corbelli, Marco. Interview with EsoTerra Magazine. "Supersonic Death Screams - An Interview with Atrax Morgue. ESOTERRA \# 9 Magazine (USA), 2001.” Interviews. Atrax Morgue Official Home Page. Libero, n.d. Web. 1 June 2012. $<$ http://digilander.libero.it/atraxmorgue/pag/navigator.html $>$.

“COUM Transmissions.” Brainwashed. Brainwashed.com, 2006. Web. 25 May 2012. $<$ http://www.brainwashed.com/tg/coum.html $>$.

Couture, François. “Merzbow.” Allmusic.com. Rovi, 7 June 2012. Web. 25 May 2012. <http://www.allmusic.com/artist/merzbow-mn0000884057>.

Cross, Ian. "Music, Cognition, Culture and Evolution." Annals of the New York. Academy of Sciences 930 (2001): 28-42. Print. 
Ctephin + Xdugef. 6x3” Deluxe Noise Filter. Roil Noise Offensive, 2007. CD.

"Ctephin + Xdugef - 6x3" Deluxe Noise Filter (CDr) at Discogs." Discogs. Discogs, 2013. Web. 20 March 2013. <http://www.discogs.com/Ctephin-Xdugef-6x3Deluxe-Noise-Filter/release/1197771>.

Davis, John. "Going Analogue: Vinylphiles and the Consumption of the 'Obsolete' Vinyl Record.” Residual Media. Ed. Acland, Charles R. Minneapolis: University of Minnesota Press, 2007. 222-236. Print.

De Certeau, Michel. Culture in the Plural. Trans. Tom Conley. Minneapolis: The University of Minnesota Press, 1997. Print.

Denial, Alex. Sexkrime Arts. Blogger, 2009. Web. 26 June 2012. $<$ http://sexkrimearts.blogspot.com>.

Drage, Tim. "My Attempts at Circuit Bending." Cementimental: Circuitbending, Experimental Noise, Harsh Noise, Rough Music. Tim Drage, Nov. 2000. Web. 31 May 2012. $<$ http://www.cementimental.com/circuitbend/index.html?bcsi-ace4aa6c9a5b57a183=1E5DF1B000000003u7VwDuL37XtByGHx5YXAICwmF2 NGCQAAAwAAALcaiwAQDgAAAgAAAGtBBgA=>. 
Dreyfus, Hubert L. and Charles Spinosa. "Heidegger and Borgmann on How to Affirm Technology." Philosophy of Technology: The Technological Condition. Eds. Robert C. Scharff and Val Dusek. Melbourne: Blackwell Publishing, 2003. 315-326. Print.

Egan, Kate. “The Celebration of a 'Proper Product': Exploring the Residual Collectible Through the 'Video Nasty'.” Residual Media. Ed. Charles R. Acland. Minneapolis: University of Minnesota Press, 2007. 200-221. Print.

Ellul, James. “On the Aims of a Philosophy of Technology.” Philosophy of Technology The Technological Condition: An Anthology. Eds. Robert C. Scharff \& Val Dusek. Malden: Blackwell Publishers, 2003. 182-186. Print.

Empiricus. “John Cage - Water Walk.” Detritus Hall. Blogger, 25 June 2008. Web. 25 May 2012. <http://detritushall.blogspot.co.nz/2008/06/john-cage-waterwalk_25.html>.

escapefromnoise. “Grunt - Live @ ???” Online video clip. YouTube. YouTube, 17 Sep. 2011. Web. 4 June 2012. <http://www.youtube.com/watch?v=HoZXcvXyYK8>.

Fiske, J. "Commodities and Culture: Formations of the People." Reading the Popular. Boston: Unwin Hyman, 1989. 23-47. Print. 
Ford, Simon. Wreckers of Civilisation: The Story of COUM Transmissions and Throbbing Gristle. London: Black Dog Publishing, 1999. Print.

Freak Animal. 11 Lahti: Freak Animal, 1998. Print.

Fuck, the Retarded Girl. Unplayable. Cantankerous Records, 2008. Vinyl.

"Fuck, the Retarded Girl - Unplayable (Vinyl) at Discogs." Discogs. Discogs, 2012. Web. 20 July 2012. <http://www.discogs.com/release/1530612>.

Gambino, Ferruccio. “A Critique of Fordism and the Regulation School.” Wildcat. Wildcat, 1996. Web. 14 March 2013. <http://www.wildcatwww.de/en/zirkular/28/z28e_gam.htm>.

Gibson, William. "Rocket Radio.” Voidspace. Michael Foord, n.d. Web. 28 Aug. 2012. <http://www.voidspace.org.uk/cyberpunk/gibson_rocketradio.shtml>

Gilbert, Jeremy and Ewan Pearson. Discographies: Dance Music, Culture and the Politics of Sound. London: Routledge, 1999. Print. 
Graham, Stephen. "Where Is the Underground?" The Journal of Music. The Journal of Music, 2010. Web. 5 Aug. 2011. <http://journalofmusic.com/focus/whereunderground $>$.

Hall, Stuart. "Encoding/Decoding." Media Texts: Authors and Readers. Eds. David Graddol and Oliver Boyd-Barrett. Clevedon: Multilingual Matters, Ltd., 1994. 200-211. Print.

Haraway, Donna. “A Cyborg Manifesto: Science, Technology, and Socialist-Feminism in the Late Twentieth Century." Philosophy of Technology - The Technological Condition: An Anthology. Eds. Robert C. Scharff \& Val Dusek. Malden: Blackwell Publishers, 2003. 429-450. Print.

Hartmann, Björn. "Netlabels and the Adoption of Creative Commons Licensing in the Online Electronic Music Community.” bjoern.org. Björn Hartmann, n.d. Web. 18 May 2013. <http://bjoern.org/papers/hartmann-cc2004.pdf>.

Hegerty, Paul. Noise Music: A History. London: The Continuum International Publishing Group, Ltd., 2008. Print.

Heidegger, Martin. “The Question Concerning Technology.” Philosophy of Technology: The Technological Condition. Eds. Robert C. Scharff and Val Dusek. Melbourne: Blackwell Publishing, 2003. 252-264. Print. 
Henning, Michelle. "New Lamps for Old: Photography, Obsolescence and Social Change.” Residual Media. Ed. Charles R. Acland. Minneapolis: University of Minnesota Press. 2007. 48-65. Print.

Hesmondhalgh, David. "Bourdieu, the Media and Cultural Production.” Media, Culture \& Society 28 (2006): 211-231. Print.

Hodkinson, Paul. “'Net.Goth': Internet Communication and (Sub)Cultural Boundaries." The Post-Subcultures Reader. Eds. David Muggleton and Rupert Weinzierl. New York: Berg, 2003. 285-298. Print.

holotone. "John Cage - Water Walk." Online video clip. YouTube. YouTube, 4 May 2007. Web. 25 May 2012. <http://www.youtube.com/watch?v=SSulycqZH$\mathrm{U}>$.

Howe, Brian. "BoyZone, Clang Quartet, Jeff Rehnlund and Relay for Death: Green Noise Through Recycled Cassette Tapes.” Independent Weekly. Foundation, 2008. Web. 28 June 2012. <http://www.indyweek.com/indyweek/boyzone-clangquartet-jeff-rehnlund-and-relay-for-death/Content?oid=1209439>.

Hynes, Stephen. “Urban Isolation.” Hynes Developments. Hynes Developments, n.d. Web. 23 June 2013. < http://www.hynesdevelopments.com/thoughts/essays>. 
Ihde, Don. "A Phenomenology of Technics." Philosophy of Technology - The Technological Condition: An Anthology. Eds. Robert C. Scharff \& Val Dusek. Malden: Blackwell Publishers, 2003. 507-529. Print.

“Industrial Records.” Brainwashed. Brainwashed, Inc., n.d. Web. 26 June 2012. $<$ http://brainwashed.com/tg/industrial.html $>$.

“Interviews.” Atrax Morgue Official Home Page. Libero, n.d. Web. 26 Feb. 2013. $<$ http://digilander.libero.it/atraxmorgue/pag/navigator.html $>$.

Jenkins, Henry. “The Cultural Logic of Media Convergence.” International Journal of Cultural Studies 7.1 (2004): 33-43. Web. 16 May 2013.

$<$ http://eng1131adaptations.pbworks.com/f/Jenkins, + Henry+++ The + Cultural + Logic + of + Media + Convergence.pdf $>$.

jesusfaggotchrist. "does power electronics really make any sense?” Noisefanatics.com. phpBB, 16 May 2012. Web. 8 March 2013. $<$ http:/ / chondriticsound.com/forum/viewtopic.php?f=24\&t=50672\&start $=60$ $>$.

Johnson, Randal. Introduction. Bourdieu, Pierre. The Field of Cultural Production. Trans. Randal Johnson. Cambridge: Polity Press, 1993. Print. 
Jonas, Hans. "Toward a Philosophy of Technology.” Philosophy of Technology: The Technological Condition. Eds. Robert C. Scharff and Val Dusek. Melbourne: Blackwell Publishing, 2003. 191-204. Print.

Julian, Leigh 'Stench'. Smell the Stench. Todd Novosad, 2006. Web. 5 Aug. 2011. $<$ http://www.smellthestench.net/ $>$.

Julius, Anthony. Transgressions: The Offences of Art. London: Thames \& Hudson. 2002. Print.

Kahn-Harris, Keith. “'Roots?' The Relationship Between the Global and the Local Within the Extreme Metal Scene." The Popular Music Studies Reader. Eds. Andy Bennett, Barry Shank and Jason Toynbee. Abingdon: Routledge, 2006. 128-134. Print.

---. "Unspectacular Subculture? Transgression and Mundanity in the Global Extreme Metal Scene." After Subculture: Critical Studies in Contemporary Youth Culture. Eds. Andy Bennett and Keith Kahn-Harris. New York: Palgrave MacMillan, 2004. 107-118. Print.

KingHotPants. "Infinity Factory Throbbing Gristle Genesis P-Orridge Part 2 of 4." Online video clip. Infinity Factory. YouTube, 7 Nov. 2009. Web. 25 May 2012. $<$ http://www.youtube.com/watch?v=s7Pv-351KDI $>$. 
Kraft, Amy. "Prepare for the Singularity." SmartPlanet. CBS Interactive, Inc., 24 March 2012. Web. 26 Feb. 2013. <http://www.smartplanet.com/blog/smarttakes/prepare-for-the-singularity/24642>.

Levy, Pierre. “The Social Movement of Cyberculture." Cyberculture. Minneapolis: University of Minnesota, 2001. 103-114. Print.

Lytton, Edward Bulwer. "Book IV. - The Dweller of the Threshold." Zanoni. The Gutenberg Book Project, 18 Feb. 2006. Web. 26 Nov. 2012. <http://www.gutenberg.org/files/2664/2664-h/2664-h.htm>.

Maniacs Only. phpBB, n.d. Web. 16 May 2013. <http://www.maniacsonly.com/>.

Marchart, Oliver. "Bridging the Micro-Macro Gap: Is There Such a Thing as a PostSubcultural Politics?” The Post-Subcultures Reader. Eds. David Muggleton and Rupert Weinzierl. New York: Berg, 2003. 83-97. Print.

Marche, Stephen. "Is Facebook Making Us Lonely?” The Atlantic. The Atlantic Monthly Group, 2 April 2012. Web. 23 June 2013.

<http://www.theatlantic.com/magazine/archive/2012/05/is-facebook-makingus-lonely/308930/>. 
Marinetti, Filippo Tommaso. "The Founding and Manifesto of Futurism.” Futurism: Manifestos and Other Resources. Kim Scarborough, 14 June 2002. Web. 25 May 2012. <http://www.unknown.nu/futurism/manifesto.html>.

McDonald, Heather. "New Wave Music History." LoveToKnow Music. Love'ToKnow Corp., 2013. Web. 31 May 2013. $<$ http://music.lovetoknow.com/New_Wave_Music_History $>$.

McGee, Hal. “Microcassettes.” Noisefanatics.com. phpBB, 24 Jan. 2010. Web. 14 March 2013.

$<$ http:/ / chondriticsound.com/forum/viewtopic.php?f=43\&t=33410\&start=15 $>$.

Medina, Oscar Paul. "Luigi Russolo: How the Art of Noise Revolutionised $20^{\text {th }}$ Century Music.” Hydra Magaz̨ine. Hydra Magazine, 27 Aug. 2010. Web. 21 June 2013. <http://www.hydramag.com/2010/08/27/luigi-russolo-how-the-art-of-noiserevolutionized-20th-century-music/ $>$.

mengenerated. "Vomir Live at Optimus Prime II." Online video clip. YouTube. YouTube, 1 Nov. 2008. Web. 26 Nov. 2012. $<$ http://youtu.be/I3zeYV4oN2A>. 
Merchant, Carolyn. "Mining the Earth's Womb." Philosophy of Technology - The Technological Condition: An Anthology. Eds. Robert C. Scharff \& Val Dusek. Malden: Blackwell Publishers, 2003. 417-428. Print.

“Merzbow.” JaME World. Japanese Music Entertainment, 2012. Web, 28 May 2012. <http://www.jame-world.com/uk/artists-overview-845-merzbow.html>.

Mesthene, Emmanuel G. “The Social Impact of Technological Change.” Philosophy of Technology: The Technological Condition. Eds. Robert C. Scharff and Val Dusek. Melbourne: Blackwell Publishing, 2003. 617-637. Print.

“Microcassette Minicassette." Comcast.net. Comcast Interactive Media, n.d. Web. 20 July 2012. <http://home.comcast.net/ trafficgard/Micro-mini-cassette.htm>.

mojuvideo. "Incapacitants Live in Tokyo Part 1/2 (Full Set)." Online video clip. YouTube. YouTube, 12 May 2009. Web. 26 Nov. 2012. <http://youtu.be/HdiWGq8955M>.

Mumford, Lewis. "Tool Users vs. Homosapiens and the Megamachine." Philosophy of Technology - The Technological Condition: An Anthology. Eds. Robert C. Scharff \& Val Dusek. Malden: Blackwell Publishers, 2003. 344-351. Print.

My Lovely Figment. Dictafawn Microcassette Label. Blogger, 2011. Web. 26 June 2012. $<$ http://dictafawn.blogspot.com>. 
Nash, Matilda. "Sustainable Urbanisation, Sustainable Urban Health.” Derpolicy Blog. Devpolicy Blog from the Development Policy Centre, 10 Jan. 2013. Web. 23 June 2013. <http://devpolicy.org/sustainable-urbanisation-sustainable-urbanhealth-20130110/>.

Nessi, Frederico. “Throbbing Gristle.” Artlurker. WordPress, 2012. Web. 11 July 2012. <http://www.artlurker.com/2008/09/throbbing-gristle-by-federico-nessi/>.

Noisefanatics.com. phpBB, n.d. Web. 20 Feb. 2012. $<$ http://chondriticsound.com/forum/ $>$.

NON. Pagan Murak. Graybeat Records, 1981. Vinyl.

Notes on Breakcore. Dir. Kleinl, David and Bertram Könighofer. Widerstand Records, 2006. Web. 14 March 2012. <http://notes.breakcore.net/>.

Oliver, Kelly. "Stopping the Anthropological Machine: Agamben with Heidegger and Merleau-Ponty.” PhaenEx 2.2 (2007): 1-23. Web. 26 Feb. 2013. <http://www.phaenex.uwindsor.ca/ojs/leddy/index.php/phaenex/article/vie $\mathrm{w} / 236 / 396>$. 
PayPal. PayPal Pte. Ltd., 1999. Web. 20 July 2012. <http://www.paypal.com>.

People Who Do Noise. Dir. Cornelius, Adam. Adam Cornelius Productions, 2008. DVD.

Pfaffenberger, Bryan. "Fetishized Objects and Humanized Nature: Towards an Anthropology of Technology.” Man, New Series. 23.2 (Jun., 1988): 236-252. Print.

PressPausePlay. Dir. Dworsky, David and Victor Köhler. House of Radon, 2011. Web. 20 April 2012. <http://vimeo.com/34608191>.

Prior, Nick. "Putting a Glitch in the Field: Bourdieu, Actor Network Theory and Contemporary Music.” Cultural Sociology. 2.3 (2008): 301-319. Print.

raperies (like draperies). “does power electronics really make any sense?” Noisefanatics.com. phpBB, 19 March 2012. Web. 8 March 2013. $<$ http://chondriticsound.com/forum/viewtopic.php?f=24\&t=50672>.

Ray, Michael. “Ted Kaczynski (American criminal).” Encyclopaedia Britannica.

Encyclopaedia Britannica, Inc., 2013. Web. 14 March 2013.

<http://www.britannica.com/EBchecked/topic/1379789/Ted-Kaczynski>.

Reynolds, Simon. "Notes on the Noughties: The Changing Sound of the Underground." The Guardian. Guardian News and Media Limited, 2009. Web. 20 July 2012. 
<http://www.guardian.co.uk/music/musicblog/2009/dec/21/changingsound-underground $>$.

Russolo, Luigi. The Art of Noises. Trans. Barclay Brown. New York, USA: Pendragon Press. 1986. Print.

Scarborough, Kim. Futurism: Manifestos and Other Resources. Kim Scarborough, 14 June 2002. Web. 25 May 2012. <http://www.unknown.nu/futurism/>.

Schaefer, Peter. “Whitehouse.” Allmusic.com. Rovi, 7 June 2012. Web. 25 May 2012. <http://www.allmusic.com/artist/whitehouse-mn0000820195>.

Schenck, Jeff. “Wasn't tape trading also 'piracy'?” Metalluminati. The Metalluminati, 29 March 2012. Web. 12 March 2013. <http://metalluminati.com/wasnt-tapetrading-also-piracy/>.

Schumacher, Cory. 4 Teeth in a Ziplock Bag. [Self-Released], 2011. CD.

Scott, Ryan. "Emil Beaulieau Live.” Online video clip. YouTube. YouTube, 2 June 2006. Web. 26 Nov. 2012. <http://youtu.be/_W-1FVzIf00>.

Semprebon, Rolf. "Pagan Muzak - Non.” Allmusic. Rovi Corp., 2012. Web. 11 July 2012. <http://www.allmusic.com/album/pagan-muzak-mw0000989009>. 
Serafin, Stefania. "Acoustics of the Intonarumori." The American Institute of Physics.

American Institute of Physics, 17 May 2005. Web. 24 May 2012.

$<$ http://www.aip.org/149th/serafin.html $>$.

Shuker, Roy. Wax Trash and Vinyl Treasures: Record Collecting as a Social Practice. Farnham: Ashgate Publishing Limited, 2010. Print.

SI. "Détournement as Negation and Prelude." The Situationist International Text Library.

Nothingness.org, 2001. Web. 30 March 2013.

<http://library.nothingness.org/articles/SI/en/display/315>.

Sleep Of Ages. "DISCOGS ASSHOLE.” Noisefanatics.com. phpBB, 23 Jan. 2012. Web. 8 April 2013.

$<$ http:/ / chondriticsound.com/ forum/viewtopic.php?f=6\&t=49792\&hilit $=$ coll ecting\&start $=15>$.

Sofia, Zoë. “Container Technologies.” Hypatia 15.2 (2000): 181-201. Web. 12 March 2013. <http://www.jstor.org/stable/3810663>.

SoundCloud. SoundCloud, Ltd., 2012. Web. 26 Nov. 2012. <http://soundcloud.com/>. 
Spencer, Amy. DIY: The Rise of Lo-Fi Culture. London: Marion Boyars Publishers, Ltd., 2005. Print.

SPK. Factory. Side Effects, 1979. Vinyl.

---. "Slogun". Factory. Side Effects, 1979. Vinyl.

Spoto, Stephanie. “A Brief Look at Black Metal as a Continuation of Occult

Traditions." Academia.edu. Academia, Aug. 2009. Web. 4 July 2013.

<http://academia.edu/621587/A_Brief_Look_at_Black_Metal_as_a_Continua tion_of_Occult_Traditions>.

Stahl, Geoff. "Tastefully Renovating Subcultural Theory: Making Space for a New Model.” The Post-Subcultures Reader. Eds. David Muggleton and Rupert Weinzierl. New York: Berg, 2003. 27-40. Print.

Staub, Ian Matthew. "Redubbing the Underground: Cassette Culture in Transition." Hons. thesis. Wesleyan University, Middletown, 2010. Honors Theses - All. Web. 4 July 2013. <http://wesscholar.wesleyan.edu/etd_hon_theses/418/>.

Stench, Ryan. Pure Stench. Blogger, n.d. Web. 19 April 2013.

$<$ http://purestench.blogspot.com>. 
Sterne, Jonathan. "Digital Media and Disciplinarity." The Information Society 21 (2005): 249-256. Web. 11 Nov. 2011. < http://sterneworks.org/dmdisciplinarity.pdf>.

---. “The MP3 as Cultural Artefact.” New Media and Society. 8.5 (2006): 825-842. Print.

Strate, Lance. “10. Mumford, technics, and ecological history.” BioMedSearch.com. BioMedSearch.com, 2004. Web. 12 March 2013.

<http://www.biomedsearch.com/article/10-Mumford-technics-ecologicalhistory/130975653.html>.

Straw, Will. "Embedded Memories." Residual Media. Ed. Charles R. Acland. Minneapolis: University of Minnesota Press, 2007. 3-15. Print.

---. “Scenes and Sensibilities.” Public 22-23 (2001): 245-257. Print.

---. "Systems of Articulation, Logics of Change: Communities and Scenes in Popular Music." Cultural Studies 5.3 (1991): 368-388. Print.

“[T+020] Fukte \& Orgasm Denial - Disk Failure.” Toxic Industries. Toxic Industries, 2010. Web. 20 July 2012.

$<$ http://www.toxicindustries.net84.net/release_details.php?cat=T+020>.

Taylor, Timothy D. "Postwar Music and the Technoscientific Imaginary." Strange Sounds: Music, Technology and Culture. New York: Routledge. 41-71. Print. 
Tellnes, Gunnar. “President's Column: Positive and Negative Public Health Effects of Urbanisation.” European Journal of Public Health 15.5 (2005): 552-553. Web. 23 June 2013. <http://eurpub.oxfordjournals.org/content/15/5/552.full>.

Théberge, Paul. “'Plugged In': Technology and Popular Music.” The Cambridge Companion to Pop and Rock. Eds. Simon Frith, Will Straw and John Street. London: Cambridge University Press, 2001. 2-25. Print.

thephenomenalsneeze. "Review :: Throbbing Gristle :: The Second Annual Report." Machine Dream. Blogger, 2012. Web. 14 Jan. 2013. <http://www.machinedream.net/2012/05/review-throbbing-gristle-secondannual.html>.

The Thing on the Doorstep. "Throbbing Gristle Biography." The Thing on the Doorstep. The Thing on the Doorstep, n.d. Web. 12 March 2013. $<$ http://thethingonthedoorstep.be/artists.php?id=111>.

THKD. "Blut Der Nacht - Demo MMXI (Fallen Empire, 2011)." That's How Kids Die. WordPress, 2012. Web. 25 July 2012. <http://thatshowkidsdie.com/2012/01/03/blut-der-nacht-demo-mmxi-fallenempire-2011/> . 
---. "Worship Black Metal Cassettes: Scratching the Surface of Crepusculo Negro and Rhinocervs.” That's How Kids Die. WordPress, 4 Feb. 2012. Web. 13 March 2013. <http://thatshowkidsdie.com/2012/02/04/worship-black-metalcassettes-scratching-the-surface-of-crepusculo-negro-and-rhinocervs/>.

Thompson, Fred. "Fordism, Post-Fordism and the Flexible System of Production." Fred Thompson's home page. Willamette University, n.d. Web. 14 March 2013. <http://www.willamette.edu/ fthompso/MgmtCon/Fordism_\&_Postfordism .html>.

Throbbing Gristle. The Second Annual Report. Industrial Records, 1977. Vinyl.

---. Throbbing Gristle.com. Industrial Records, Ltd., UK, 9 June 2012. Web. 25 May 2012. $<$ http://www.throbbing-gristle.com/>.

---. 24 Hours. Industrial Records, 1980. Cassette.

“Throbbing Gristle.” Sputnik. Music. Sputnikmusic.com, 2005. Web. 27 July 2012. <http://www.sputnikmusic.com/bands/Throbbing-Gristle/3142/>.

timdrage. "Cementimental Live 4 Feb 2012 @ Splitting the Atom V, The Green Door Store, Brighton.” Online video clip. YouTube. YouTube, 7 Feb. 2012. Web. 31 May 2012. <http://www.youtube.com/watch?v=Nx_oNL2sCuo>. 
Tommuel. "Arachnid Claims Its Prey - A Tribute To Atrax Morgue • 2xCS." Noisefanatics.com. phpBB, 8 May 2012. Web. 26 Feb. 2013.

$<$ http:/ / chondriticsound.com/forum/viewtopic.php?f=1\&t=51544\&hilit=atra $\mathrm{x}+$ morgue $>$.

Toxic Industries. Toxic Industries, 2011. Web. 26 June 2012. <http://www.toxicindustries.net84.net/home.php>.

Tumblr. Tumblr Inc., n.d. Web. 14 March 2012. <http://www.tumblr.com>.

Unsound Magazine. 1.1 San Francisco: Unsound/Auto-Text Publications, 1983. Print.

--- 1.4 San Francisco: Unsound/Auto-Text Publications, 1984. Print.

--- 1.5 San Francisco: Unsound/Auto-Text Publications, 1984. Print.

---. 3.2 San Francisco: Unsound/Auto-Text Publications, 1988. Print.

Vale, V. and Andrea Juno. Industrial Culture Handbook: Re \#6/7. San Francisco:

RE/Search Publications, 1983. Print. 
Van Dorston, A.S. “A History of Punk.” Fast 'n’ Bulbous. WordPress, 1990. Web. 14 Jan. 2013. <http://fastnbulbous.com/punk/>.

Van Isacker, B. "Racist Boyd Rice Video Interview Causes Controversy." Side-Line Music Magazine. Side-Line, 21 July 2008. Web. 26 Nov. 2012. <http://www.sideline.com/news_comments.php?id=33873_0_2_0_C>.

Weinzierl, Rupert and David Muggleton. "What Is 'Post-Subcultural Studies' Anyway?”. The Post-Subcultures Reader. Eds. David Muggleton and Rupert Weinzierl. New York: Berg, 2003. 3-26. Print.

Whelen, Andrew. "Extreme Music and Graphic Representation Online.” 2010 IEEE International Symposium on Technology and Society. University of Wollongong. 466474. Web. 17 April 2012. $<$ http:/ /ieeexplore.ieee.org/stamp/stamp.jsp?tp=\&arnumber $=5514605>$

Whitehouse. Birthdeath Experience. Susan Lawly, 1993 [Reissue]. CD.

---. Erector. Susan Lawly, 1995 [Reissue]. CD.

WordPress. Automattic Inc., 2005. Web. 14 March 2012. <http://www.wordpress.com>. 
Worthless Recordings. Blogger, n.d. Web. 26 June 2012.

$<$ http://worthlessrecordings.blogspot.com/>.

Yudkowsky, Eliezer. “Bystander Apathy.” Less Wrong. Less Wrong, 13 April 2009. Web.

23 June 2013. < http://lesswrong.com/lw/9j/bystander_apathy/>.

Zchivago, Jonny. “Throbbing Gristle - '24 Hours' (Cassette Version) Industrial Records 1980.” Die or D.I.Y.? Blogger, 2011. Web. 20 Aug. 2012.

<http://dieordiy.blogspot.co.nz/2011/09/throbbing-gristle-24-hourscassette.html>.

Zylo, Arvo. "Escape from Noise: Is This Not Music?” Newcity Music. Newcity

Communications, Inc., 2012. Web. 20 July 2012.

<http://music.newcity.com/2012/04/04/escape-from-noise-is-this-not-

music/>. 
